\title{
Novel interaction partners of the chromatin remodeler CHD7, a protein mutated in CHARGE syndrome
}

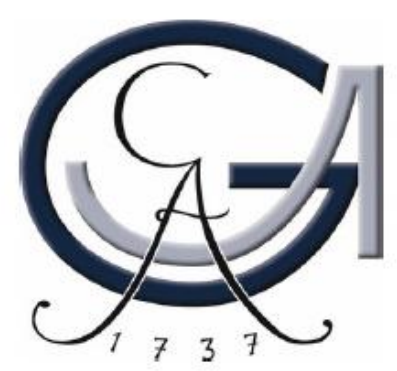

Dissertation

zur Erlangung des Doktorgrades

der Mathematisch-Naturwissenschaftlichen Fakultäten

der Georg-August-Universität zu Göttingen

vorgelegt von

Tserendulam Batsukh

aus Ulaanbaatar, Mongolei

Göttingen, 2012 
D7

Referent: Prof. Dr. Dr. Wolfgang Engel

Korreferent: Prof. Dr. Sigrid Hoyer-Fender

Tag der mündlichen Prüfung: 
Dedicated to my family,

whose love and supports were always present and encouraged me in my path. 


\section{Table of contents}

Table of Contents .. $\mathrm{i}$

List of Tables and Figures ..............................................................................................

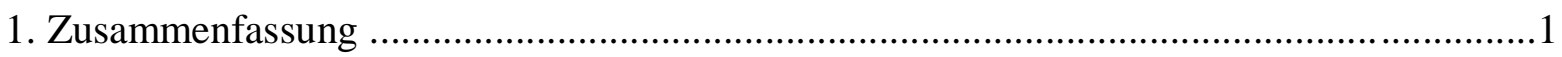

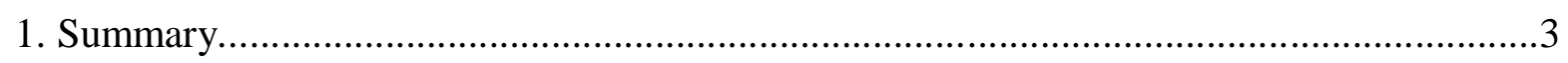

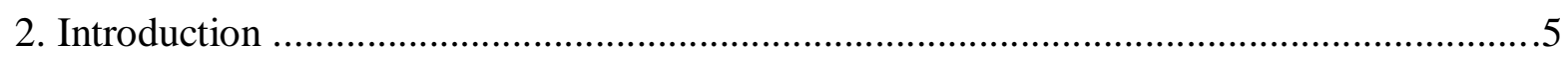

2.1 Chromodomain helicase DNA-binding family of chromatin remodelers...........5

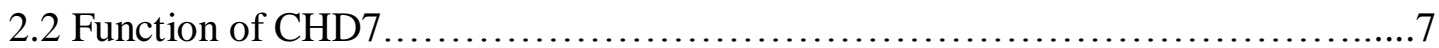

2.3 Role of CHDs in human diseases........................................ 9

2.4 CHD7 and CHARGE syndrome........................................ 10

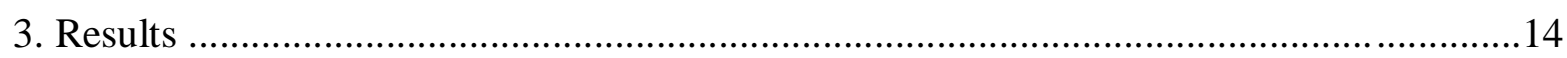

3.1 CHD8 interacts with CHD7, a protein which is mutated in CHARGE

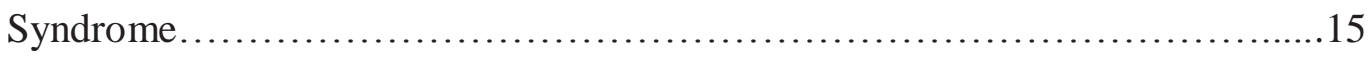

3.2 Identification and characterization of FAM124B as a novel component

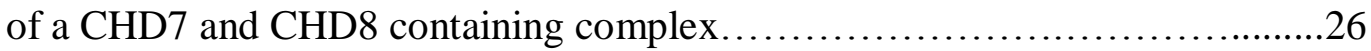

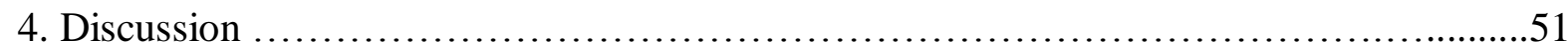

4.1 Known CHD7 complexes and function.................................51

4.2 Known CHD8 complexes and function...................................53

4.3 CHD8 builds together with CHD7 a complex .............................55

4.4 Evaluating the effect of $4 \mathrm{CHD} 7$ missense mutations on the interaction

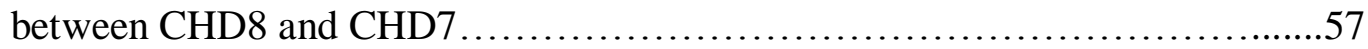

4.5 FAM124B is associated with CHD7 and CHD8 ............................58

4.6 Subcellular localization and expression profile of Fam124B in

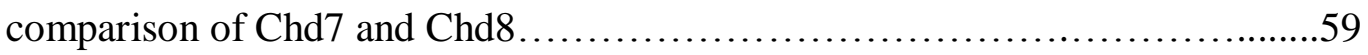

4.7 Structure and Function of FAM124B .....................................63

4.8 Future endeavors and perspectives..................................64

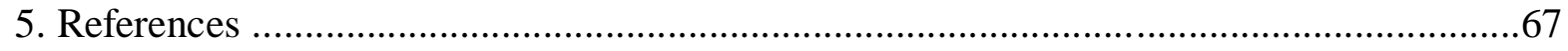

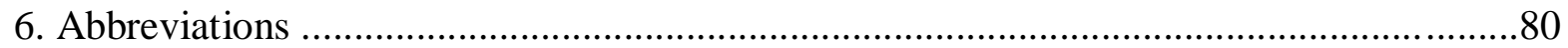

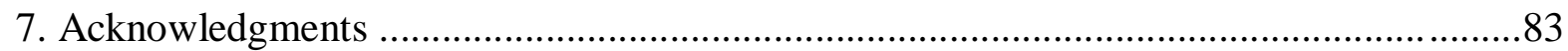

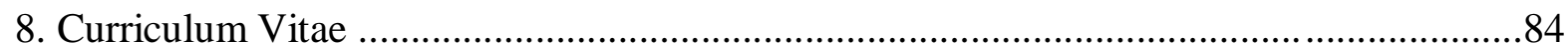

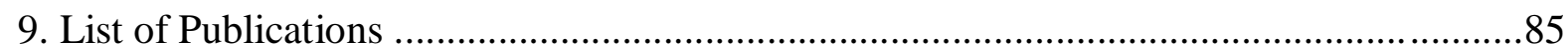




\section{List of Tables and Figures}

Figure 2.1. Mechanism for ATP-dependent chromatin remodeling .......................5

Figure 2.2. Structural domains of human CHD family of proteins $\ldots \ldots \ldots \ldots \ldots \ldots \ldots \ldots \ldots$

Table 2.1. Overview of the functions of the CHD family of proteins ..................................

Table 2.2. Human diseases associated with CHD proteins........................... 10

Figure 2.3. Distribution of pathogenic mutation types in the $C H D 7$ gene..................12

Figure 4.1. Models for CHD7complexes........................................ 53

Figure 4.2. Models for CHD8 complexes........................................55

Figure 4.3. CHD7 and CHD8 endogenous interaction in HeLa cells shown by the Duolink PLA method. .56

Figure 4.4. Hypothetical Enhancer and Promoter interaction via CHD7 and CHD8 containing protein/transcription factors (TF) complex mediated DNA-loop model..................................................58

Figure 4.5. Immunostaining Fam124B of adult brain shown in comparison with Chd7 and Chd8 60

Figure 4.6. Chd7, Chd8 and Fam124B immunostainings on sagittal section of an E12.5 wildtype embryo

Figure 4.7. Chd7, Chd8 and Fam124B immunostaining on coronal section of the E12.5 mouse embryo.

Figure 4.8. A homologous part of FAM124B protein alignment from Human to Zebrafish by Constraint-based Multiple alignment tool.

Figure 4.9. Effect of CHD7 knockdown on expression of transcription factor Twist involved in neural crest formation 


\section{Zusammenfassung}

CHARGE Syndrom, ein autosomal dominant vererbtes Malformationssyndrom wird durch Mutationen im Chromodomänen Helikase DNA bindenden protein 7 (CHD7) Gen hervorgerufen. In 10\% der „typischen“ und 40-50\% der ,atypischen“ CHARGE Patienten findet sich keine Mutation im CHD7 Gen und somit bleibt die Ursache der Symptomatik in diesen Fällen unklar. CHD7 ist ein nukleär lokalisierter chromatin remodeler, der in großen Multiproteinkomplexen detektiert werden konnte und die Expression verschiedener Gene reguliert. Die Charakterisierung von CHD7 Interaktionspartnern ist möglicherweise hilfreich um die Pathogenese des CHARGE Syndroms zu verstehen. Für einige andere genetisch bedingte Erkrankungen konnte gezeigt werden, dass Mutationen in Interaktionspartnern zu demselben oder einem ähnlichen Krankheitsbild führen. Daher vermuten wir, dass CHD7 Interaktionspartner gute Kandidaten sind, die möglicherweise im mutierten Zustand ebenfalls zum CHARGE Syndrom führen.

Im ersten Teil dieser Arbeit wurde CHD8 als ein Interaktionspartner von CHD7 identifiziert. Die Interaktion des CHD7 Teilstückes (Aminosäuren: 1593-2178) mit einem CHD8 Teilstück (Aminosäuren: 1789-2302) wurde mittels verschiedener molekularer Techniken validiert. Zusätzlich konnten wir zeigen, dass die Interaktion im Nuckleoplasma stattfindet. Darüber hinaus wurde der Einfluss von 3 in der Literatur beschriebenen Mutationen (p.His2096Arg, p.Val2102Ile und p.Gly2108Arg) und einer neu identifizierten (p.Trp2091Arg) CHD7 missense Mutation auf die CHD7-CHD8 Interaktion mittels Yeast two hybrid (Y2H) und Co-Immunopräzipitation (Co-IP) untersucht. Während wir mittels $\mathrm{Y} 2 \mathrm{H}$ zeigen konnten, dass die CHD7-CHD8 Interaktion durch die CHD7 missense Mutationen p.Trp2091Arg, p.His2096Arg und p.Gly2108Arg aufgehoben wird, konnte dieser Effekt mittels Co-IP nicht nachgewiesen werden. Daher vermuten wir, dass CHD7 und CHD8 einerseits direkt miteinander interagieren (gezeigt durch die direkten $\mathrm{Y} 2 \mathrm{H}$ Experimente) und zusätzlich indirekt über sog. Linker Proteine, die zusammen mit CHD7 und CHD8 einen großen Proteinkomplex formen (Erklärung für die Co-IP Ergebnisse). Zusätzlich haben wir CHD7 negative CHARGE Patienten auf Mutationen im CHD8 Gen untersucht.

Im zweiten Teil der Doktorarbeit zeigen wir die Ergebnisse der SILAC und Massenspektrometrie Analyse, bei der wir das bisher uncharakterisierte Protein FAM124B als eine Komponente eines CHD7-CHD8 enthaltenden Komplexes identifizierten. Die Interaktion mit dem CHD8 Teilstück (Aminosäuren 1789-2302) wurde mittels direktem Y2H und Co-IPs 
validiert, während eine Interaktion mit dem CHD7 Teilstück (Aminosäuren 1593-2178) nur mittels Co-IP bestätigt werden konnte, wodurch gezeigt wurde, dass FAM124B nicht direkt mit der o.g. CHD7 Region interagiert. Zusätzlich erfolgte eine Charakterisierung von FAM124B. Wir konnten zeigen, dass FAM124B, wie CHD7 und CHD8 im Zellkern lokalisiert ist. Fam124B wird bei der Maus in den Organen, die beim CHARGE Syndrom betroffen sind expremiert. Eine starke Expression konnte in dem sich entwickelnden Gehirn, Herzen, Lunge und im Rückenmark von E12.5 Mauseembryonen nachgewiesen werden. Kürzlich konnte gezeigt werden, dass Mutationen in CHD8 Autismus (ASD) und Entwicklungsstörungen des Nervensystems (NDD) bewirken können. Zusammenfassend, weisen unsere Daten darauf hin, dass das bisher uncharakterisierte Protein FAM124B eine sehr wichtige Funktion in der Embryonalentwicklung hat und möglicherweise an der Pathogenese des CHARGE Syndroms und ASD/NDD beteiligt ist.

Um eine mögliche Rolle von FAM124B an der Pathogenese des CHARGE Syndroms und Neurocristopathien $\mathrm{zu}$ analysieren, planen wir die Herrunterregulierung von Fam124B in Xenopus laevis um anschließend den Einfluss von Fam124B auf Gene, die an der Neuralleistenzellformation beteiligt sind zu testen. Die Generierung eines Fam124B knockout Mausmodels und die weitere Charakterisierung von CHD7 Interaktionspartnern werden zur Erlangung tiefgreifender Kenntnisse des molekularen Mechanismus des CHARGE Syndroms und Autismus Erkrankungen hilfreich sein. 


\section{Summary}

CHARGE syndrome, an autosomal dominant inherited multiple malformation syndrome is caused by mutations in the chromodomain helicase DNA binding protein 7 gene (CHD7). In $10 \%$ of 'typical' CHARGE patients and $40-50 \%$ of 'atypical' CHARGE patients no mutation in the CHD7 gene is detectable and therefore the molecular cause is still unknown. CHD7 is a nuclear chromatin remodeling protein found in big protein complexes and regulating gene expression of various genes. We suggested that the characterization of CHD7 interacting partners can be useful for understanding the pathogenesis of CHARGE syndrome. Furthermore, for other genetic diseases it was shown that mutations in interacting partners lead to the same or a similar phenotype. Therefore, we hypothesized that CHD7 interacting partners are good candidates, leading to CHARGE syndrome when they are mutated.

In the first part of the thesis, CHD8 was identified as an interacting partner of CHD7. The interaction of the CHD7 part (1593 - 2178aa) with the CHD8 part (1789 - 2302aa) was validated by different molecular techniques. Additionally, we could show that the interaction takes place in the nucleoplasm. Furthermore, the influence of 3 known (p.His2096Arg, p.Val2102Ile and p.Gly2108Arg) and one (p.Trp2091Arg) newly identified CHD7 missense mutation on the CHD7-CHD8 interaction was elucidated by direct Yeast two hybrid (Y2H) and co-immunoprecipitation (Co-IP) methods. By $\mathrm{Y} 2 \mathrm{H}$ we could demonstrate that the missense mutations p.Trp2091Arg, p.His2096Arg and p.Gly2108Arg disrupt the CHD7-CHD8 interaction, while no influence on the interaction could be seen in Co-IP assays. Therefore, we suggest that CHD7 and CHD8 interact directly (shown by $\mathrm{Y} 2 \mathrm{H}$ ) and indirectly via additional linker proteins which build together with CHD7 and CHD8 a large protein complex (explaining the Co-IP result). In addition, we reported about the sequence analysis of the CHD8 gene in CHD7 mutation negative patients with CHARGE syndrome.

In the second part of the thesis, we showed the results of a SILAC and mass-spectrometry approach that identified the hitherto unknown protein FAM124B as a member of CHD7-CHD8 containing complex. The interaction with the CHD8 part (1789 - 2302aa) was validated by direct Y2H and Co-IP methods whereas the interaction with the CHD7 part (1593 - 2178aa) could be only confirmed with the Co-IP assay, demonstrating that FAM124B interacts not directly with the analyzed CHD7 region. Furthermore, we characterized FAM124B. We could show that FAM124B is localized in the nucleoplasm like CHD7 and CHD8. Murine Fam124B is expressed in the organs affected in CHARGE syndrome. High expression could be observed in the developing brain, heart, lung and spinal cord of E12.5 mouse embryos. Recently, CHD8 
mutations are shown to be a cause of autism spectrum disorders (ASD) as well as neurodevelopmental disorders (NDD). In conclusion, our results indicate that the hitherto uncharacterized protein FAM124B might be very important for embryonic development and could be involved in the pathogenesis of CHARGE syndrome and ASD/NDDs.

Moreover, to analyse the possible role of FAM124B in the pathogenesis of CHARGE and neurocristopathies, we plan to perform a knockdown of FAM124B in Xenopus laevis and test its influence on genes related to neural crest formation. Generation of a knockout mouse model for Fam124B and further characterization of the CHD7 interacting complex members will help to learn more about the molecular mechanism behind CHARGE syndrome and ASD/NDDs. 


\section{Introduction}

\subsection{Chromodomain helicase DNA-binding family of chromatin remodelers}

Chromatin is a DNA-protein complex offering the possibility to package large amounts of DNA into the small area of the nucleus by wrapping the DNA. The basic unit of the chromatin assembly is called nucleosome that consists of eight histone proteins (Ho \& Crabtree 2010). Depending on the chromatin condensation grade (loosely or tightly packed DNA), the transcription of a certain gene is possible or not, because transcription factors and RNApolymerases need free access to their binding sites. Therefore, the condensation of DNA provides an important mechanism to regulate gene expression in living cells (Wolffe 1992, Hall \& Georgel 2007). Chromatin remodelers can alter the structure of chromatin by different mechanisms: nucleosome sliding, histone exchange, nucleosome eviction and alteration of the nucleosome structure (Wolffe 1992, Allis et al. Epigenetics 2007, Hall \& Georgel 2007) (Fig. 2.1).

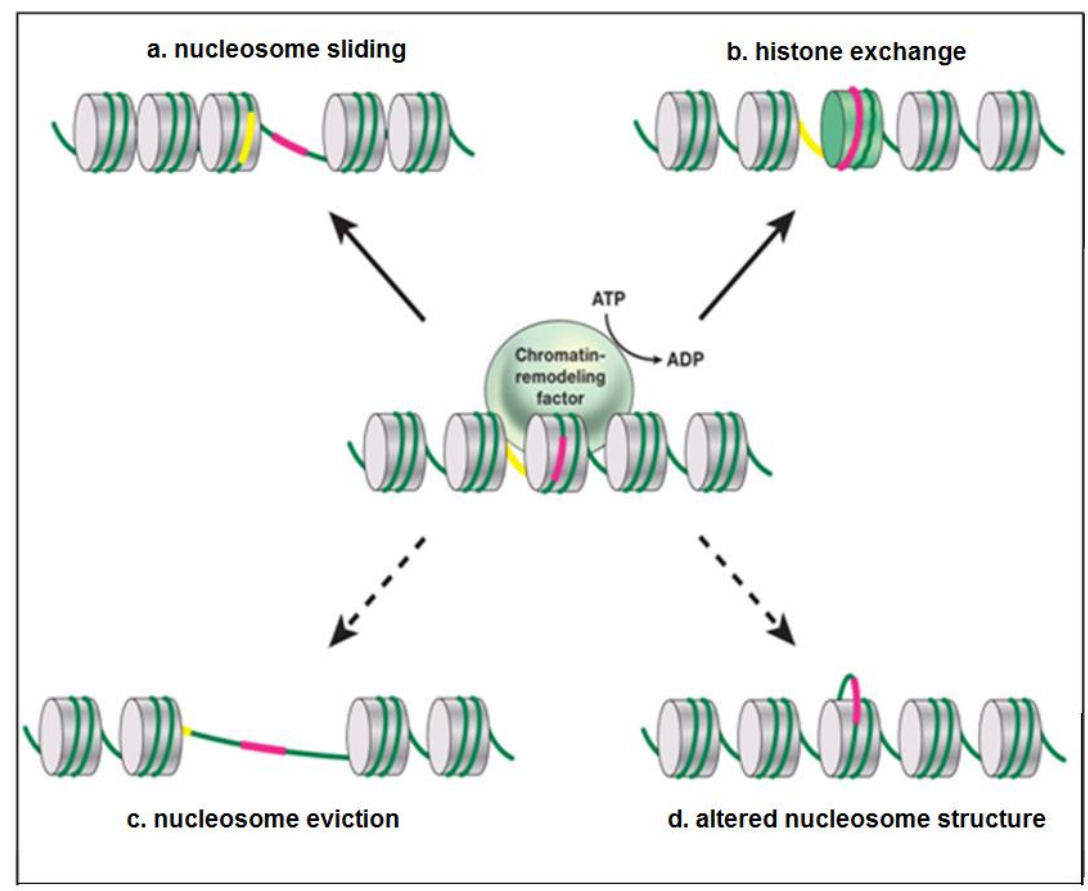

Figure 2.1. Mechanism for ATP-dependent chromatin remodeling. Different chromatin remodeling models are described by showing the change in position or composition of nucleosomes relative to the DNA wrapped around it. The central panel indicates a starting chromatin region where linker DNA is indicated in yellow and nucleosomal DNA in red. a: nucleosome sliding movement along the DNA, b: exchange of a variant histone for a standard histone to create a variant nucleosome, $\mathbf{c}$ : eviction of nucleosomes to open a large region of DNA. This mechanism might depend on other proteins, such as histone chaperones or DNA-binding factors, in addition of remodeling proteins, $\mathbf{d}$ : creating a loop on the surface of the nucleosome (Adapted and modified from Allis et al. Epigenetics 2007). 
Several chromatin remodeling complexes are known. The Chromodomain Helicase DNA binding (CHD) gene family belongs to the group of ATP-dependent chromatin remodelers (Ho \& Crabtree 2010). In human, the CHD family consists of 9 members. All of them share the unique combination of two chromodomains (chromatin organization modifier) (Messmer et al. 1992), a sucrose non-fermenting (SNF2)-like helicase/ATPase domain and DNA-binding domains (Hall \& Georgel 2007; Marfella \& Imbalzano 2007) (Fig. 2.2).

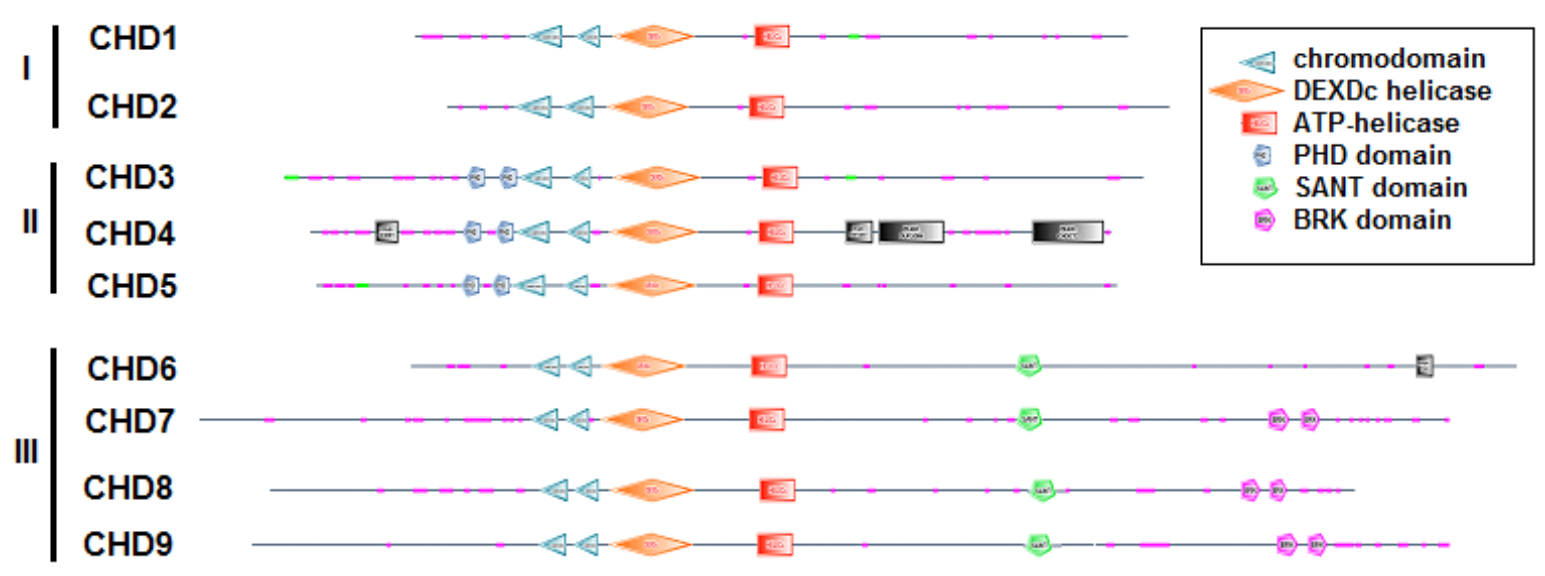

Figure 2.2. Structural domains of human CHD family of proteins. Full length protein sequences were analyzed by SMART program and modified. (http://smart.embl-heidelberg.de/). CHD1-2 (Subgroup I) have the simplest protein structure which is N-terminal 2 chromodomains, in the middle part a DEXDc helicase (DEAD like helicase), ATP-helicase (ATPase) domain and C-terminal a DNA-binding domain. CHD3-5 (Subgroup II) have in addition N-terminal double PHD (lant homeo domain) domains followed by the chromodomains. CHD69 (Subgroup III) proteins have in addition a C-terminal SANT domain followed by two BRK domains.

The SNF2-like ATPase domain was found in many proteins which are involved in chromatin assembly, transcription regulation, DNA repair, DNA replication, development and differentiation (Tsukiyama 2002, Smith \& Peterson 2005, de la Serna et al. 2006).

Mutational analysis of helicase and chromodomains revealed their crucial role for proper binding with chromatin (Kelley et al. 1999). Detailed functional analysis of chromodomains led to the suggestion that they mediate chromatin interactions through the direct binding of DNA, RNA, and methylated histone H3 (Akhtar et al. 2000, Bouazoune et al. 2002, Fischle et al. 2003, Min et al. 2003, Brehm et al. 2004, Flanagan et al. 2005, Pray-Grant et al. 2005, Sims et al. 2005, Kim et al. 2006).

Because of additional domains, the CHD family of protein members is further divided into 3 subgroups (Hall \& Georgel 2007, Marfella \& Imbalzano 2007) (Fig. 2.2). CHD1 and CHD2 belong to the first subgroup. They have the simplest protein structure among the other family members consisting of 2 chromodomains, a SNF2-like helicase/ATPase domain and DNA- 
binding domains. Although the subgroup I members are highly homologous to one another, they are significantly divergent in the 3 ' region.

The second subgroup contains CHD3, CHD4 and CHD5. They share in addition two Nteminal PHD (plant homeo domain) zinc finger domains (Sims \& Wade 2011) which are known to be involved in special chromatin remodeling mechanisms (Eberharter et al. 2004, Ragvin et al. 2004) as well as in epigenetic processes by binding to methylated histone peptides (Pena et al. 2006, Shi et al. 2006).

CHD6-9 belong to subgroup III. All subgroup III members have two BRK domains ( $\underline{B}$ rahma and $\underline{K}$ ismet domain) at C-terminus with unknown function, three conserved regions (CR1-3) with unknown function and a SANT domain ( $\underline{S}$ witching-defective protein $3, \underline{A}$ daptor

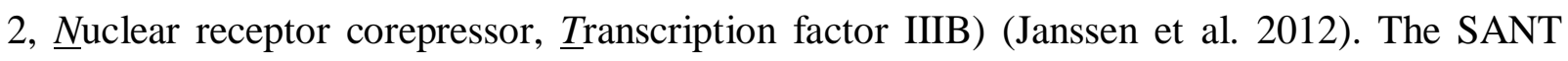
domain is suggested to act as a histone tail binding module (Boyer et al. 2004, Hall \& Georgel 2007) (Fig. 2.2).

\subsection{Function of CHD7}

Table 2.1 gives an overview of all human $C H D$ family members and their possible or known functions in humans or other species as well as their existing mutant models. A more detailed description is given for the CHD7 gene. CHD7 is involved in transcriptional regulation (Schnetz et al. 2009) and mutations in this gene lead to CHARGE syndrome (see 2.4) (Vissers et al. 2004).

The CHD7 gene is located on chromosome 8q12.1 and consists of 38 exons with the ATG in exon 2 and the stop codon in exon 38 . The genomic size is $188 \mathrm{~kb}$ and the gene encodes a protein with a predicted size of $336 \mathrm{kDa}$ (http://www.sciencegateway.org/tools/ proteinmw.htm). CHD7 is evolutionary highly conserved among species (orthologs were described in Xenopus, mouse, chicken, zebrafish, C.elegans and Drosophila melanogaster (Bosman et al. 2005, Aramaki et al. 2007, Shrinivasan et al. 2008, Bajpai et al. 2010). CHD7 expression is tissue and embryonic stage dependent and its expression pattern in human, mouse, chicken, zebrafish and in other species match with the developmental defects in CHARGE syndrome (Bosman et al. 2005, Lalani et al. 2006, Sanlaville et al. 2006, Aramaki et al. 2007). Since the discovery that $C H D 7$ mutations lead to CHARGE syndrome in human, the CHD7 gene has been studied more functionally. Several animal models for CHARGE syndrome were created (Table 2.1) (Siebert et al. 1985, Bergman et al. 2005, Hurd et al. 2007, Bajpai et al. 2010, Schnetz el al. 2010, Zentner et al. 2010, Patten et al. 2012). 


\begin{tabular}{|c|c|c|}
\hline Genes & Molecular functions & Mutants phenotype and in vivo function \\
\hline CHDI & $\begin{array}{l}\text { Transcriptional repressor. Interacts with SSRP1. } \\
\text { Transcription elongation, Transcription activator } \\
\text { (Gaspar-Maia A. et al. 2009) }\end{array}$ & $\begin{array}{l}\text { Maintenance of mouse embryonic stem cell. (Gaspar- } \\
\text { Maia A. et al. 2009) }\end{array}$ \\
\hline CHD2 & Unknown & $\begin{array}{l}\text { Chd } 2 \text { null mice embryos have growth retardation and die } \\
\text { before birth, } \\
\text { Decreased neonatal viability, non-neoblastic lesions } \\
\text { (Marfella et al., 2006) }\end{array}$ \\
\hline CHD3 & $\begin{array}{l}\text { Component of Nurd complex ( Tong et al. 1998, Xue } \\
\text { et al. 1998, Zong et al. 1998) } \\
\text { Drosophila: Nucleosome-stimulated ATPase activity } \\
\text { and mobilizes nucleosomes (Brehm et al. 2004) } \\
\text { Transcriptional repression (Sims et al. 2003) }\end{array}$ & $\begin{array}{l}\text { Several deficient model system of CHD3 suggest that it } \\
\text { has a role in transcription repression ( Kehle et al. 1998, } \\
\text { Wade et al. 1998, Solari \& Ahringer et al. 2000) }\end{array}$ \\
\hline CHD4 & $\begin{array}{l}\text { Component of Nurd complex ( Tong et al. 1998, Xue } \\
\text { et al. 1998, Zong et al. 1998) } \\
\text { Transcriptional repression (Sims et al. 2003) }\end{array}$ & $\begin{array}{l}\text { T-cell development, Lymphocyte differentiation } \\
\text { (Williams et al. 2004) }\end{array}$ \\
\hline CHD5 & Unknown & $\begin{array}{l}\text { Potential tumor suppressor in breast, colon, and } \\
\text { neuroectodermal cancers ( Sims and Wade 2011) }\end{array}$ \\
\hline CHD6 & $\begin{array}{l}\text { Localizes to sites of transcription and is induced by } \\
\text { DNA damage (Jennifer et al. 2011) }\end{array}$ & $\begin{array}{l}\text { One patient with translocation } \mathrm{t}(18 ; 20)(\mathrm{q} 21.1 ; \mathrm{q} 11.2) \text { has } \\
\text { mild to moderate mental retardation and minor facial } \\
\text { anomalies, including a broad, square face, hypertelorism, } \\
\text { flat nasal bridge, prominent ears, and a short neck. } \\
\text { (Karlscheuer et al. 2008) } \\
\text { CHD6 mutation in some transitional cell carcinoma (Gui } \\
\text { et al. 2011) }\end{array}$ \\
\hline CHD7 & $\begin{array}{l}\text { CHD7 binds in a cell type and developmental stage } \\
\text { specific manner to methylated histone H3K4 in } \\
\text { enhancer region (Bergman et al. 2005) } \\
\text { Transcriptional regulation of nuclear genes (Schnetz } \\
\text { el al. 2010) } \\
\text { Transcriptinal regulation of ribosomal RNA } \\
\text { biogenesis in nucleolus. Interacts through rDNA with } \\
\text { treacle, the protein involved in Treacher Collins } \\
\text { syndrome (Zentner et al. 2010) } \\
\text { Fine tuning effect on ES specific genes in mutant null } \\
\text { mouse ESCs. Chd7 colocalizes with ES cell master } \\
\text { regulators Oct4, Sox2 and Nanog. (Schnetz el al. } \\
\text { 2010) }\end{array}$ & $\begin{array}{l}\text { Whirligig Chd7 null mouse embryo dies at E10.5. } \\
\text { Heterozygous mice shows head bobbing and circling } \\
\text { behavior due to inner ear defect, heart malformations, } \\
\text { cleft palate, choanala atresia, genital anomalies etc. } \\
\text { (Bergman et al. 2005, Bosman et al. 2010) } \\
\text { Homozygous Chd7 gene trap mutant mice die pränatally. } \\
\text { Heterozygous associated with defects in multiple } \\
\text { developing tissues (Hurd et al. 2007) } \\
\text { Xenopus and human neural crest cell study showed it is } \\
\text { essential role for formation of multipotent migratory } \\
\text { neural stem cells. } \\
\text { Chd7 is required for the organization of the neural retina } \\
\text { in zebrafish. Knockdown of Chd7 display an abnormal } \\
\text { organization of motor neurons and severe loss of the } \\
\text { facial nerves (Siebert et al. 1985, Bajpai et al. 2010, } \\
\text { Patten et al. 2012) }\end{array}$ \\
\hline CHD8 & $\begin{array}{l}\text { CTCF-CHD8 has a role in insulation and epigenetic } \\
\text { regulation at active insulator sites. (Ishihara et al. } \\
\text { 2006) } \\
\text { CHD8 regulates HOXA2 gene expression negatively } \\
\text { (Yates et al. 2010) } \\
\text { Coregulator of androgen-responsive transcription } \\
\text { (Menon et al. 2010) } \\
\text { Xenopus: Duplin regulates Wnt signalling negatively } \\
\text { by binding beta-cathenin (Sacomoto et al. 2010) } \\
\text { CHD8 regulates beta-cathenin targeted genes } \\
\text { negatively. CHD8 interacts with the WAR complex } \\
\text { members (Thompson et al. 2008) }\end{array}$ & $\begin{array}{l}\text { Duplin knockout mice show early embryonic lethality } \\
\text { and growth retardation (Nishiyama et al. 2004) }\end{array}$ \\
\hline CHD9 & $\begin{array}{l}\text { It might be involved in differentiation of osteogenic } \\
\text { cells (Shur and Benayahu. 2005, Shur et al. 2006) }\end{array}$ & \\
\hline
\end{tabular}

Table 2.1. Overview of the functions of the CHD family of proteins.

Most of the malformations present in CHARGE patients have been observed in animal models of mouse, xenopus and zebrafish, e.g craniofacial malformations and heart defects etc 
(Bosman et al. 2005, Adams et al. 2007, Hurd et al. 2007, Cleary et al. 2009, Layman et al. 2009, Randall et al. 2009, Bajpai et al. 2010, Bergman et al. 2010, Jacobs-McDaniels \& Albertson 2011, Layman et al. 2011, Patten et al. 2012). Recent functional studies could show that CHD7 binding sites have features of enhancer elements (Heintzman et al. 2009). Indeed, a comparative gene expression study in embryonic stem cells (ESCs) derived from wild type, heterozygous and homozygous CHD7 mutant mice demonstrated that CHD7 binds predominantly to methylated histone $\mathrm{H} 3 \mathrm{~K} 4$ in enhancer elements and regulates genes in a cell type and stage specific manner (Schnetz et al. 2009, 2010).

Kismet is the ortholog of CHD supgroup III (CHD6-9) members in Drosophila. Srinivasan et al. (2008) studied Kismet and could demonstrate that it regulates gene transcription by

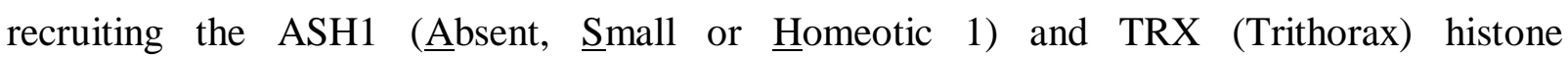
methyltransferases to chromatin.

In addition, a Chd7 knockdown in Xenopus multipotent migratory neural crest cells revealed that crucial transcription factors like Sox2, Slug, and Twist are diminished. Therefore, the authors suggest an important role for CHD7 in gene expression programs for neural crest cell migration and specification (Bajpai et al. 2010). However, a recent study of Randall et al. (2009) demonstrated that a Chd7 rescue in only neural crest cells cannot correct the phenotype of pharyngeal arch defects, while a Chd7 rescue in both neural crest cells and in ectoderm could do it. These findings demonstrate the necessity of CHD7 expression in ectoderm.

\subsection{Role of CHDs in human diseases}

To date, $C H D 3, C H D 4, C H D 5, C H D 7$ and $C H D 8$ are known to be involved in human diseases (Table 2.2). In dermatomyositis, which is a connective tissue disease, CHD3 and CHD4 have been characterized as autoantigens in inflammation of both muscle and skin (Airio et al. 1995, Ge et al. 1995, Seelig et al. 1995, 1996). CHD3 is also suggested to play a role in the pathogenesis of Hodgkin's lymphoma by interacting with Ki-1/57 (Lemos et al. 2003), an intracellular phosphoprotein which is a marker for malignant cells in Hodgkin's lymphoma (Schwab et al. 1982, Rhode et al. 1992).

CHD5 is found to be deleted in neuroblastoma and glioma cell lines (Thompson et al. 2003, Law et al. 2005, White et al. 2005). Neuroblastoma is an embryonal malignancy of the sympathetic nervous system arising from neuroblasts. It frequently affects infants, usually under two years old (www.nhs.uk/conditions/Neuroblastoma/Pages/Introduction.aspx). CHD5 is located on chromosome 1p36.31. Deletions of $1 \mathrm{p} 36$ are common in human neuronal, 
epithelial and hematopoietic cancers. Bagchi et al. (2007) demonstrated that CHD5 acts as a tumor suppressor that controls proliferation, apoptosis, and senescence.

Recent bioinformatic studies of Neale et al. (2011), O'Roak et al. (2012) and Talkowski et al. (2012) revealed chromosomal rearrangements, nonsense and missense mutations disrupting the CHD8 in patients with Autism Spectrum Disorders (ASD) and neurodevelopmental disorders (NDD), suggesting a role of CHD8 in the pathogenesis of these diseases (Neale et al. 2011, O’Roak et al. 2012, Talkowski et al. 2012).

\begin{tabular}{|c|c|c|}
\hline CHD Protein & Disease & Reference \\
\hline CHD3 & $\begin{array}{l}\text { Dermatomyositis } \\
\text { Hodgkin's lymphoma }\end{array}$ & $\begin{array}{l}\text { Nilasena et al. 1995, Seelig et al. 1995, Seelig et al. } 1996 \\
\text { Schwab U et al. } 1982\end{array}$ \\
\hline CHD4 & Dermatomyositis & Nilasena et al. 1995, Seelig et al. 1995, Seelig et al. 1996 \\
\hline CHD5 & Neuroblastoma & $\begin{array}{l}\text { Thompson et al. 2003, Law et al. 2005, White et al. } 2005 \\
\text { Bagchi et al } 2007\end{array}$ \\
\hline CHD8 & Autism spectrum disorders and NDD & Neale et al. 2011, Talkowski et al. 2012, O'Roak et al. 2012 \\
\hline CHD7 & $\begin{array}{l}\text { CHARGE Syndrome } \\
\text { Kallman syndrome, normosmic IHH }\end{array}$ & $\begin{array}{l}\text { Visser et al. 2004, Williams et al.2005 } \\
\text { Kim et al. 2008, Jongmans et al. 2009, Bergman et al. 2011a }\end{array}$ \\
\hline
\end{tabular}

Table 2.2. Human diseases associated with CHD proteins (Adapted and modified from Marfella \& Imbalzano 2007). NDD = neurodevelopmental disorders, IHH = idiopathic hypogonadotropic hypogonadism.

\subsection{CHD7 and CHARGE syndrome}

CHARGE syndrome is an autosomal dominant inherited disease caused by heterozygous CHD7 mutations (Vissers et al. 2004). The name "CHARGE" is an acronym describing commonly occurring clinical symptoms like Coloboma, Heart malformation, Atresia of the choanae, Retardation of Growth and development and Genital anomalies (Pagon et al. 1981, Blake et al. 1998, Jongmans et al. 2006, Lalani et al. 2006, Bergman et al. 2011b). Additional symptoms like cleft lip/palate and tracheoesophageal fistula can occur, leading to a high variability in the clinical presentation of CHARGE syndrome patients. Therefore, diagnostic criteria were set up to help clinicians finding the right diagnosis. The currently used criteria for CHARGE syndrome were defined by Blake et al. (1998) and updated by Verloes in 2005.

According to Blake et al. (1998), major criteria are: anomalies of ear (90-100\% of patients with CHD7 mutation), ocular coloboma and/or microphthalmia (80-90\%), cranial nerve dysfunction, swallowing and breathing difficulties (70-90\%). Minor criteria according to Blake are: genital anomalies, developmental and growth retardation, congenital heart defects, cleft lip/palate, tracheoesophageal fistulas and facial dysmorphism (Horsch \& Scheele 2011). If four 
main or three main and three minor criteria are present, patients will be clinically diagnosed with CHARGE syndrome. In Verloes's criteria (2005) eight key features are proposed, three major (coloboma, choanal atresia, semicircular canals anomalies) and five minors (rhombencephalic anomalies, hypothalamic-hypophyseal dysfunction, external/middle ear malformations, malformation of mediastinal viscera, and mental retardation). If $2 / 3$ major elements and at least 3/5 minor traits are present, CHARGE can be diagnosed. Verloes also classified CHARGE "borderline phenotypes" in two groups: partial (or incomplete) CHARGE and atypical CHARGE. The diagnosis "partial CHARGE" get those patients who present 2 major and only 1 minor sign, whereas the diagnosis "atypical CHARGE" is given to those patients who have 2 major and no minor, or 1 major and at least 3 minor signs (Verloes 2005).

CHD7 mutations have been found also in patients with Kallman Syndrome (KS) (Table 2.2) (Kim et al. 2008, Jongmans et al. 2009, Bergman et al. 2011a). Kallman syndrome is a clinically and genetically heterogenous disease which combines the absence of puberty (Hypogonadotropic Hypogonadism) with defective sense of smell (hyposmia or anosmia) (Dodé \& Hardelin 2009). It is suggested that Kallmann syndrome is a mild variant of the phenotypic spectrum of CHARGE syndrome.

Mutations in the $C H D 7$ gene are distributed along the coding region, no mutation hotspots could be observed. Most frequent are nonsense and frameshift mutations (approximately 75\% of all mutations) followed by missense and splice site mutations (20\% of all mutations). Complete and partial deletions/duplications and chromosomal rearrangements are rarely found in CHARGE syndrome patients (Fig. 2.3) (Janssen et al. 2012).

But not in all clinically diagnosed patients with CHARGE syndrome mutations in the CHD7 gene were found (Jongmans et al. 2006, Lalani et al. 2006, Bergman et al. 2011a). Depending on different studies and which diagnostic criteria are used, the CHD7 mutation detection rate is in range of $33-100 \%$ for patients suspected of CHARGE syndrome and in average calculated as 58\% (Vissers et al. 2004, Aramaki et al. 2006, Felix et al. 2006, Jongmans et al. 2006, Lalani et al. 2006, Sanlaville et al. 2006, Vuorela et al. 2007, Asakura et al. 2008, Wincent et al. 2008, Lee et al. 2009, Wessels et al. 2010). The average detection rate is much higher in patients diagnosed as "typical CHARGE syndrome patients". For instance, Jongmans et al. (2006) found CHD7 mutations in more than $90 \%$ of patients who fulfilled the diagnostic criteria of Blake et al. (1998) and/or Verloes (2005). Therefore, in 10\% of typical 


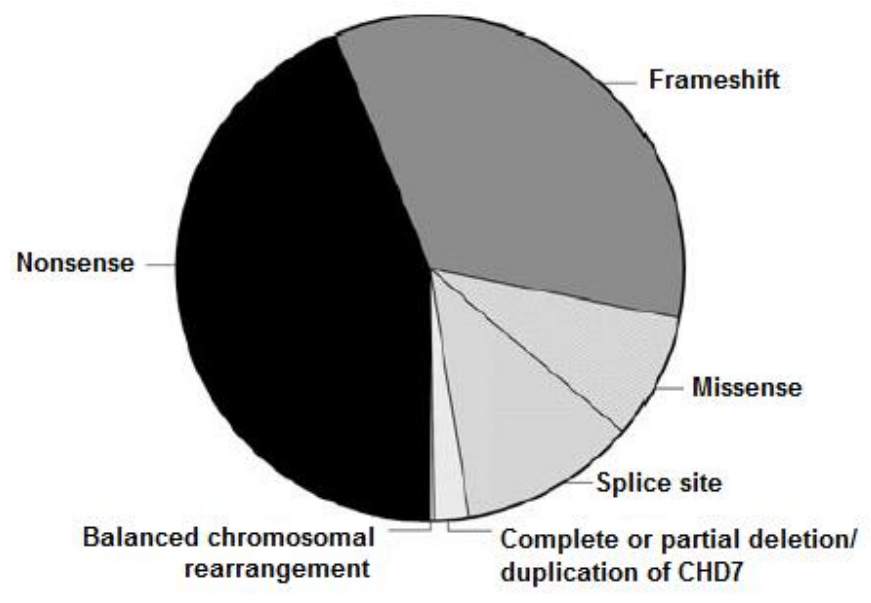

Figure 2.3. Distribution of pathogenic mutation types in the $C H D 7$ gene. Nonsense and frameshift mutations are in over $75 \%$ of the patients with CHARGE syndrome. Missense and splice site mutations occur in $20 \%$. Complete and partial deletions/duplications and chromosomal rearrangements happen rarely (Adapted from Janssen et al. 2012).

CHARGE syndrome patients the molecular cause of the disease is unknown. Similar as in many other autosomal dominant diseases, also in CHARGE syndrome, genetic heterogeneity of more than one gene resulting in the disease is realized. For example, Noonan syndrome is caused by mutations in Ras/MAP kinase pathway genes such as PTPN11, SOS1, KRAS, RAF1, NRAS, BRAF or MAP2K1 (Tartaglia et al. 2001, Carta et al. 2006, Schubbert et al. 2006, Nava et al. 2007, Razzaque et al. 2007, Roberts et al. 2007, Zenker et al. 2007, Sarkozy et al. 2009, Cirstea et al. 2010), while Cornelia de Lange syndrome is caused by mutations in NIPBL, SMC1A and SMC3 (interaction partner of SMC1A) (Krantz et al. 2004, Tonkin et al. 2004, Musio et al. 2006, Deardorff et al. 2007).

Therefore, we suggest genetic heterogeneity in CHARGE syndrome. Possibly, mutations in CHD7 interaction partners lead also to a CHARGE syndrome phenotype. Thus, aim of the study was:

* to identify and characterize CHD7 interaction partners in order to understand the genetic basis behind CHARGE syndrome

$>\quad$ Identification, validation and characterization of exact interacting area of CHD7 and CHD8

$>\quad$ What is the influence of some missense mutations of CHD7 to its' interacting capacity to CHD8 
$>\quad$ Identification of a novel interacting member of the CHD7-CHD8 complex by SILAC (Stable isotope labeling by amino acids in cell culture) and mass-spectrometry approach

$>\quad$ Characterization of FAM124B protein, a novel hitherto unknown interacting member of CHD7 and CHD8 containing complex. 


\section{Results}

3.1 CHD8 interacts with CHD7, a protein which is mutated in CHARGE syndrome

3.2 Identification and characterization of FAM124B as a novel component of a CHD7 and CHD8 containing complex

Each chapter within the results starts with a brief description of the aims of the particular manuscript in context of the complete thesis, the status of the manuscript, and the author's contribution to the work. 


\subsection{CHD8 interacts with CHD7, a protein which is mutated in CHARGE syndrome}

In this part of my thesis, we identified CHD8, another member of the CHD family of proteins, as an interaction partner of CHD7. CHD7 mutations are found in two-third of patients with CHARGE syndrome. Because of the information that some hereditary diseases are caused by alterations in several genes (genetic heterogeneity) of whom some of the gene products interact with each other, we studied interaction partners of CHD7. We used a part of CHD7 (amino acid 1593-2183) for a yeast two hybrid library screen and found CHD8 (amino acid 17892091) as a potential interaction partner. The exact interacting area of both CHD proteins was identified by direct yeast two hybrid. The interaction of CHD7 and CHD8 was confirmed by direct yeast two-hybrid, co-immunoprecipitation and bimolecular fluorescence complementation assays. Furthermore, we studied the influence of 3 known (p.His2096Arg, p.Val2102Ile and p.Gly2108Arg) and one newly identified missense mutation (p.Trp2091Arg) of the CHD7 gene on the CHD7 and CHD8 interaction. Therefore, we performed direct $\mathrm{Y} 2 \mathrm{H}$ and CoIP experiments. Interestingly, the CHD7-CHD8 interaction was disrupted by the missense mutations p.Trp2091Arg, p.His2096Arg and p.Gly2108Arg in the direct Y2H experiment, while no influence on the CHD7-CHD8 binding capacity could be observed in CoIP studies. We explained the different findings of direct Yeast two hybrid and Co-IP results in that way that with Yeast two hybrid experiments a direct interaction between two proteins could be tested while Co-IPs cleaned up a whole complex and possible linker proteins can bridge the mutated area. In addition, twenty five CHD7 negative CHARGE patients were screened for CHD8 mutations. But no mutation could be detected in the candidate gene CHD8 in our patients. As a result we hypothesized that CHD7 and CHD8 interact directly and indirectly via linker proteins. Further characterization of the complexes might help to better understand the pathogenesis of CHARGE syndrome.

Tserendulam Batsukh, Lasse Pieper, Anna M. Koszucka, Nina von Velsen, Sigrid Hoyer-Fender, Miriam Elbracht, Jorieke E.H. Bergman, Lies H. Hoefsloot, Silke Pauli

Status: Published in Human Molecular Genetics (Impact Factor 8.058). Volume 19, No. 14, 2010, pp.2858-2866, (doi:10.1093/hmg/ddq189)

\section{Author contributions to the work:}

1. Tserendulam Batsukh: Performed direct yeast two hybrid and CoImmunoprecipitation experiments; made the constructs of 4 missense mutations in 
pGBKT7-CHD7 and Co-IP constructs pCMV-Ha-CHD7 (wild type and mutated) and pCMV-Myc-CHD8; involved in manuscript preparation.

2. Lasse Pieper: performed BiFC-assay and made the constructs of pGBKT7-CHD7 wildtype and pGBKT7-CHD8 wildtype; performed direct $\mathrm{Y} 2 \mathrm{H}$ experiments.

3. Anna M.Koszucka: performed the yeast two hybrid library screening.

4. Nina von Velsen: performed the CHD8 mutational analysis in $C H D 7$ mutation negative CHARGE patients.

5. Sigrid Hoyer-Fender: generated the BiFC assay vectors FPCA-V1 and FPCA-V2 from pEGFP-N1 vector (BD-Bioschience).

6. Miriam Elbracht: patient care; providing patient data and DNA samples

7. Jorieke E.H. Bergman: patient care; providing patient data and DNA samples

8. Lies H. Hoefsloot: patient care; providing patient data and DNA samples

9. Silke Pauli: Concept and research design; interpretation of the results and preparation of the manuscript. 


\title{
CHD8 interacts with CHD7, a protein which is mutated in CHARGE syndrome
}

\author{
Tserendulam Batsukh ${ }^{1}$, Lasse Pieper ${ }^{1}$, Anna M. Koszucka ${ }^{1,3}$, Nina von Velsen ${ }^{1}$, \\ Sigrid Hoyer-Fender ${ }^{2}$, Miriam Elbracht ${ }^{4}$, Jorieke E.H. Bergman ${ }^{5}$, Lies H. Hoefsloot ${ }^{6}$ \\ and Silke Pauli ${ }^{1, *}$
}

${ }^{1}$ Institute of Human Genetics, University of Göttingen, 37073 Göttingen, Germany, ${ }^{2}$ Johann-Friedrich-Blumenbach Institute of Zoology and Anthropology-Developmental Biology, University of Göttingen, 37077 Göttingen, Germany, ${ }^{3}$ Department of Biochemistry, University of Erlangen-Nürnberg, 91058 Erlangen, Germany, ${ }^{4}$ Institute of Human Genetics, RWTH Aachen University, 52074 Aachen, Germany, ${ }^{5}$ Department of Genetics, University Medical Centre Groningen, University of Groningen, 9700 RB Groningen, The Netherlands and Department of Human Genetics, Institute of Genetic and Metabolic Disease, Radboud University Nijmegen Medical Center, $6500 \mathrm{HB}$ Nijmegen, The Netherlands

Received February 25, 2010; Revised April 5, 2010; Accepted May 5, 2010

\begin{abstract}
CHARGE syndrome is an autosomal dominant disorder caused in about two-third of cases by mutations in the $C H D 7$ gene. For other genetic diseases e.g. hereditary spastic paraplegia, it was shown that interacting partners are involved in the underlying cause of the disease. These data encouraged us to search for CHD7 binding partners by a yeast two-hybrid library screen and CHD8 was identified as an interacting partner. The result was confirmed by a direct yeast two-hybrid analysis, co-immunoprecipitation studies and by a bimolecular fluorescence complementation assay. To investigate the function of $\mathrm{CHD} 7$ missense mutations in the CHD7-CHD8 interacting area on the binding capacity of both proteins, we included three known missense mutations (p.His2096Arg, p.Val2102lle and p.Gly2108Arg) and one newy identified missense mutation (p.Trp2091Arg) in the CHD7 gene and performed both direct yeast two-hybrid and co-immunoprecipitation studies. In the direct yeast two-hybrid system, the CHD7-CHD8 interaction was disrupted by the missense mutations p.Trp2091Arg, p.His2096Arg and p.Gly2108Arg, whereas in the co-immunoprecipitation studies disruption of the CHD7-CHD8 interaction by the mutations could not be observed. The results lead to the hypothesis that $\mathrm{CHD} 7$ and $\mathrm{CHD} 8$ proteins are interacting directly and indirectly via additional linker proteins. Disruption of the direct CHD7-CHD8 interaction might change the conformation of a putative large CHD7CHD8 complex and could be a disease mechanism in CHARGE syndrome.
\end{abstract}

\section{INTRODUCTION}

CHARGE syndrome (OMDM 214800) is an aufosomal dominant malformation syndrome. The disorder is characterized by variable combinations of coloboma, heart defects, atresia of the choanae, retarded growth and development, genital hypoplasia, ear anomalies and deafiness $(1-3)$. Additional features such as cranial nerve palsy, semicircular canal agenesis, cleft lip/palate, tracheo-oesophageal fistula and renal anomalies are described (4-6).
Mutations in the $C H D 7$ gene are the major cause of CHARGE syndrome $(4,5,7-10)$. A large cohort of patients, who had received the clinical diagnosis CHARGE syndrome, was tested for $\mathrm{CHD} 7$ mufations and the clinical spectrum was studied. Prominent differences in the phenotype could not be observed between the mutation-positive and the mutationnegative groups (4).

$\mathrm{CHD} 7$ belongs to the $\mathrm{CHD}$ (chromodomain helicase DNA binding) family of proteins, which share the combination of two N-terminal chromodomains, followed by a

To whom correspondence should be addressed at: Institute of Human Genetics, Heinrich-Dutcer-Weg 12, D-37073 Göttingen, Germany. Tel: +49 551399016; Fax: +49 551397567; Email: spauli@gwdg.de

(1) The Author 2010. Published by Oxford University Press. All rights reserved.

For Permissions, please emait: journats.permissions@oxfordjournats.org 
SWL/SNF2-like ATPase/helicase domain (11-13). The CHD group can be further divided into three subgroups according to sequence similarities and additional functional domains. CHD7 belongs together with CHD6, CHD8 and CHD9 to subgroup III. Distinctive features of this subgroup are the presence of three conserved regions (CR1-CR3), a SANT domain and two BRK domains $(14,15)$. To date, the molecular functions of subgroup III members are poorly understood.

CHD family members are involved in chromatin remodelling as it was shown for CHD1 $(14,16)$. Alterations in chromatin structure are important for the regulation of gene transcription, DNA repair, replication and recombination. Chromatin remodelling enzymes can be divided into two categories, those that alter chromatin structure by histone modification (17) and those that alter the histone-DNA contacts within the nucleosome by using energy of ATP hydrolysis (18). Members of the CHD group belong to the SNF2 superfamily of ATPdependent chromatin remodelers $(12,15)$. For most SNF2-like ATPases, it was shown that they are components of large multisubunit complexes. For some CHD family members, several protein-protein interactions have been described. Chd1 of $S$. cerevisiae is a component of the two highly homologous acetyltransferase complexes SAGA and SLIK (19), CHD3 acts together with CHD4 as components of the nucleosomeremodelling and histone deacetylase (NuRD) complex (14). CHD8 interacts directly with WDR5 (20), a component of the histone H3 Lys-4 methyltransferase MLL complex (21).

CHD7 interacts in vitro with its chromodomains with methylated forms of H3K4 (22). It was shown that during mouse ES cell differentiation, the CHD7 sites change with the $\mathrm{H} 3 \mathrm{~K} 4$ pattern and the CHD7 sites are predominantly located distal to transcription statt sites (22). Because of these observations, it was suggested that $\mathrm{CHD} 7$ plays a role in enhancer mediated transcription of key target genes (22).

On the basis of sequence similarities between $\mathrm{CHD} 7$ and other CHD members, it can be suggested that CHD7 acts in a large multisuburit complex. Therefore, binding partners of CHD7 could be candidate genes for CHARGE syndrome.

Fot other diseases, e.g. hereditary spastic paraplegia (HSP), it was shown that interacting partners are involved in the underlying cause of the disease. Mutations in spastin (SPG4) and in its binding partner ZFYVE27 (SPG33) lead to HSP (23). In Connelia de Lange syndrome, mutations in the cohesion regulators NIPBL and ESCO2 and in different components of the cohesion complex (SMC1A and SMC3) were reported (24). These data from the literature encouraged us to search for CHD7 binding partners by a yeast two-hybtid library screen using a part of CHD7 as bait. In our yeast twohybrid library screen, we identified CHD8, another CHD subgroup III member, as a specific interaction partner of CHD7. We confirmed this result by direct yeast two-hybrid studies, co-immunoprecipitation experiments and by a bimolecular fluorescence complementation assay (BiFC-Assay). Furthermore, we characterized the interacting part of $\mathrm{CHD} 7$ and $\mathrm{CHD} 8$, introduced four missense mutations in the $\mathrm{CHD} 7$ interacting part and performed direct yeast two-hybrid experiments and co-immunoprecipitation studies. In the yeast two-hybrid system, the CHD7-CHD8 interaction was distupted by three missense mutations (p.Trp2091Atg, p.His2096Atg and p.Gly2108Arg), whereas in the co-immunoprecipitation studies no distuption of the CHD7-CHD8 interaction by the mutations could be observed. These findings indicate that $\mathrm{CHD} 7$ and $\mathrm{CHD} 8$ are interacting directly and indirectly via additional linker proteins. Loss of the direct CHD7-CHD8 interaction might change the conformation of a possible CHD7-CHD8 containing complex, which might be a disease mechanism in CHARGE syndrome.

\section{RESULTS}

Identification of CHD8 as a potential binding partner of CHD7 by Y2H library screening

To identify CHD7 interacting proteins, we screened a human foetal brain cDNA libraty (BD Clontech). The plasmid CHD7-CR1-3-pGBKT7 (amino acids 1591-2181) containing the three conserved regions CR1-CR3 and the SANT domain of the $\mathrm{CHD} 7$ protein was used as bait. We screened $3.34 \times 10^{7}$ clones and identified 21 clones, which were able to grow in selective media. Eighteen clones were also positive for $\alpha$-galactosidase expression. From these clones, plastnids were isolated and sequenced. Eleven clones contained parts of the coding region of CHD8. One clone showed a correct reading frame, whereas in 10 clones the reading frame of the CHD8 region to the GAL4 activation domain was incorrect. The correct clone encodes the protein region from amino acids 1789-2091 (NP_065971.2) of the CHD8 protein and this clone was used in further experiments.

\section{Confirmation of the CHD7-CHD8 interaction by direct Y2H experiments}

To specify the CHD7-CHD8 interacting area, we performed direct $\mathrm{Y} 2 \mathrm{H}$ experiments using the plasmids CHD7-CR1pGBKT7 (amino acids 1593-1768), CHD7-CR2-pGBKT7 (amino acids 1701-1948) and CHD7-CR3-pGBKT7 (amino acids $1950-2172$ ) as bait, respectively. These plastnids contain either the conserved region 1, or 2 or 3 (Figs 1 and 2A). CHD7-CHD8 interaction could only be observed in the part-spanning amino acids $1950-2172$, containing the conserved region 3 (CR3) of the CHD7 protein (Fig. 2A). The three known missense mutations p.His2096Arg, p.Val2102Ile and p.Gly2108Atg $(4,25,26)$ identified in CHARGE patients are located within this CHD7-CHD8 interacting area. Furthermore, we identified in a patient with atypical CHARGE syndrome another new missense mutation (p.Trp2091Arg) which resides also in this region. We created four new bait constructs for the interacting region (amino acids 19502172), each containing one of these missense mutations (CHD7-His2096Atg-pGBKT7, CHD7-Val2102Ile-pGBKT7, CHD7-Gly2108Atg-pGBKT7 and CHD7-Trp2091ArgpGBKT7, Fig. 1) and performed direct yeast two-hybrid experiments with the CHD8-pGADT7-Rec plastnid as prey. The CHD7-CHD8 interaction was distupted by the missense mutations p.Trp2091Atg, p.His2096Arg and p.Gly2108Atg, but not by the missense mutation p.Val2102Ile.

To narrow down the interacting area of $\mathrm{CHD} 8$, we created two new prey constructs, CHD8-pGADT7-1 (amino acids 17891983) and CHD8-pGADT7-2 (amino acids 1985-2091). The CHD8-pGADT7-2 includes the first BRK domain, while 


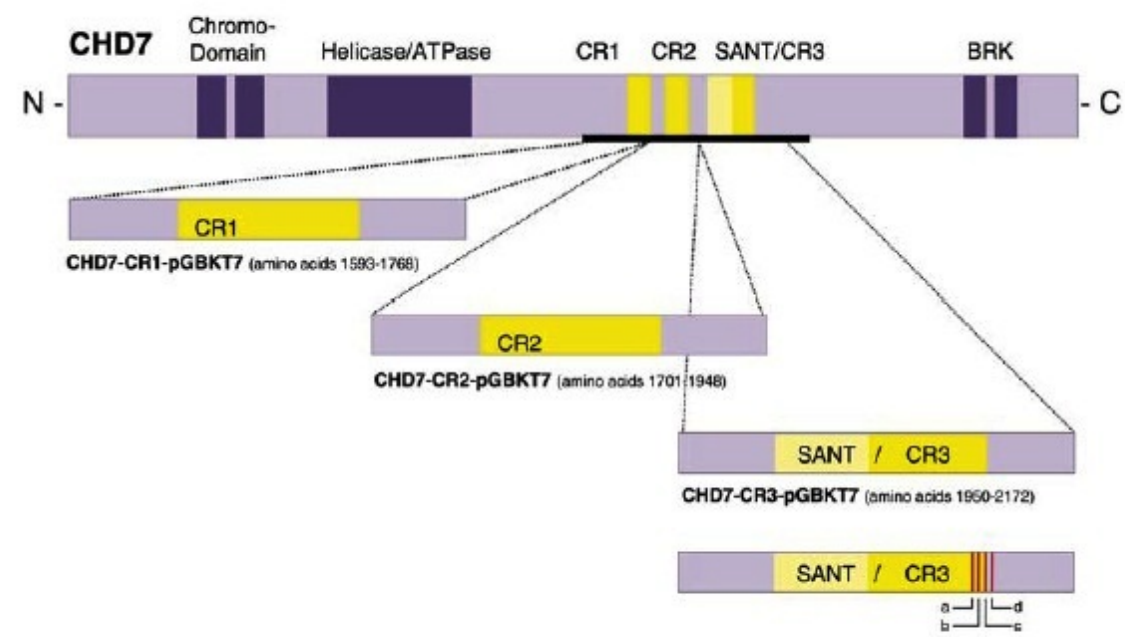

Figure 1. Schematic overview of the CHDT protein and the constructs used as baits in the yeast two-hybrid assay. CHD7 consists of two N-terminal chromedemains, followed by a SWT2/SNF2-like ATP ase/helicase demain, three conserved regions (CR1 CR3), a SANT domain and two BRK dornains. The plasmids CHD7-CR1-pGEKT7, CHD7-CR2-pGEKT7 and CHD7-CR3-pGEKT7 diwide the CHD7-CR1-3-pGBKT7 bait plasmids (black lane spantining amine acids

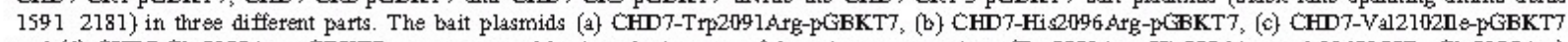

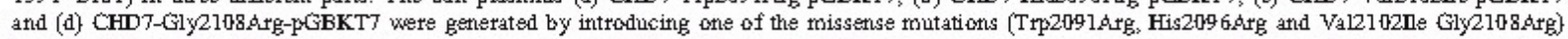
inte the CHD7-CR3-p广EKT 7 part spantring the amine acids 19502172 of the $\mathrm{CHD} 7$ protein.

CHD8-pGADT7-1 does not code for a known protein domain We performed again a firect yeast two hybrid with all four $\mathrm{CHD} 7$ plasmids containing missense mutations and with the plasmid CHD7-CR3-pGBKT7 as positive control and the plasmid CHD 7-CR1-pGBKT7 as negative contro1. We identified the $\mathrm{CHD} 7-\mathrm{CHD} 8$ interaction within the $\mathrm{CHD} 8$ part spanning the amino acids $1789-1983$. This result supports our observation that the missense mutations p.Trp2091 Arg, p.His2096 Arg and p.Gly2108Arg disnut the interaction (Fig. 2B).

\section{CHD7-CHD8 interaction analysed by bimolecular fluorescence complementation assay (BiFC-Assay)}

To confirm the $\mathrm{CHD} 7-\mathrm{CHD} 8$ interaction, we performed a BiFC-Assay. The principle of this technique is based on the observation that splitted $N$ - and C-terminal EGFP fragments do not emit a bright fluorescence. If the two splitted non-functional EGFP halves are fused to proteins that interact, they can functionally complement and emit a bright fluorescence (27). HeLa cells were either transiently $\mathrm{Co}$-transfected with the plasmids CHD7-FPCA-V1 and CHD8-FPCA-V2 or transfected with a single plasmid as negative control. After $24 \mathrm{~h}$, the cells were analysed for the presence of fluorescence complementation As shown in Figure 3, we observed in co-transfected cells a bright green fluorescence in the nucleus. Single-transfected cells did not show any fluorescence signal. Because fluorescence complementation was only observed in $\mathrm{CHD} 7-\mathrm{CHD} 8 \mathrm{co}$-transfected cells, these results confirm the $\mathrm{CHD} 7-\mathrm{CHD} 8$ interaction shown in the yeast two-hybrid system.

\section{CHD8 co-immunoprecipitates with $\mathrm{CHW} 7$}

To further verify the $\mathrm{CHD} 7-\mathrm{CHD} 8$ interaction, we performed co-immunoprecipitation studies in HeLa cells. After transfection and cell culture for $24 \mathrm{~h}$, the cells were lysed and protein extracts were prepared A part of the $\mathrm{CHD} 7$ protein (amino acids 1593-2178) was fused to an HA-tag, while a part of the $\mathrm{CHD} 8$ protein (amino acids $1789-2302$ ) was fused to a c-Myc tag. The CHD7 part fused to the HA-tag was estimated to produce a $\sim 70 \mathrm{kDa}$ protein fragment, while the $\mathrm{CHD} 8$ part labelled with a c-Myc tag was calculated to have a size of approximately $61 \mathrm{kDa}$. Using a c-Myc antibody for precipitation, we detected with an HA antibody a $\sim 70 \mathrm{kDa}$ band corresponding to the estimated size of the $\mathrm{CHD} 7$ part (Fig. 4A). The reciprocal experiment, precipitation with an $\mathrm{HA}$ antibody and detection with the c-Myc antibody lead to a specific band of about $68 \mathrm{kDa}$ in size (Fig. $4 \mathrm{~B}$ ). To further confirm the specificity of the observed bands, we precipitated with c-Myc and detected with the c-Myc antibody again the specific $68 \mathrm{kDa}$ band strongly supporting that this band corresponds to the CHD8-c-Myc fusion protein The reciprocal experiment was also performed (Fig. 4C and D).

To investigate the influence of the missense mutations in the $C H D 7$ gene in the $\mathrm{CHD} 7-\mathrm{CHD} 8$ interacting area in an in vivo system, we performed co-immunoprecipitation studies with the CHD7-His2096Arg-pCMV-HA, CHD7Va12102Пle-pCMV-HA, CHD7-G1y2108Arg-pCMV-HA and CHD7-Trp209lArg-pCMV-HA plasmids, respectively. Interestingly, in all four cases, the mutated $\mathrm{CHD} 7$ part was co-immunoprecipitated with the $\mathrm{CHD} 8$ part (Fig. $4 \mathrm{E}$ and $\mathrm{F}$ ).

\section{DISCUSSION}

Mutations in the $C H D 7$ gene lead to CHARGE syndrome, which is a well-known congenital malformation syndrome. The $\mathrm{CHD} 7$ protein belongs to the $\mathrm{CHD}$ (chromodomain helicase DNA-binding domain) family of ATP-dependent chromatin remodelling enzymes. The human $\mathrm{CHD}$ family consists of 
A

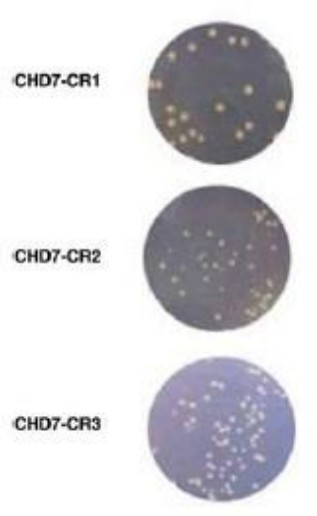

$-L T$
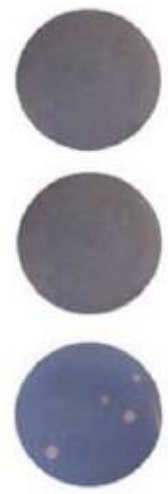

-LTHA

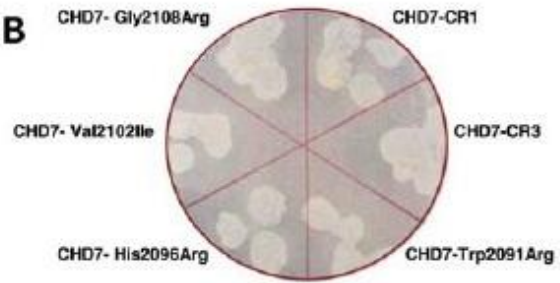

-LT

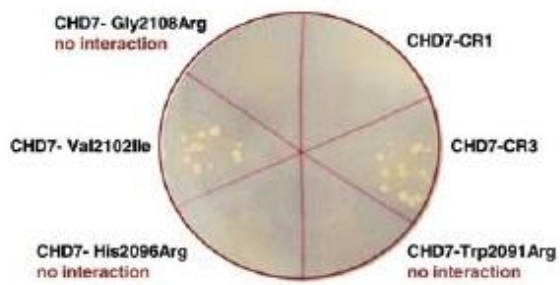

-LTHA

Figure 2. Yeast two-hybrid assay. (A) Direct yeast two-hybrid experiment with the constructs CHD7-CR1-pGBKT7, CHD7-CR2-pGBKT7 and CHD7-CR3-pGBKT T as baits, which diwide the CHD7-CR.1-3-psBKT7 bait plasmids (amine acids 1591 2181) in three different parts. CHDT CHD8 interaction takes place in the part spanting amine acids 19502172 , containing the conserved region 3 (CR3) of the CHD7 protein. (B) Direct yeast twe-hybrid experiment with all four CHD7 plasmids containing a missense mutation and the plasmid CHD7-CR3-pGBKT7 as positive control and the plasmid CHD7-CR 1-pGBKT7 as negative control. The CHD8 plasmid CHD8-pGedDT7-1 (amine acids 1789 1983) was used as prey. The CHD7 CHD8 interaction

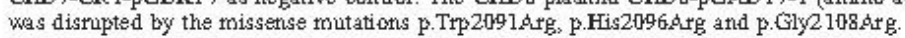

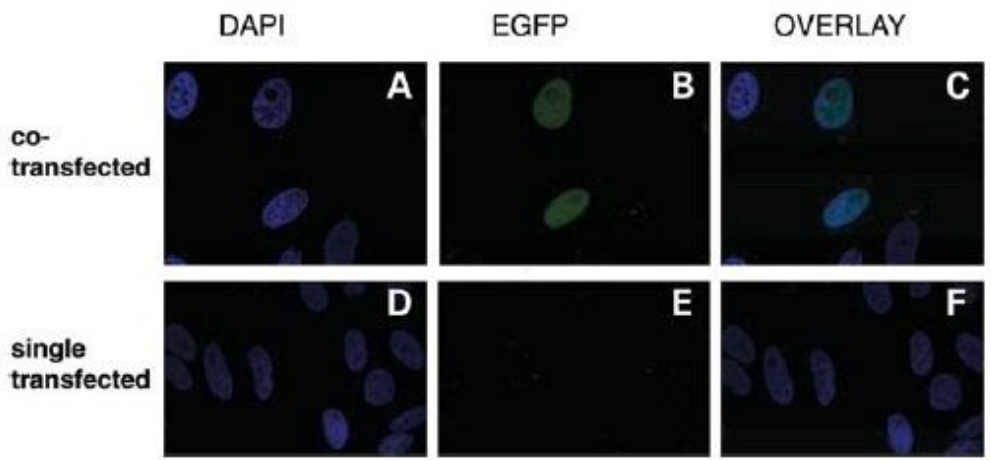

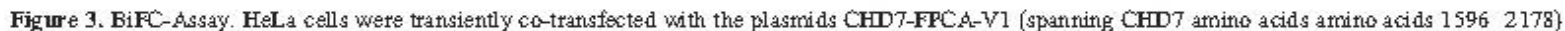
and CHD8-FPC fuorescent signal demonstrating CHDT CHDB interaction by fluotescence complementation and with localization in the nucleus, (C) overlay of ( $d$ ) and (B). As negative control HeLa cells were transfected with a single construct (D F)

nine members, which can be grouped in three subgroups based on homologies in the sequence and domain architecture (12). Chromatin remodelling is an important mechanism for the regulation of gene expression and it is known that chromatin remodelling is carried out by multi-protein complexes (28). It can be hypothesized that $\mathrm{CHD} 7$ is also a component of a multisubunit complex. Identification and characterization of $\mathrm{CHD} 7$ binding proteins might provide insights into the molecular mechanism in which $\mathrm{CHD} 7$ is involved.

In this study, we identified $\mathrm{CHD} 8$, another subgroup III member of the CHD family of proteins, as an interacting partner of $\mathrm{CHD} 7$ by a yeast two-hybrid library screen. The specificity of the interaction was confirmed by direct yeast two-hybrid studies, co-immunoprecipitation experiments and by a BiFC-Assay. CHD8 consists, such as $\mathrm{CHD} 7$, of two Nterminal chromodomains, followed by a SW2/SNF2-like ATPase/helicase domain and specific for subgroup III members of three conserved regions (CR1-CR3), a SANT domain and two BRK domains (12). It has been shown that CHD8 interacts with human Staf (ZNF 143), a zinc finger transcription factor, which controls the expression of the U6 gene (29). Furthermore, $\mathrm{CHD} 8$ was co-purified with components of 

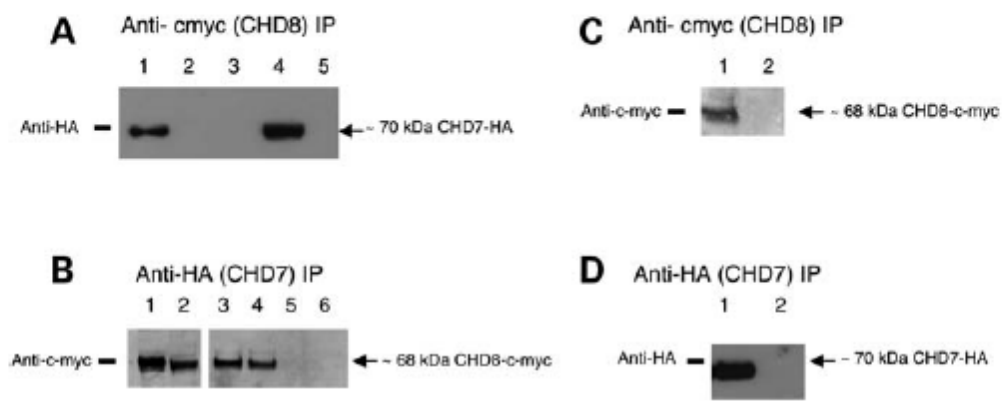

E Anti-cmyc (CHD8) IP
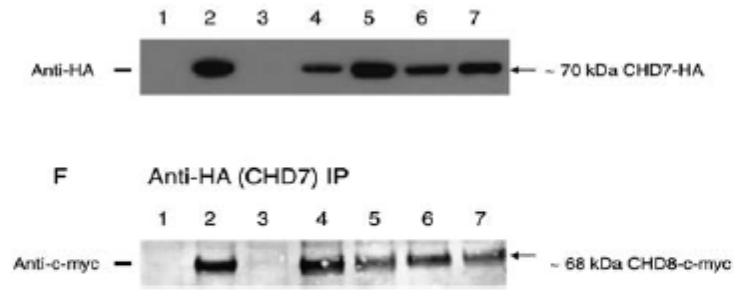

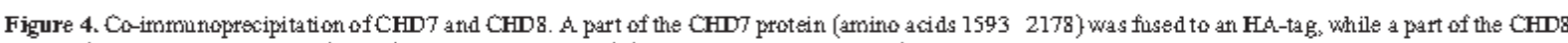
protein (amine acids 1789 2302) was fused to a c-Mlyc tag. (A) Using a c-MYyc antibody for precipitation, we detected a $\sim 70 \mathrm{kDa}$ band with an He antibody corresponding to the estimated size of the CHD7 part (lane 1). Lane 1: ce-transfected Co-IP, lane 2: CHD7 single-transfected HeLa cells and CHD7 co-IP as negatiwe contrel, lane 3: untransfected HeLa cells as negatiwe control, lane 4: co-transfected input, lane 5: untransfected input. (B) The reciprocal experiment, precipitation with an He antibody and detection with the c-MYc antibody leads to a specific band of approximately $68 \mathrm{kDa}$. Lane 1: CHD8 input, lane 2: co-transfected input, lanes 3 and 4: co-transfected Co-IP, lane 5: CHD single-transfected HeLa cells and CHD8 Co-IP as negative control, lane 6: untransfected HeLa cells as negative control. (C) Precipitation with c-Myc and detection with the c-Myc antibody. Lane 1: co-transfected Co-IP, lane 2: untransfected Co-IP as negative control. A specific $68 \mathrm{kD}$ a band was detected, strongly supporting that this band corresponds to the CHD8-c-Myc fusion protein. (D) The reciprocal

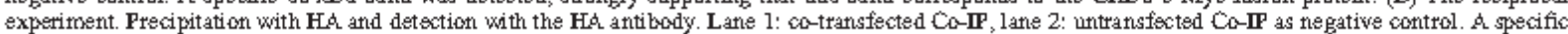
$\sim 70 \mathrm{kDa}$ band, corresponding to the CHD7-Hh fusion protein could be detected. (E and F) Investigation of the influence of four missense mutations in the CHD7 gene on the CHD7 CHD8 interaction by co-immuneprecipitation studies. Lane 1: untransfected Co-IP as negative control, lane 2: wild-type co-transfected Co-IP as positive control, lane 3: CHD7 single-transfected HeLa cells and CHD7 co-IP as negative control, lane 4: co-transfected Co-IP with

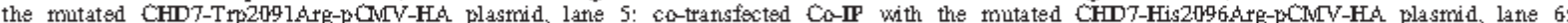

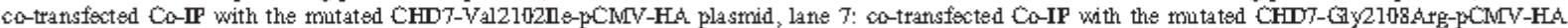
plasmid. (E) Precipitation with c-MYyc and detection with the Hol antibody. (F) Precipitation with Hed and detection with the c-MIyc antibody.

the MLL 1-WDR 5 complex $(20,30)$ and was found to interact directly with beta-catenin and playing a role in the regulation of beta-catenin target genes (20). Mouse Chd8 was shown to bind via its BRK domains Ctcf, an insulator binding protein involved in insulation and epigenetic regulation (31). With its tandem chromodomains, CHD 8 binds in vitro specifically to histone $\mathrm{H} 3$ di-methylated at lysine 4 (32). CHD 8 was also found to be associated with the elongating form of RNA polymerase $I$ and to control the expression of cyclin E2 and thymidylate synthetase (32).

In Drosop hila melanogaster, kismet is the only gene related to the subgroup III members of the $\mathrm{CHD}$ gene family. Kismet encodes for two isoforms, a large protein with a molecular weight of $574 \mathrm{kDa}$ (KIS-L) and a small isoform of $225 \mathrm{kDa}$ (KIS-S) $(33,34)$. Kis-L is highly related to the human $\mathrm{CHD} 7$ or other $\mathrm{CHD}$ subgroup III members. Kis- $\mathrm{L}$ belongs to the trithorax group and was shown to play an important role in body segmentation and segment identity of Drosophila larvae (33). Furthemore, it was suggested that lis- $L$ is involved in an early step of transcriptional elongation by RNA Polymerase II ( $\mathrm{Pol}$ II), because it is co-localized with most RNA-Polymerase $I$ sites $(32,35,36)$. In kismet mutant larvae, a reduction in the levels of elongating $P_{0} 1 \mathrm{II}$ and the elongation factors SPT6 and CHDl was observed (35). In contrast to Drosop hila, CHD8 depletion in mammals does not reduce in general the levels of Ser2-phosphorylated RNA Polymerase II (32). It was suggested that in mammals, the function of kismet is overtaken by several subgroup III members (CHD6-CHD9) and that depletion of one subgroup III member leads to a gene-specific and not a general effect (32). In the present study, we could show that two subgroup III members, namely $\mathrm{CHD} 7$ and $\mathrm{CHD} 8$, interact. We hypothesize that $\mathrm{CHD} 7$ and $\mathrm{CHD} 8$ together build a core component of a complex with similar functions such as kismet. Interestingly, the situation that two members of the same subgroup interact was found for the subgroup $I$ members $\mathrm{CHD} 3$ and CHD4. In Drosopirita, there is only a single gene related to subgroup II, named Mi-2. This Drosopsila gene encodes also for two transcripts $(15,37)$. In mammals, CHD 3 and CHD4 were found to build together a core component of the NuRD complex $(14,38)$.

Mutations in $\mathrm{CHD} 7$ interacting genes, which are involved in the same molecular mechanism, may also cause CHARGE syndrome. In three children with developmental delay, cognitive impaiment and similar dysmorphic features a submicroscopic deletion on chromosome 14q11.2 was detected (39). 
The minimal overlapping region of approximately $35 \mathrm{~kb}$ includes only the SUPTI $6 \mathrm{H}$ and the CHDS gene, leading to the suggestion that haploinsufficiency of $\mathrm{CHD} 8$ plays a role in the patient's phenotype (39). Because the patient's phenotype is different from the phenotype seen in CHARGE syntrome patients, we suggested that the heterozygous deletion of $C H D B$ is not a possible tisease mechanism in CHARGE syndrome. However, nucleotide alterations (e.g. missense mutations) in a gene can lead to a more severe or different phenotype than gross deletions, because an aberrant protein can tisturb the function of its interacting partner. Therefore, we performed $C H D \&$ sequence analysis in 25 patients suspected of CHARGE syndrome, where the sequence and MLPA analysis of the CHD7 gene revealed no mutations or deletions/duplications. No pathogenic mutations in CHDS were identified (data not shown). However, small exon de1etions or duplications in the CHD\& gene were not excluded by the sequence analysis. Our results could neither indicate that $C H D \&$ mutations are causative for $C H A R G E$ syndrome, nor could $C H D \&$ be excluded as a candidate gene in the pathogenesis of this disease. Further investigations of the CHD 8 gene in a larger cohort of $\mathrm{CHD} 7$ negative $\mathrm{CHARGE}$ patients are needed to clarify this aspect. To investigate the effect of CHD7 missense mutations in the $\mathrm{CHD} 7-\mathrm{CHD} 8$ interacting sequence on the binding capacity of both proteins, three known $C H D 7$ missense mutations were included (p.His2096Arg, p.Val2 102He and p.Gly2l08Arg) $(4,25,26)$ as well as a new identified missense mutation (p.Trp209 $1 \mathrm{Arg}$ ) in the CHD7 gene recently found by our group in a CHARGE patient. We performed tirect yeast twohybrid analyses and co-immunoprecipitation stuties. In the tirect yeast two-hybrid system, the $\mathrm{CHD} 7-\mathrm{CHD} 8$ interaction was disrupted by the missense mutations, p.Trp2091 Arg, p.His2096Arg and p.Gly2108Arg. The missense mutation p.Gly2 108Arg was described in two different families with five affected members (26). From the five affected members, only one fulfilled the diagnostic criteria for CHARGE syntrome while the others showed a very mild phenotype. Our patient with the missense mutation p.Trp2091Arg is also affected with atypical CHARGE syndrome. She has bilateral coloboma and microphthalmia of the left eye, microcephaly, mental retardation and unilateral deafiness.

In contrast to the results obtained in the direct yeast twohybrid experiments, co-immunoprecipitation studies did not reveal a disruption of the $\mathrm{CHD} 7-\mathrm{CHD} 8$ interaction by the mutations described above. This discrepancy strongly indicates that $\mathrm{CHD} 7$ and $\mathrm{CHD} 8$ might be components of a larger complex. Direct yeast two-hybrid studies analyse the tirect interaction of two proteins. A complex of proteins with different influences on binding partners, e.g. bridging proteins, cannot be studied by this method. However, co-immunoprecipitation studies can detect linker proteins between $\mathrm{CHD} 7$ and $\mathrm{CHD} 8$ which stabilizes a possible protein complex. For example, it was shown that mouse Chds binds Ctcf via its BRK domains (31). For human $\mathrm{CHD} 7$, there was also an interaction with $\mathrm{CTCF}$ via its $\mathrm{BRK}$ domains observed (40). We suggest that $\mathrm{CHD} 7$ and $\mathrm{CHD} 8$ are inferacting directly (as we showed by our yeast two-hybrid results) and infirectly via additional linker proteins such as CTCF. Further studies are needed to discover such linker pro- teins, which could influence the severity of $C H D 7$ mutations or which could be another underlying cause of CHARGE syntrome, if present in a mutated contition

\section{MATERIALS AND METHODS}

\section{Yeast two-hybrid analysis}

Yeast two-bybrid screen. For the identification of putative CHD 7 interacting partners, we used the MATCHMAKER ${ }^{\text {TM }}$ human foetal brain cDNA library (BD, Clontech), which was pre-transformed into the yeast strain Y187. The bait plasmid CHD7-CR1-3-pGBKT7 was constructed by subcloning a fragment of $\mathrm{CHD} 7$ (amino acids 1591-2181, containing the area of conserved regions $1-3$ ) into the pGBKT7 vector (Clontech) in frame to the GALA DNA-binding domain. The correct reating frame and the correct sequence were confirmed by sequencing the plasmid.

The bait plasmid CHD7-CR1-3-pGBKT7 was transformed into AHI09 yeast strain cells and was tested for toxicity and autoactivation of the bait reporter genes. No toxicity for the yeast cells and no self-activation of the bait reporter genes could be observed. The AHl09 yeast strain cells containing the bait plasmid were mated with the MATCHMAKER library Y187 cells. After mating, tiploids were plated on leucine-tryptophan-histidine-adenine lacking SD medium (-LTHA-SD metium) plates. Colonies growing on the -LTHA-SD medium plates were picked and spread on -LTHA-SD medium plates containing X- $\alpha$-Gal. Blue colonies were cultured for plasmid isolation, which was carried out using the YEASTMAKER ${ }^{\text {TM }}$ Yeast Plasmid Isolation Kit (BD, Clontech) according to the manufacturer's instructions. Isolated plasmids were subcloned into competent $E$. colt cells. Transformants were spread out on Ampicillin containing plates for the selection of clones bearing the pGADT7-Rec library vector. Inserts of the pGADT7-Rec vector were characterized by sequence analysis.

To avoid false positive results, the candidate plasmid CHD8-pGADT7-Rec (amino acids 1789-2091) was retransformed into AHI09 yeast cells together with the empty bait vector pGBKT 7 and selected on -LTHA-SD plates. No colonies were able to survive, inticating lack of self-activation of the system by the CHD8-pGADT7-Rec plasmid.

Direct yeast two hybrid. Direct yeast two-hybrid analysis was performed for confirmation of the $\mathrm{CHD} 7-\mathrm{CHD} 8$ interaction. For this purpose, the identified CHD8-pGADT7-Rec prey plasmid and the CHD7-CR1-3-pGBKT7 bait plasmid were co-transformed into AHlog yeast strain cells. The co-transformants were grown on -LT-SD metium plates for transformation control and the interaction was verified on selective -LTHA-SD medium plates.

To specify the $\mathrm{CHD} 7-\mathrm{CHD} 8$ interacting area, we generated three constructs CHD7-CR1-pGBKT7, CHD7-CR2-pGBKT7 and $C H D 7-C R 3-p G B K T 7$ which divide the CHD7-CR1-3-pGBKT7 bait plasmids (amino acids $1591-$ 2181) in three different parts (Figs 1 and $2 A$ ). The first fragment consists of the CRl region and corresponds to amino acids 1593-1768. The second fragment spans the $\mathrm{CR} 2$ part (amino acids 1701-1948), while the third fragment consists 
of the SANT domain and the $\mathrm{CR} 3$ region, corresponting to amino acids $1950-2172$. These $\mathrm{CHD} 7$ fragments were subcloned into the pGBKT 7 vector (Clontech) and the three constructs CHD7-CR1-pGBKT7, CHD7-CR2-pGBKT7 and CHD 7-CR3-pGBKT7 were used as baits for direct yeast twohybrid analysis.

To study the effect of lowown $\mathrm{CHD} 7$ missense mutations on the CHD7-CHD8 interaction, the bait plasmids CHD7His2096Arg-pGBKT7, CHD7-Va12 102Ile-pGBKT7, CHD7Gly2 108Arg-pGBKT7 and CHD7-Trp2091Arg-pGBKT7 were generated by introducing one of the missense mutations (His2096 Arg, Val2 102Tle Gly2108Arg and Trp2091 Arg) into the $C H D 7$ region spanning amino acids $1950-2172$. An overview of the used plasmids is given in Figure 1 .

To narrow down the interacting area of $\mathrm{CHD} 8$, we created two prey constructs, CHD8-pGADT7-1 (amino acids 17891983) and CHD8-pGADT7-2 (amino acids 1985-2091) tividing the $C H D 8$ interacting area found in the initial library screen All plasmids were checked for the correct sequence and reading frame by sequence analysis.

\section{Cell culture}

HeLa cells were cultured in Dulbecco's motified Eagle's media (DMEM) (PAN BIOTECH), supplemented with 10\% foetal calf serum (PAN BIOTECH) and $1 \%$ penicillin/streptomycin (PAN BIOTECH). For transfection, cells were plated into two chamber culture slides (BD Falcon) and $50 \mathrm{ml}$ flasks (Sarstedt). After $24 \mathrm{~h}$ when the cells" confluence reached about $70-80 \%$, they were transfected with the plasmid DNA using OptiMEM serum-free medium (Gibco) and Lipofectamine 2000 transfection reagent (Invitrogen) according to the manufacturer's instruction After transfection, cells were grown for additional $24 \mathrm{~h}$ in DMEM.

\section{Co-immunoprecipitation}

For co-immunoprecipitation stuties, we generated the plasmid CHD7-CR1-3-pCMV-HA by cloning a part of the CHD7 gene (amino acids 1593-2178, NP_060250.2) in frame to the hemagglutinin (HA) epitope tag into the pCMV-HA vector (Clontech). A part of the CHDS gene (amino acids 17892302, NP_065971.2) was cloned in frame to the N-terminal c-Myc epitope tag into the pCMV-Myc vector (Clontech) for the construction of the CHD8-pCMV-c-Myc plasmid. The CHD7 missense mutations (His2096Arg, Val2 102Mle Gly2 108Arg and $\operatorname{Tr} 2091 \mathrm{Arg})$ were introduced into the CHD7-CR1-3-pCMV-HA plasmid, leading to the four new plasmids CHD7-His2096Arg-pCMV-HA, CHD7-Val2 102IlepCMV-HA, CHD7-G1y2108Arg-pCMV-HA and CHD7Trp2091Arg-pCMV-HA. The correct reading frame and sequence was confirmed by sequence analysis.

HeLa cells cultured in $50 \mathrm{ml}$ flasks (Sarstedt) were transiently co-transfected with one of the CHD7 constructs (wildtype plasmid CHD7-CR1-3-pCMV-HA or mutant constructs) and CHD8-pCMV-c-Myc. After incubation for $24 \mathrm{~h}$ at $37^{\circ} \mathrm{C}$, transfected cells were washed twice with ice-cold DPBS. After washing, the cells were treated for $30 \mathrm{~min}$ on ice with $400 \mu 1$ lysis buffer (Immunoprecipitation kit, Roche). Centrifugation at $14000 \mathrm{~g}$ for $20 \mathrm{~min}$ was carried out to remove cell debris. Forty microlitre of total protein extract was used for westem blot analysis. When both transfected proteins were detected by westem blot analysis, the remaining protein extract which was stored at $4^{\circ} \mathrm{C}$ was incubated with either $1 \mu \mathrm{g}$ of monoclonal anti-HA (Roche) or 1:100 diluted anti-c-Myc (Millipore) antibody at $4^{\circ} \mathrm{C}$ ovemight. Eighty microlitre of protein $G$ (Immunoprecipitation lit, Roche) was added to the inmunocomplex and incubated for $2 \mathrm{~h}$ at $4^{\circ} \mathrm{C}$. Centrifugation at $350 \mathrm{rpm}$ for $3 \mathrm{~min}$ was carried ouf to collect the agarose beads. The beads were washed two times in $500 \mu 1$ lysis buffer to remove unbound proteins. A resuspension of the beads in NuPAGE LDS Sample buffer (Invitrogen) with $0.1 \mathrm{~m} \mathrm{DTT}$ followed. After denaturation for $10 \mathrm{~min}$ at $75^{\circ} \mathrm{C}$, the denaturated beats were loaded onto a $4-12 \%$ NuPAGE Bis-Tris gel (Invitrogen). Proteins were immunoblotted with the anti-c-Myc antibody (Millipore) at a dilution of $1: 500$ or the anti-HA antibody (Roche) at a tilution of 1:1000. The following secondary antibodies were used: allaline phosphatase labelled anti-mouse antibody produced in goat (SIGMA) was used for anti-c-Myc and horseratish peroxidase labelled anti-rat antibody produced in goat (Thermo Scientific) was used for anti-HA detection

\section{Bimolecular fluorescence complementation assay (BiFC-A55ay)}

For the BiFC-Assay, we cloned a part of the CHD7 gene (amino acids 1596-2178, NP_060250.2) in the FPCA-V1 vector and a part of the CHDS gene (amino acids 17912302, NP_0659712) in the FPCA-V2 vector. The FPCA-V1 vector was generated from the $\mathrm{PEGFP}-\mathrm{Nl}$ vector (BD Bioscience). The FPCA-V1 vector contains a CMV promotor followed by a multiple cloning site in which we introduced the CHD7 part, a spacer region and the C-terminal end of EGFP (amino acids 158-239). The FPCA-V2 vector, generated from the pQM-Ntag/B plasmid (Abcam, UK), contains a CMV promoter, followed by an E2 tag, the $N$-terminal part of EGFP (amino acids 1-157), a spacer and the multiple cloning site in which we introduced the CHDs part. HeLa cells were co-transfected with $0.5 \mu \mathrm{g}$ of each construct. After incubation for $24 \mathrm{~h}$ at $37^{\circ} \mathrm{C}$, the cells were washed with DPBS, fixed with $4 \%$ paraformaldehyde and again washed with DPBS. After the washing step, cover slips were attached onto slides using Vectashield mounting solution containing DAPI (4,6-diamidino-2-phenylindole). Fluorescence imaging was performed using the Olympus BX60 microscope (Olympus, Hamburg, Germany).

\section{Mutational analysis}

CHD 8 analysis was performed in 25 patients suspected of CHARGE syndrome, where the sequence and deletion analysis (MLPA, MRC Holland) of the CHD7 gene revealed no mutation. The coding sequence of all 37 coding exons and flanking intronic sequences of the $C H D \&$ gene were analysed by $\mathrm{PCR}$ and sequenced in both directions in $\mathrm{CHD} 7$ negative CHARGE patients. Primer sequences and PCR conditions are available on request.

The ethical approval was obtained from the Ethics Committee of the Georg-August University Göttingen. 


\section{ACKNOWLEDGEMENTS}

We thank W. Engel for his support and helpful discussions. We also thank $P$. Burfeind for careful reading of the manuscript, S. Kaulfuss for her help in microscopy and imaging and $M$. Steckel for excellent technical assistance.

Confict of Interest statement. None declared.

\section{FUNDING}

This work was supported by the Forschungsförderungsprogramm of the Medical School of the University of Göttingen (to S.P.).

\section{REFERENCES}

1. Hall, B.D. (1979) Choanal atresia and associated multiple anomalies. J. Pediat., 95, 395398.

2. Hittner, HM., Hirsch, N.J., Kreh, G.M. and Rudolph, A.J. (1979) Colobornatous microphthalmia, heart disease, hearing loss, and mental retardation a syndrome. J. Pediatr. Ophthaimol. Strabismus, 16, 122128.

3. Pagon, R.A, Graham, J.MI H, Zonana, J. and Yong, S.L. (1981) Coloborna, congenital heart disease, and choanal atresia with multiple anomalies. CHARGE association. J. Pediatr., 99, 223227

4. Lalani, S.R., Safmllah, A.M., Fernbach, S.D., Harutyunyan, K.G., Thaller, C., Peterson, L.E., MICPherson, J.D., Gibus, R.A., White, L.D., Hefiner, MI et al (2016) Spoctrum of CHD7 mutations in 110 individuals with CH\&RCE syndrome and genotype phenetype correlation. Am. J. Hiam. Genet, 78, 303 314.

5. Jongmans, M.C., Adrmiraal, R.J., wan der Donk, K.P., Vissers, L.E., Baas, A.F., Kapusta, L., van Hagen, J.M., Deninai, D., de Ravel, T.J., Veltman, I.A et al (20H6) CH.R.GE syndrome: the phentotypic spectrum of mutations in the CHD7 gene. J. Med. Genet, 43, 306 314.

6. Sarlaville, D. and Verloes, $d$ ( $(2 W T)$ CHLRGE syndrome: an update. $E_{\text {tar. }} J$. Hram Genet., 15, 389399.

7. Vissers, L.E., wan Rawenswaaij, C.MI., Admiraal, R., Hurst, J.A., de Vries, B.B., Jatissen, I.M., van der Vliet, W.A., Huys, E.H., de Jong, F.J., Hamel, B.C. et al (2h-4) MLtations in a new member of the chromodemain gene family cause CHdRGE syndrome. Nat Genet, 36, 955957.

8. Sarlawille D., Etchewers, H.C., Gorzales, MI., Martintowic, I. Clément-Ziza, M., Delezoide, A.L., Aubry, MLC., Felet, A., Chemouny, S., Cruad, C. et $\alpha$ l. (2016) Phenotypic spectrum of CHed.GE syndrome in fetuses with CHD7 truncating mutations correlates with expression during human development. J. Med. Genet, 43, 211217.

9. Aramaki, MI., Udaka, T., Kesakd, R., Makita, Y., Okameto, N., Yoshihashi, H., Oki, H., Nanae, K., Moriyama, N., Okn, S. et al (2016) Phenetypic spectrum of CHLLR.GE syndrome with CHD7 mutations. J. Pediatr., 148, 410 414 .

10. Wincent, J., Holmberg, E., Strö̈mland, K, Seller, ML., Mirzaei, L. Djureinowic, T., Robinson, K., Anderlid, B. and Schoumans, I. (20r8) CHD7 mutation spectrum in 28 Swedish patients diagnosed with CHAR GE syndrome. Clin. Genet., 74, 3138.

11. Woodage, T., Bastai, M. $\boldsymbol{A}_{\text {., }}$ Baxevanis, A.D., Hieter, F. and Collins, F.S (1997) Characterization of the CHD fanily of proteins. Proc Nat Acad $S C$. USA, 14, 11472 11477.

12. Flaus, A., Martin, D.M., Barten, G.J. and Owen-Hughes, T. (20-6) Identification of multiple distinct $\mathrm{Snf}$ subfamilies with conserved structural motifs. Nucleic Acid's Res., 31, 2887 29h5.

13. Flanagan, J.F., Blus, B.J., Kim, D., Clines, K.L., Rastinejad, F. and Khorasanizadeh, S. (2WWT) Molecular implications of evolutionary differences in CHD double chromodomains. J. MOl. B iol., 369, 334342

14. Hall, J.A. and Georgel, F.T. (20مT) CHD proteins: a diverse farnily with strong ties. Biochem Cell Biol, 85, 463476

15. Marfella, C. $G$. and Imbalzane, $A$. N. (2W T) The Chd farnily of chromatin remodelers. Mutut. Res, $61 \mathrm{~B}, 30 \mathrm{~T}$.
16. Delmas, V., Stekes, D.G. and Perry, R.P. (1993) A mammalian

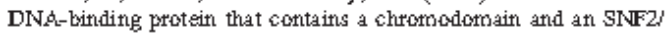
SWI2-like helicase domain. Proc. Nati Acad Sci. USA, 90, 24142418. 17. Zhang, Y. and Reinberg, D. (20H) 1) Transcription regulation by histone methylation: interplay between different covalent modifications of the core histone tails. Genes Dev, 15,23432360 .

18. Becker, P.B. and Herr, W. (2hr2) ATP-dependent nucleosome remodeling. Anutc Rev. Biachem., 71, 247 273

19. Pray-Grant, M.G., Daniel, J. $\boldsymbol{d}$, Schieltz, D., Yates, J.R. 3rd and Grant, P.A. (20-15) Chdl chromodomain links histone $\mathrm{H}_{3}$ methylation with SAGQb-and SLIK-dependent acetylation. Natare, 27, 434438.

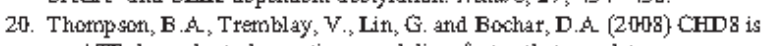
an $A$ TP-dependent chromatin remodeling factor that regulates beta-catenin target genes. Mol. Cell $B$ iol. 28, 3894 39h 4.

21. Song, J.J. and Kingston, R.E. (2015) WDRS interacts with mixed lineage leukernia (MLL) protein wia the histone H3-kinding pocket. $J$. Biol Chem., 12, 35258 35264

22. Schnetz, M.F., Bartels, C.F., Shastri, K, Balasubramarian, D., Zentner, $G . E$, Balaji, R., Zhane, $X$, Sone, L., Wang, $Z$, Laframboise, $T$. et al. (20199) Genomic distribution of $\mathrm{CHD} 7$ on chromatin tracks H3K4 methylation patterns. Genome Res., 19, 590 601.

23. Mantian, A.U., Krawen, P., Sauter, S.ML, Beehur, J., Chronowska, d., Paulus, W. Neesen, J. and Engel, W. (2016) ZFYVE27 (SFG33), a novel spastin-binding protein, is mutated in hereditary spastic paraplegia. Am J. Hram. Genet, 79, 351357 .

24. Dearderff, MLA., Kaur, M., Yaeger, D., Rampuria, A., Korelev, S., Fie, I., Gil-Rodríguez, C., Atnede, ML., Lays, B., Kline, A.D. et al. (20H7) Mutations in cohesin complex members SMC 3 and SMClA cause a mild variant of comelia de Lange syndrome with predominant mental retardation. Am. J. Hikm. Genet, BO, 485494

25. Fólix, T.M., Hanshaw, B.C., Mueller, R., Bitoun, P. and Murray, J.C. (2016) CHW7 gene and non-syndromic cleft lip and palate. Am. J. Med Genet $A, 1,2110,2114$

26. Jongmans, M.C., Hoefsloot, L.H., wan der Donk, K.P., Addmiraal, R.J., Magee, A., wan de Laar, I., Hendriks, Y., Verheij, J.B., Walpole, I., Brunner, H.G. et al (20)8) Familial CHARGE syndrome and the CHD7 gene: a tecurrent missense mutation, intrafarnilial tecurrence and variability. Am. $J$. Med. Genet. $A, 1,4350$

27. Remy, I. and Wichnick, S.W. (2hH4) A cDNA library functional screening strategy based on fluorescent protein complementation assays to identify nowel components of signaline pathweys. Methods, 32, 381388.

28. Saha, A., Wittmeyer, J. and Caims, B.R. (20156) Chromatin remodelling: the industrial rewolution of DNA around histones. Nat Rev. Mol. Cell $B$ iol., 7,437447

29. Yuan, C.C., Zhae, X., Florens, L., Swanson, S.K., Washbum, MLP. and Hernandez, N. (2007) CHD8 associates with human Staf and contributes to efficient U6 RNA polymerase III transcription. Mol. Cell $B$ iol, 27, 87298738

37. Dou, Y., Miline, T.A., Tackett, A.I., Smith, E.R., Fukuda, A, Wysocka, I., dullis, C.D., Chait, B.T., Hess, J.L. and Roeder, R.G. (2.065) Physical association and coordinate function of the $\mathrm{H} 3 \mathrm{~K} 4$ methyltransferase MLL 1 and the H4 K16 acetyltransferase MOF. Cell, 17, 873885 .

31. Ishihara, K, Oshimura, MI. and Nakas, M. (2006) CTCF-dependent chromatin insulator is linked to epigenetic remodeling. Mol Cell., 1 , $733 \quad 742$.

32. Rodriguez-Paredes, M., Ceballos-Cháwez, M., Esteller, M., Garcia-Dominguez, MI. and Reyes, J.C. (20.59) The chromatin remodeling facter CHD8 interacts with elongating RNA polymerase II and controls expression of the cyclin E2 gene. Mrcleic Acids Res., 37, 2449 246n.

33. Daubresse, G., Deuring, R., Moore, L., Papoulas, O., Zakrajsek, I., Waldrip, W.R., Scott, M.P., Kentrison, J.A and Tamkun, J.W. (1999) The Drosophila kismet gene is related to chromatin-remodeling facters and is required for both segmentation and segment identity. Development, 126, 11751187

34. Therrien, M., Morrison, D.K, Wong, A.M. and Rukin, G.ML (20rW) A genetic screen for modifiers of a kinase suppressor of Ras-dependent rough eye phenotype in Drosophila. Genetics, 156, $1231 \quad 1242$.

35. Stiniwasan, S., Armstrong, I.A., Deuring, R., Dahlsween, I.K., McNeill, H. and Tamkon, J.W. (20r5) The Drosophila trithorax group protein Kismet facilitates an early step in transcriptional elongation by R.No. Polymerase II. Development, 132, 16231635 . 
36. Stiniwasan, S., Derighi, K.MI. and Tamkun, J.W. (20108) Dresephila Kismet regulates histone $\mathrm{H3}$ lysine 27 methylation and early elongation by RIA polymerase II. PLOS Genet., 4, el0r 217 .

37. Khattak, S., Lee, B.R., Che, S.H., Ahuin, J. and Spoerel, N.A. (20r.2) Genetic characterization of Drosephila Mi1-2 ATPase. Gene, 26, 107114

38. Xue, Y., Wong, J., Merene, G.T., Young, M.K., Coté, I. and Wang, W. (1998) NURD, a nowel complex with both ATP-dependent chromatinremodeling and histone deacetylase activities. MoL Cell., 2, $851 \quad 861$.
39. Zahir, F., Firth, H.V., Baress, A., Delaney, A.D., Eydeux, F., Gibson, W.T., Langleis, S., Martin, H., Willatt, L., Marra, ML.A. et al (20.07) Newel deletions of $14 q 11.2$ associated with developmental delay, cognitive impaiment and similar minor anomalies in three children. Med. Genet, 44, 556 561.

41. dellen, ML.D., Religa, T.L., Freund, S.ML and Bycroft, ML (20r) Solution structure of the BRK domains from CHDT. I. Mol. Biol, 31 , 11351140 


\subsection{Identification and characterization of FAM124B as a novel component of a CHD7 and CHD8 containing complex}

Mutations in the chromodomain helicase DNA binding protein 7 gene (CHD7) lead to CHARGE syndrome, an autosomal dominant heterogeneous disorder. Earlier, we could show that a part of CHD7 interacts with a part of CHD8, another chromodomain helicase DNA binding protein which has been recently demonstrated to be involved in the pathogenesis of neurodevelopmental (NDD) and autism spectrum disorders (ASD). We searched for novel CHD7 and CHD8 interacting partners using stable isotope labeling by amino acids in cell culture (SILAC) in combination with mass spectrometry. As result we identified as a potential interaction partner of both CHD7 and CHD8 a new uncharacterized protein, named FAM124B (Family with sequence similarity 124B). Furthermore, the confirmation of the SILAC results by co-immunoprecipitation and yeast two hybrid experiments demonstrated that FAM124B is a potential novel component of a CHD7 and CHD8 containing complex. Interestingly, our studies of Fam124B expression in E12.5 mouse embryos and in adult mouse brain show an overlap of the Fam124B expression with the expression patterns of Chd7 and Chd8. Therefore we conclude that Fam124B is a novel protein possibly involved in the pathogenesis of CHARGE syndrome and neurodevelopmental disorders.

Tserendulam Batsukh, Yvonne Schulz, Stephan Wolf, Tamara I. Rabe, Thomas Oellerich, Henning Urlaub, Inga-Marie Schaefer, Silke Pauli

Status: submitted to PLoS ONE (Impact factor 4.41).

\section{Author contributions to the work:}

1. Tserendulam Batsukh: Generated the contructs; performed the experiments; involved in the manuscript writing.

2. Yvonne Schulz: helped in paraffin embedding and sectioning of mouse embryonic tissues.

3. Stephan Wolf: provided all mice for the experiments and was involved in mouse care.

4. Tamara I. Rabe: helped in in situ hybridization experiments and assisted in interpretation of the in situ hybridization results.

5. Thomas Oellerich and Henning Urlaub: adviced and were involved in SILAC experiments; performed the mass-spectrometry of SILAC probes and did the data analysis. 
6. Inga-Marie Schaefer: helped us in interpreting the immunohistochemical stainings on different mouse tissues and assisted in picture creations.

7. Silke Pauli: conceived and made experimental design; interpreted the data and prepared the manuscript. 


\title{
Identification and characterization of FAM124B as a novel component of a CHD7 and CHD8 containing complex
}

Tserendulam Batsukh ${ }^{1}$, Yvonne Schulz ${ }^{1}$, Stephan Wolf ${ }^{1}$, Tamara I. Rabe ${ }^{2}$, Thomas Oellerich ${ }^{3}$, Henning Urlaub $^{3}$, Inga-Marie Schaefer ${ }^{4}$, Silke Pauli ${ }^{1}$

\footnotetext{
${ }^{1}$ Institute of Human Genetics, University Medical Center, Göttingen, Germany

${ }^{2}$ Department of Molecular Cell Biology, Max Planck Institute for Biophysical Chemistry, Göttingen, Germany

${ }^{3}$ Bioanalytical Mass Spectrometry Group, Max Planck Institute for Biophysical Chemistry, Göttingen, Germany

${ }^{4}$ Department of Pathology, University Medical Center, Göttingen, Germany
}

\begin{abstract}
Background: Mutations in the chromodomain helicase DNA binding protein 7 gene (CHD7) lead to CHARGE syndrome, an autosomal dominant multiple malformation disorder. Proteins involved in chromatin remodeling typically act in multiprotein complexes. We could previously demonstrate that a part of human CHD7 interacts with a part of human CHD8, another chromodomain helicase DNA binding protein presumably being involved in the pathogenesis of neurodevelopmental (NDD) and autism spectrum disorders (ASD). Because identification of novel CHD7 and CHD8 interacting partners will provide further insights into the pathogenesis of CHARGE syndrome and ASD/NDD, we searched for additional associated polypeptides using the method of stable isotope labeling by amino acids in cell culture (SILAC) in combination with mass spectrometry.
\end{abstract}

Principle findings: The hitherto uncharacterized FAM124B (Family with sequence similarity 124B) was identified as a potential interaction partner of both CHD7 and CHD8. We confirmed the result by co-immunoprecipitation studies and showed by direct yeast two hybrid experiments a direct binding to the CHD8 part. Furthermore, we characterized FAM124B as a mainly nuclear localized protein with a widespread expression in embryonic and adult mouse tissues.

Conclusion: Our results demonstrate that FAM124B is a potential interacting partner of a CHD7 and CHD8 containing complex. From the overlapping expression pattern between Chd7 and Fam124B at murine embryonic day E12.5 and the high expression of Fam124B in the developing mouse brain, we conclude that Fam124B is a novel protein possibly involved in the pathogenesis of CHARGE syndrome and neurodevelopmental disorders. 
Key words: $F A M 124 B, C H D 8, C H D 7$, interaction studies, expression pattern

\section{INTRODUCTION}

In humans, CHD7 (NM_017780) is one of nine members of the chromodomain helicase DNA binding domain (CHD) family that plays a role in controlling gene expression by ATPdependent chromatin remodeling. Mutations in the CHD7 gene are the major cause of CHARGE syndrome (OMIM 214800), an autosomal dominant congenital malformation disorder characterized by the combination of eye, ear, craniofacial structure, and heart defects [1-6]. However, in 5-10\% of patients with a typical presentation of CHARGE syndrome and in $40-60 \%$ of patients with an atypical presentation the underlying cause of the symptoms remains unclear [7]. For other autosomal dominant disorders, e.g. Noonan syndrome, a genetic heterogeneity is known, wherein mutations in different genes lead to a near similar phenotype. Therefore, we suggest that also in CHARGE syndrome mutations in one or more unknown genes are involved in the pathogenesis of this disease.

Proteins involved in chromatin remodeling are typically found in multiprotein complexes. In recent and earlier studies different CHD7 interacting partners have been described [8-13]. In human neural crest-like cells CHD7 was shown to be associated with components of the BAF(Brahma associated factor complex) and PBAF - complexes (Polybromo containing complex) [10]. Both belong to the SWI/SNF-family of ATP-dependent chromatin remodeling complexes and can act as transcriptional activators or repressors [14]. In murine embryonic stem (ES) cells a co-localization between Chd7 and the proteins p300, Oct4, Sox2, Nanog, Smad1 and Stat3 at enhancer elements was shown [9] leading to the hypothesis that these proteins are cofactors in enhancer promoter interactions [9]. CHD7 was also found to be associated with treacle, the protein that is involved in the pathogenesis of Treacher Collins syndrome [12]. These studies demonstrate that there are numerous CHD7 interacting partners, leading to the suggestion that there are cell type specific compositions of CHD7 containing complexes and that the subunits may change during development [7].

Recently, we could demonstrate that a part of the human CHD7 protein interacts with a part of the CHD8 protein, another CHD family member. Studies in Drosophila melanogaster demonstrated that kismet is the only gene related to the human subgroup III members (CHD6CHD9). Kismet has a functional role in transcriptional regulation by promoting early elongation by RNA Polymerase II as well as by recruiting the histone methyltransferases ASH1 and TRX to chromatin [15]. Rodriguez-Paredes et al. suggested that in mammals the function of kismet is overtaken by several subgroup III members (CHD6-CHD9) [16] and we 
hypothesized that CHD7 and CHD8 build a core component of a complex with similar functions such as kismet [11]. CHD8 was found to be associated with the WAR complex [17]. This complex includes WDR5, ASH2L and RbBP5 (WAR) and is known as a subcomplex of mixed lineage leukemia (MLL) complexes, the Drosophila homolog to TRX complexes. The MLL complexes act as histone H3 Lys-4 methyltransferases [18].

Furthermore, CHD8 binds directly beta-catenin and regulates negatively beta-catenin-targeted gene expression [17]. Microdeletions, chromosomal rearrangements disrupting CHD8 as well as de novo missense and nonsense mutations in the CHD8 gene were described in autism spectrum (ASD) and in neurodevelopmental (NDD) disorder patients, indicating that alterations in $C H D 8$ can contribute to ASD and NDD [19-22].

Identification of novel CHD7 and CHD8 interacting partners will provide further insights into the pathogenesis of CHARGE syndrome and ASD/NDD. Therefore, we tried to detect new binding partners by using the method of stable isotope labeling by amino acids in cell culture (SILAC) in combination with mass spectrometry. We identified FAM124B (Family with sequence similarity 124B) as a potential interaction partner of both CHD7 and CHD8. Additionally, we confirmed the interaction by co-immunoprecipitation and performed direct yeast two hybrid experiments. Furthermore, we examined the intracellular localization and tissue-specific expression of Fam124B during mouse embryogenesis and in adult mouse tissues.

\section{RESULTS}

\section{Identification of FAM124B as part of the CHD7 and CHD8 interactomes}

In order to identify novel CHD7 and CHD8 interaction partners we applied stable isotope labeling by amino acids in cell culture (SILAC) in combination with mass spectrometry [23,24] (Figure 1). To achieve differential isotope labeling of HeLa cells, one cell batch was cultured in the presence of lysine and arginine containing light $(\mathrm{L})$ isotopes of carbon and nitrogen $\left({ }^{12} \mathrm{C}\right.$ and ${ }^{14} \mathrm{~N}$, L-lysine and L-arginine) while the other batch was cultured in the presence of lysine and arginine containing heavy $(\mathrm{H})$ isotopes of carbon and nitrogen $\left({ }^{13} \mathrm{C}_{6}{ }^{15} \mathrm{~N}_{2}\right.$-lysine and ${ }^{13} \mathrm{C}_{6}{ }^{15} \mathrm{~N}_{4}$-arginine). Accordingly, the two culture conditions confer distinct molecular masses on the cellular proteins and in this way proteins derived from SILAC-labeled cells can be distinguished and thus attributed to the $\mathrm{L}$ - or $\mathrm{H}$-labeled cell batch by mass spectrometry. For elucidation of the CHD7- or CHD8 interactomes, the H-labeled cells were firstly co-transfected with the plasmids CHD7-CR1-3-pCMV-HA (containing amino acids 1593 - 2178, NP_060250.2, in fusion with an HA-tag) and CHD8-pCMV-cmyc (spanning 
amino acids 1789 - 2302, NP_065971.2, in fusion with an cmyc-tag). 24 hours post transfection, expression of the tagged proteins was confirmed by western blotting. Subsequently the respective H-labeled cells were lysed and the CHD7 part was purified by anti-HA immunoprecipitation. As a negative control the same immunoprecipitation was performed in lysates of non-transfected L-labeled HeLa cells. The purified proteins from both the H- and L-states were then pooled in equimolar amounts and subsequently digested with the endoproteinase trypsin. Derived peptides were identified by liquid-chromatography (LC)coupled tandem mass spectrometry (MS/MS), allocated to the corresponding proteins by database search and finally quantified using the MaxQuant software. An at least five-fold enrichment of heavy versus light peptides was considered to mark proteins that were specifically co-purified with the HA-tagged CHD7 part. The same experimental workflow was also performed with inverse labeling. In at least three biological replicates FAM124B was copurified with CHD7 and CHD8, which identifies this so far uncharacterized protein as a novel effector of the CHD7/8 interactome (Table S1-S3).

\section{Full length cloning and transcript analysis of FAM124B}

Information of the genomic and cDNA structure of FAM124B was obtained from NCBI database. In humans, two transcript variants are described. Transcript variant 1 contains two exons with the ATG in exon one and the stop codon in exon 2 resulting in a protein with 455 amino acids (NP_001116251.1). Transcript variant 2 contains an alternate exon with an inframe stop codon leading to a shorter protein product with 272 amino acids (NP_079061.2). In mice, one transcript homologous to the human transcript variant 1 containing 456 amino acids was described (NP_775601.1). We validated the information by full length cloning and sequencing of human and mouse cDNAs derived from HeLa cells and mouse adult brain tissue, respectively.

\section{FAM124B co-immunoprecipitates with a part of CHD7 and a part of CHD8}

Co-Immunoprecipitation studies on HeLa cells were performed to confirm the CHD7-CHD8FAM124B interaction. HeLa cells were co-transfected with either the CHD7-CR1-3-pCMVHA (amino acids 1593 - 2178, NP_060250.2) plasmid and FAM124B-1,3-pCMV-cmyc (transcript variant 1, NP_001116251.1) or with CHD8-pCMV-cmyc (amino acids 1789 2302, NP_065971.2) and FAM124B-1,3-pCMV-HA (transcript variant 1, NP_001116251.1). Total protein was isolated after 24 hours. Immunoprecipitation with either the anti-CHD7 (abcam, ab31824) or the anti-CHD8 antibody (abcam, ab84527) and detection with either the anti-cmyc (abcam, ab9106) or anti-HA antibody (Roche) lead to an approximately $51 \mathrm{kDa}$ 
band corresponding to the estimated size of FAM124B transcript variant 1 (Figure 2A). Reciprocal immunoprecipitation with anti-cmyc antibody and detection with the anti-CHD7 antibody demonstrated a specific band of $\sim 70 \mathrm{kDa}$, the estimated size for the CHD7 part fused to the HA-tag (Figure 2B). Using the anti-HA-antibody for precipitation, we detected a $\sim 68 \mathrm{kDa}$ band corresponding to the estimated size of the CHD8 part fused to the cmyc tag (Figure 2C) by using the anti-CHD8 antibody.

The same experimental procedure was then performed with the plasmid FAM124B-1,2pCMV-HA (transcript variant 2, NP_079061.2). Similar to the results for the FAM124B transcript variant 1, we could demonstrate an interaction with the CHD7 and CHD8 part with FAM124B transcript variant 2 (Figure 2D-F).

\section{FAM124B interacts directly with a part of CHD8}

$\mathrm{Y} 2 \mathrm{H}$ experiments were performed to determine a direct interaction between CHD7, CHD8 and both variants of FAM124B using the following plasmids: FAM124B-1,3-pGADT7 (full lengths transcript variant 1), FAM124B-1,2-pGADT7 (full lengths transcript variant 2), CHD7-CR1-3-pGBKT7 (amino acids 1591-2181, NP_060250.2) and CHD8-pGBKT7 (amino acids 1789-2302, NP_065971.2). The yeast two hybrid experiments revealed that both transcripts of FAM124B directly interact with the CHD8 part, while no direct interaction with the CHD7 part, spanning the amino acids 1591-2181, could be observed (Figure 3). Because FAM124B transcript variants 1 and 2 have in common exon 1 , we hypothesized that the FAM124B-CHD8 interacting area is located within exon 1 of FAM124B.

\section{Subcellular localization of FAM124B in HeLa cells}

To determine the subcellular localization of endogenous FAM124B in HeLa cells, we performed immunofluorescence staining by using a rabbit anti-FAM124B antibody (ProteinTech). FAM124B is localized mainly in the nucleus (Figure 4A). To test the specificity of the polyclonal anti-FAM124B antibody, we transiently transfected HeLa cells with either the plasmid FAM124B-1,3-pCMV-HA or the FAM124B-1,3-pCMV-cmyc to overexpress hemagglutinin (HA) or cmyc epitope tagged FAM124B-1,3 (transcript variant 1, NP_001116251.1). By using the rabbit anti-FAM124B antibody, the overexpressed protein was detectable mainly in the nucleus at an exposure time of $200 \mathrm{msec}$. By raising the exposure time to $2 \mathrm{sec}$, overexpressed and endogenous FAM124B could be observed. Immunofluorescence staining of recombinant HA tagged FAM124B using the anti-HA antibody (Roche) or staining of the recombinant cmyc tagged FAM124B using the anti-cmyc- 
antibody (abcam, ab9106) confirmed the results that FAM124B is preferentially expressed in the nucleus and that the rabbit anti-Fam124B antibody is specific (Figure 4B, C).

\section{Tissue specific expression of murine Fam124B}

The expression pattern of murine Fam124B was studied by semiquantitative reverse transcription polymerase chain reaction (RT-PCR) on RNA of wild type CD1 mouse tissues and E9.5 and E12.5 embryos (Figure 5A). The RT-PCR results were validated by quantitative real-time PCR (qRT-PCR) in 3 biological and 3 technical replicates (data not shown). Relative mRNA expression levels were determined by using $\Delta \mathrm{Ct}$ values and were normalized to the housekeeping genes Gapdh, Hprt and Sdha. Although, quantitative RT-PCR shows a high variability of the Fam124B expression status in different animals, the semiquantitative RTPCR results could be confirmed, with highest expression rate in lung and lowest in liver. Immunohistochemical staining (IHC) performed on adult mouse tissues confirmed the semiquantitative and quantitative RT-PCR results (Figure 5B). Furthermore, we evaluated the expression level of Fam124B in sections of adult mouse brains. Immunohistochemical examination demonstrated an expression of Fam124B in different brain areas (Figure 6A). Fam124B is highly expressed in the cortex, the hippocampus subfields 1-3 (CA1-3), the dentate gyrus, the caudate putamen, and the cerebellum. In situ hybridization (ISH) of cortex and hippocampus sections with a full-length Fam124B RNA probe supported the results obtained by IHC (Figure 7A, B).

To explore the expression pattern of Fam124B during mouse development, we extended our IHC studies to sections of E12.5 mouse embryos, the timepoint when organogenesis takes place. Similar to adult mouse tissues, Fam124B expression at E12.5 was observed in different inner organs, with lowest expression in liver tissue (Figure 8A-H). In the developing heart, high expression was detected particularly in the endothelial cells of the atrium and along the trabeculated endocardium of the ventricle, while no expression could be observed in blood cells (Figure 8D). At E12.5 when the developing lung is not yet divided into lobes, Fam124B expression could be observed in the stroma cells and in the epithelial cells of the segmental bronchi (Figure 8G). Furthermore, Fam124B was expressed in the developing cochlea and the surrounding tissue (Figure $8 \mathrm{E}$ ) as well as in neural cells. The dorsal root ganglia and the precartilage condensation zones in the neural arch showed Fam124B expression, while Fam124B expression was significantly reduced in the cartilage (Figure 8B). High Fam124B expression could be found in the spinal cord (Figure $8 \mathrm{~F}$ ) and in the developing brain (Figure 9). 


\section{DISCUSSION}

Loss of function mutations in CHD7 lead to CHARGE syndrome, a well known malformation syndrome affecting several organs and sensory systems. CHD7 regulates the transcription of tissues-specific target genes through the mechanism of ATP-dependent chromatin remodeling $[7-9,12]$. Chromatin remodeling proteins are typically found in large multiprotein complexes. For CHD7 several tissues-specific interacting partners are described $[9,10,12,13]$. Thus, it can be suggested that there are cell type and developmental stage specific compositions of CHD7 containing complexes. However, the precise complex compositions for each tissue are still unknown. In an earlier study, we could demonstrate that a part of human CHD7 interacts with a part of human CHD8 both directly and indirectly, via potential linker proteins [11]. Loss of function mutations in CHD 8 as well as de novo missense mutations were described in autism spectrum (ASD) and neurodevelopmental (NDD) disorder patients [19-22]. Interestingly, Betancur and colleagues described autism spectrum disorders in about two thirds of children with CHARGE syndrome [25], which supports our hypothesis of a CHD7-CHD8 containing complex regulating the same cell type specific target genes.

The identification and characterization of associated factors of a CHD7-CHD8 containing complex might play an important role in understanding the pathophysiology of CHARGE syndrome and ASD/NDD. Therefore, to further characterize this complex and to identify additional associated polypeptides interacting with the recently described human CHD7 and CHD8 part, we used the method of stable isotope labeling by amino acids in cell culture (SILAC) in combination with mass spectrometry. As a result of three biological replicates we identified the hitherto uncharacterized protein FAM124B as a potential interacting partner. In humans, two FAM124B transcript variants are present, while in mice, only one transcript, homologous to the human transcript variant 1 , exists. The interaction of both human FAM124B transcript variants with the CHD7 and CHD8 part was confirmed by coimmunoprecipitation experiments. Direct yeast-two hybrid studies were performed to specify the FAM124B - CHD7 - CHD8 interaction areas. Both transcripts of human FAM124B interact directly with the CHD8 part containing the amino acids 1789-2302 (NP_065971.2), while the FAM124B - CHD7 interaction is an indirect interaction or the interacting area is outside of the used CHD7 part spanning amino acids 1591-2181 (NP_060250.2). The biological role of human FAM124B or its orthologs in P.troglodytes, C.lupus, B.taurus, R.norvegicus, M.musculus, G.gallus, D.rerio is still unknown. Bioinformatic analysis of the amino acid sequence failed to identify any known functional domain. To gain further insight into the biological role of FAM124B and its mouse ortholog, we examined the subcellular 
localization and the expression pattern. Immunofluorescence microscopy indicates that endogenous FAM124B is localized mainly in the nucleoplasm. CHD8 is described as a nuclear localized protein [26]. Concerning CHD7, a dual localization in the nucleoplasm and in the nucleolus was observed [12]. Therefore, we suggest, that the interaction between FAM124B, CHD8 and CHD7 may take place in the nucleoplasm.

We could detect Fam124B expression in various adult mouse tissues, with highest expression in lung and heart, followed by kidney, brain and testis, whereas it was lowest expressed in liver. No Fam124B expression could be observed in blood cells. In adult mouse brain sections, we demonstrated Fam124B expression in several areas. Within the brain, high expression levels were found in the stratum granulosum of the cortex, stratum granulosum and purkinjense of the cerebellum, thalamic nuclei, caudate putamen, and hippocampus.

CHD8 expression was previously found in various adult mouse tissues including heart, brain, spleen, lung, liver, skeletal muscle, kidney, and testis [26]. CHD7 expression pattern was determined by semiquantitative RT-PCR on several adult tissues including retina, cornea, brain, skeletal muscle, heart, kidney and lung [1]. Accordingly to these previously described data we could observe an overlapping expression pattern between CHD7, Chd8 and Fam124B in adult mouse tissues. Because CHARGE syndrome is a developmental disorder and NDD/ASD are caused by abnormal brain development, we extended our Fam124B expression studies to embryonic tissues. The expression pattern of CHD7 during development has been studied in embryos of different mammalian species, before [4, 5, 27-29]. During mouse development, Chd7 was found to be expressed at E12.5 in a wide range of head tissues (several brain areas with highest expression in proximity to the ventricles, in the choroid plexus, developing olfactory epithelium, ganglia of the cranial nerves, otic and optic pits, and the developing inner ear) and several regions of the body (especially the dorsal root ganglia and lung epithelium, as well as stomach epithelium, kidney, and heart) [27]. Fam124B expression at E12.5 was found in a variety of embryonic tissues (e.g. several brain areas, spinal cord, dorsal root ganglia, developing cochlea and surrounding tissues, lung, heart, and kidney), as well. Similar to the results of adult mouse tissues, Fam124B expression at E12.5 correlated in many embryonic tissues with the Chd7 expression pattern, and therefore Fam124B was found to be expressed in organs affected in CHARGE syndrome.

It has already been shown that CHD7 binds to methylated histone H3 lysine 4 (H3K4) at enhancer elements and modify cell type specific gene expression in a fine-tuning manner [8, 9]. Schnetz and colleagues hypothesized that the binding of a CHD7 containing complex to enhancer elements may modulate the expression rate of target genes through enhancer- 
promotor interactions $[8,9]$. In mouse ES cells, a subset of Chd7 sites colocalize with p300, Oct4, Sox 2 and Nanog. The subset of Chd7 sites, which are not co-occupied by these proteins, can also enhance transcription [9]. However, the associated factors of these Chd7 sites are still unknown. Possibly, the newly identified Fam124B may serve as an associated factor involved in Chd7 enhancer-mediated transcription. Furthermore, the high Fam124B expression in the developing mouse brain and in neuronal tissues at embryonic day E12.5 might indicate a role of FAM124B together with CHD8 in neurodevelopmental and autism spectrum disorders.

In summary, we identified FAM124B, a nuclear protein, as a binding partner of a part of CHD7 and CHD8. We conclude that FAM124B is an associated factor of a CHD7 and CHD8 containing complex. Fam124B is widely expressed at mouse developmental stage E12.5 with an overlapping correlation to Chd7 expression and high expression in the developing mouse brain. Therefore, we assume a role for FAM124B in the pathogenesis of CHARGE syndrome and NDD/ASD. The results of our interaction studies, the subcellular localization, and expression profile of FAM124B provide valuable information and represent a starting point for further functional investigations on FAM124B and its possible role in CHARGE syndrome and NDD/ASD.

\section{MATERIALS AND METHODS}

\section{Ethics statement/mouse strains}

The animal studies are approved by the Institutional Animal Care and Use Committee of the University of Göttingen. All mouse studies were performed on CD1 wildtype mice.

Stable isotope labeling by amino acids in cell culture (SILAC) and mass spectrometry (MS) Two HeLa cell populations were grown in SILAC DMEM culture media (10\% dialyzed FBS and $1 \%$ penstrep) (PAA Laboratories $\mathrm{GmbH}$, Pasching, Austria; Thermo Fisher Scientific, Waltham, MA). The "light" SILAC medium was supplemented with unlabeled L-lysine and Larginine, while the "heavy" SILAC medium was supplemented with arginine and lysine containing heavy isotopes of carbon and nitrogen $\left({ }^{13} \mathrm{C}_{6}\right.$-lysine and ${ }^{13} \mathrm{C}_{6}{ }^{15} \mathrm{~N}_{4}$-arginine). Upon metabolic labeling of the cells this lead to a mass shift of +6 and +10 Da per incorporated arginine and lysine, respectively. After at least 5 cell passages, co-transfection with the previously described plasmids CHD7-CR1-3-pCMV-HA and CHD8-pCMV-cmyc [11] into either L- or H-labeled HeLa cells was performed. Non transfected L- or H-labeled cells were used as negative control. After transient co-transfection, the cells were incubated at $37^{\circ} \mathrm{C}$ for 
24 hours, then washed with DPBS (PAN BIOTECH GmbH, Aidenbach, Germany) and trypsinized (Invitrogen, Carlsbad, CA, USA). To isolate the same amount of protein from both cell cultures, cell populations were accurately counted under microscope using counting chambers (Neubauer haemocytometer) (approximately 1 - 1,2 x 107 cells were used) before cell lysis, which was performed as described by Oellerich et al. (2011) [24]. Protein lysates were incubated with $4 \mu \mathrm{g}$ of monoclonal anti-Ha antibody (Roche Diagnostik GmbH, Mannheim, Germany) at $4{ }^{\circ} \mathrm{C}$ overnight. Proteins coupled with the antibody were incubated at $4^{\circ} \mathrm{C}$ with $100 \mu \mathrm{l}$ of protein $\mathrm{G}$ (Immunoprecipitation Kit, Roche Diagnostik GmbH, Mannheim, Germany) for further 2 hours. Centrifugation at $350 \mathrm{rpm}$ for $3 \mathrm{~min}$ was carried out to collect the agarose beads. To remove unbound proteins, the beads were washed two times in $500 \mathrm{ml}$ lysis buffer and one time with $1 \mathrm{ml}$ washing buffer 2 (Immunoprecipitation Kit, Roche Diagnostik GmbH, Mannheim, Germany). The beads were resuspended in $50 \mu 1$ NuPAGE LDS Sample buffer (Invitrogen, Carlsbad, CA, USA) supplemented with 0.1 M DTT. After denaturation for $10 \mathrm{~min}$ at $95^{\circ} \mathrm{C}$, the denaturated $\mathrm{H}$ - and L-labeled proteins were pooled in equimolar amounts and subsequently the samples were separated by size using an 1D-PAGE (Invitrogen, Carlsbad, CA, USA) followed by coomassie blue staining. Each gel lane was cut into 23 gel slices. Proteins from each slice were in-gel digested with trypsin (Promega, Madison, WI) according to the protocol described by Shevchenko et al. (2006) [30]. MS measurements were carried out using a nanoflow HPLC (Agilent, Boeblingen, Germany) coupled to a nanoelectrospray LTQ-Orbitrap XL mass spectrometer (Thermo Fisher Scientific, Waltham, MA) as described by Nikolov et al. (2011) [31].

\section{$R N A$ isolation and semiquantitative reverse-transcription PCR}

Total RNA was isolated from HeLa cells, MRC-CV1 cells or different mouse tissues using Trizol reagent (Invitrogen, Carlsbad, CA, USA). Homogenizing was carried out with Tissue lyser LT (Qiagen GmbH, Hilden, Germany). $5 \mu \mathrm{g}$ of total RNA from each sample was reversetranscribed using Superscript II reverse transcriptase (Invitrogen, Carlsbad, CA, USA). For each PCR reaction $0.5 \mu \mathrm{l}$ undiluted cDNA and $0.2 \mu$ platinum taq polymerase (Invitrogen, Carlsbad, CA, USA) was used. Human cDNA isolated from HeLa and MRC-CV1 cells were amplified using the following primers: 5'-CCTTCTACACACGCTGTCTTTG-3'as forward primer and 5'-GGGGATGAGCTATGCAACCTAAG-3' as reverse primer. RT-PCR on mouse tissues was carried out using the following primer pair: forward primer 5'GGTGGCCTTCATCATAATCTTC-3' and reverse primer 5'-CCAGTCACACTCTTGCT TCTGT-3'. The correct sequence was confirmed by sequence analysis. 


\section{Quantitative RT-PCR}

Realtime PCR reactions were performed using 1 $1 \mu$ of 1:10 diluted cDNA from different CD1 mouse tissues, SYBR green (Invitrogen, Carlsbad, CA, USA) and the gene-specific primers forward 5'-CCGTGTGTTCCCATCAGCAG-3' and reverse 5'CTCCTCCTCCGGCTCCTTG-3'. Relative mRNA expression levels were determined using $\Delta \mathrm{Ct}$ values and were normalized to the housekeeping genes Gapdh, Hprt and Sdha. The experiment was performed in three biological and 3 technical replicates.

\section{Co-immunoprecipitation}

For co-immunoprecipitation studies we generated the plasmids FAM124B-1,3-pCMV-HA (transcript variant 1, NP_001116251.1), FAM124B-1,2-pCMV-HA (transcript variant 2, NP_079061.2), FAM124B-1,3-pCMV-cmyc (transcript variant 1, NP_001116251.1) and FAM124B-1,2-pCMV-cmyc (transcript variant 2, NP_079061.2) by cloning the human fulllength sequence of transcript variant 1 and transcript variant 2 in frame to the hemagglutinin (HA) epitope tag into the pCMV-HA vector (Clontech, Mountain View, CA, USA) or in frame to the N-terminal c-Myc epitope tag into the pCMV-Myc vector (Clontech, Mountain View, CA, USA) by using the In fusion advantage kit (Clontech, Mountain View, CA, USA) according to the company's protocol. The correct reading frame and sequence was confirmed by sequence analysis.

Hela cells were cultured in $50 \mathrm{ml}$ flask (Sarstedt, Newton, NC, USA) and were cotransfected with CHD7-CR1-3-pCMV-HA (amino acids 1593 - 2178, NP_060250.2) and either FAM124B-1,3-pCMV-cmyc or FAM124B-1,2-pCMV-cmyc. Additionally, we co-transfected HeLa cells with CHD8-pCMV-cmyc (amino acids 1789 - 2302, NP_065971.2) and either FAM124B-1,3-pCMV-HA or FAM124B-1,2-pCMV-HA. After $24 \mathrm{~h}$ of incubation at $37^{\circ} \mathrm{C}$, coimmunoprecipitations were carried out as previously described [11]. For immunoblotting we used the following antibodies: anti-c-Myc (abcam, ab9106) at a dilution of 1:2000, anti-HA (Roche Diagnostik GmbH, Mannheim, Germany) at a dilution of 1:1000, goat anti-CHD7 (abcam, ab 65097) at a dilution of 1:2000, rabbit anti-CHD8 (abcam, ab84527) at a dilution of 1:2000. The following antibodies were used for detection: goat anti-rabbit IgG peroxidase secondary antibody (Sigma-aldrich, St.Louis, MO, USA) for anti-c-Myc and anti-CHD8, goat anti-Rat secondary antibody conjugated with horseradish peroxidase (Thermo Scientific, Rockford, IL, USA) for anti-HA, donkey anti-goat IgG peroxidase secondary antibody (SantaCruz Biotechnologies, California, USA) for anti-CHD7. 


\section{Yeast two hybrid}

For yeast two hybrid studies we generated the constructs FAM124B-1,3-pGBKT7 (transcript variant 1, NP_001116251.1), FAM124B-1,2-pGBKT7 (transcript variant 2, NP_079061.2), FAM124B-1,3-pGADT7 (transcript variant 1, NP_001116251.1) and FAM124B-1,2-pGADT7 (transcript variant 2, NP_079061.2). The human full-length sequence of transcript variant 1 and transcript variant 2 were subcloned in frame to the ATG of the pGBKT7 or pGADT7 vector (Clontech, Mountain View, CA) by using the In fusion advantage kit (Clontech, Mountain View, CA). All constructs were transformed into Y2HGold strain cells (Clontech, Mountain View, CA) and tested for toxicity and autoactivation of the bait or prey reporter genes. No toxicity for the yeast cells could be observed, but the FAM124B-1,3-pGBKT7 and FAM124B-1,2-pGBKT7 showed autoactivation. Therefore, the further experiments were performed with the FAM124B-1,3-pGADT7 and FAM124B-1,2-pGADT7 constructs. These both plasmids were co-transformed into Y2HGold strain cells together with either the CHD7CR1-3-pGBKT7 (amino acids 1591-2181, NP_060250.2) or the CHD8-pGBKT7 (amino acids 1789-2302, NP_065971.2) plasmids. The direct Yeast two hybrid was performed according to the manufactures' protocol.

\section{Cryosections}

Adult brains from CD1 mice were isolated and fixed overnight in 4\% paraformaldehyde (PFA) solution prepared in sterile PBS with DEPC water at $4{ }^{\circ} \mathrm{C}$ with gentle shaking. On the next day, the tissues were washed 3 times with sterile PBS/DEPC at $4{ }^{\circ} \mathrm{C}$ and incubated in autoclaved/sterile $30 \%$ Sucrose at $4{ }^{\circ} \mathrm{C}$ with gentle shaking till the tissues sank down. Then the brains were incubated for 30 minutes to 1 hour at $4^{\circ} \mathrm{C}$ in a $1: 1$ mixture containing $30 \%$ sucrose and Jung tissue freezing medium (Leica Microsystems, Nussloch, Germany), following an incubation in tissue freezing medium at $4{ }^{\circ} \mathrm{C}$ for 30 minutes and embedded on dry ice in tissue freezing medium. The frozen block was kept till usage at $-80^{\circ} \mathrm{C}$ and cut by cryo-microtome (Leica Instrument, Nussloch, Germany) with $20 \mu \mathrm{m}$ thickness and sticked on Menzel Superfrost microscope slides (Thermo Scientific, Rockford, IL, USA).

\section{In situ hybridization}

In situ hybridization was performed on cryosections of adult brain from CD1 mice. The following primer pairs were used to amplify by RT-PCR the whole coding region of Fam124B: forward 5'- GCCATGGATGAGATACAGGAA-3' and reverse 5'CATGAATGGGGCTGACTCTTA-3'. The PCR product was subcloned into pGEMT easy vector (Promega, Madison, WI) and transformed into E.coli. Positive plasmids were isolated 
and sequenced. For probe amplification from a correct plasmid the following primers were used for the Sp6 transcript: pGEM-T-Sp6-F (ACGTCGCATGCTCCCG) and pGEM-T-R2 (CCAGGCTTTACACTTTATGCTTCC) and for the T7 transcript: PCR-T7 (CTGCGCAACTGTTGGG) and pGEM-T-R1 (AGGCGGCCGCGAATTCAC). The PCR products were gelextracted and DIG-labelled RNA probes were synthesized using the DIG RNA Labeling Kit (SP6/T7) (Roche Diagnostik GmbH, Mannheim, Germany) according to the manufacturer's protocol. Synthesized probes were ethanol precipitated and resuspended in 100 $\mu 1$ of DEPC water/formamide 1:1 mixture and kept till usage at $-20^{\circ} \mathrm{C}$. Non-radioactive in situ hybridization have been done according to Moorman et al. (2001) The results have been observed using a BX60 microscope (Olympus, Hamburg, Germany) and images were processed by the analysis program (CellSens Dimension, Olympus).

\section{Immunohistochemistry on cells}

HeLa and MRC-CV1 cells were transfected with the FAM124B-1,3-pCMV-HA construct. Cell culture, staining procedure and fluorescence imaging was carried out as described previously [11]. As a blocking solution 10\% sheep serum diluted in DPBS with $0.1 \%$ Tween 20 (TPBS) was used. Rabbit anti-FAM124B antibody (Proteintech Group, Chicago, IL) was diluted at 1: 50. As secondary antibody anti-rabbit IgG conjugated with Cy3 (Sigma-Aldrich, St.Louis, MO, USA) antibody was used at a dilution of 1:400.

\section{Immunohistochemistry on paraffin embedded tissues}

Adult wild type CD1 mouse tissues and E12.5 embryos were paraffin embedded according to standard procedures. From the paraffin embedded tissues $7 \mu \mathrm{m}$ sections were made and incubated overnight at $45^{\circ} \mathrm{C}$. After a three time Xylene incubation (10, 5, 5 minutes) a series of ethanol incubation $(100 \%, 95 \%, 90 \%, 80 \%, 70 \%, 50 \%)$ and a washing step with DPBS for 2 minutes followed. Slides were cooked with antigen retrieval buffer (citric acid 0.1M; EDTA $0.01 \%, \mathrm{pH}$ 6.2) in a steam cooker for 10 minutes and allowed retrieval buffer to cool down on ice for at least 10 minutes. Endogenous peroxidase activity was blocked using $6 \% \mathrm{H}_{2} \mathrm{O}_{2}$ solution in water for 15 minutes. The solution was tapped off from the slides and blocked with horse serum (Vectastain Universal Quick kit, Vector Laboratories, Burlingame, CA) for 30 minutes in a humidity chamber at room temperature. Rabbit anti-FAM124B (Protein Tech), rabbit anti-CHD7 (abcam, ab31824) and rabbit anti-CHD8 (abcam, ab84527) antibodies were diluted at 1:50, 1:50 and 1:100, respectively. The primary antibodies were incubated at $4{ }^{\circ} \mathrm{C}$ overnight. After washing with TPBS for 5 minutes, a Pan specific secondary antibody (Vectastain Universal Quick kit, Vector Laboratories, Burlingame, CA) was applied for 
maximum 10 minutes and washed again with TPBS for 5 minutes. Streptavidin peroxidase (Vectastain Universal Quick kit, Vector Laboratories, Burlingame, CA) was applied on the slides for 5 minutes. Slides were then transferred to TPBS washing buffer for minimum 5 minutes. The staining was developed with DAB substrate (Roche Diagnostik GmbH, Mannheim, Germany) for around 2 minutes. The slides were rinsed for minimum 5 minutes under tap water and counterstain could be done in mayor's hematoxylin for 20-40 seconds and washed with tap water 3-4 times. Mounting of slides were done with Aqua polymount (Polysciences Inc., Warrington, PA). Imaging was performed and processed using a BX60 microscope (Olympus, Hamburg, Germany) and the analySIS program Cell-Sens Dimension.

\section{SUPPORTING INFORMATION}

Table S1 Proteins found by SILAC in combination with mass spectrometry $1^{\text {st }}$ experiment (XLS)

Table S2 Proteins found by SILAC in combination with mass spectrometry $2^{\text {nd }}$ experiment (XLS)

Table S3 Proteins found by SILAC in combination with mass spectrometry $3^{\text {rd }}$ experiment (XLS)

\section{ACKNOWLEDGMENTS}

We thank W. Engel for his support and helpful discussions and Johanna Mänz for her excellent technical assistance.

\section{REFERENCES}

1. Vissers LE, van Ravenswaaij CM, Admiraal R, Hurst JA, de Vrie BB, et al. (2004) Mutations in a new member of the chromodomain gene family cause CHARGE syndrome. Nat Genet 36: 955-957.

2. Lalani SR, Safiullah AM, Fernbach SD, Harutyunyan KG, Thaller C, et al. (2006) Spectrum of CHD7 mutations in 110 individuals with CHARGE syndrome and genotypephenotype correlation. Am J Hum Genet 78: 303-314.

3. Jongmans MC, Admiraal RJ, van der Donk KP, Vissers LE, Baas AF, et al. (2006) CHARGE syndrome: the phenotypic spectrum of mutations in the CHD7 gene. J Med Genet 43: 306-314. 
4. Sanlaville D, Etchevers HC, Gonzales M, Martinovic J, Clément-Ziza M, et al. (2006) Phenotypic spectrum of CHARGE syndrome in fetuses with CHD7 truncating mutations correlates with expression during human development. J Med Genet 43: 211-217.

5. Aramaki M, Udaka T, Kosaki R, Makita Y, Okamoto N, et al. (2006) Phenotypic spectrum of CHARGE syndrome with CHD7 mutations. J Pediatr 148: 410-414.

6. Wincent J, Holmberg E, Strömland K, Soller M, Mirzaei L, et al. (2008) CHD7 mutation spectrum in 28 Swedish patients diagnosed with CHARGE syndrome. Clin Genet 74: 31-38.

7. Janssen N, Bergman EH Jorieke, Swertz MA, Tranebjaerg L, Lodahl M, et al. (2012) Mutation Update on the CHD7 Gene Involved in CHARGE Syndrome. Hum Mutat doi: 10.1002/humu.22086

8. Schnetz MP, Bartels CF, Shastri K, Balasubramanian D, Zentner GE, et al. (2009) Genomic distribution of CHD7 on chromatin tracks H3K4 methylation patterns. Genome Res 19: 590-601.

9. Schnetz MP, Handoko L, Akhtar-Zaidi B, Bartels CF, Pereira CF, et al. (2010) CHD7 targets active gene enhancer elements to modulate ES cell-specific gene expression. PLoS Genet 6: e1001023.

10. Bajpai R, Chen DA, Rada-Iglesias A, Zhang J, Xiong Y, et al. (2010) CHD7 cooperates with PBAF to control multipotent neural crest formation. Nature 463: 958-962.

11. Batsukh T, Pieper L, Koszucka AM, vonVelsen N, Hoyer-Fender S, et al. (2010) CHD8 interacts with CHD7, a protein which is mutated in CHARGE syndrome. Hum Mol Genet 19: 2858-2866.

12. Zentner GE, Hurd EA, Schnetz MP, Handoko L, Wang C, et al. (2010a) CHD7 functions in the nucleolus as a positive regulator of ribosomal RNA biogenesis. Hum Mol Genet 19: 3491-3501.

13. Takada I, Mihara M, Suzawa M, Ohtake F, Kobayashi S, et al. (2007) A histone lysine methyltransferase activated by non-canonical wnt signalling suppresses PPAR-gamma transactivation. Nat Cell Biol 9: 1273-1285.

14. Ho L and Crabtree GR. (2010) Chromatin remodelling during development. Nature 28: 474-84. Review 
15. Srinivasan S, Dorighi KM, Tamkun JW. (2008) Drosophila kismet regulates histone H3 lysine 27 methylation and early elongation by RNA polymerase II. PLoS Genet 4: e1000217.

16. Rodríguez-Paredes M, Ceballos-Chávez M, Esteller M, García-Domínguez M and Reyes JC. The chromatin remodeling factor CHD8 interacts with elongating RNA polymerase II and controls expression of the cyclin E2 gene. Nucleic Acids Res 37: 2449-2460.

17. Thompson BA, Tremblay V, Lin G and Bochar DA. (2008) CHD8 is an ATPdependent chromatin remodeling factor that regulates beta-catenin target genes. Mol Cell Biol 28: 3894-3904.

18. Yokoyama A, Cleary ML. (2008) Menin critically links MLL proteins with LEDGF on cancer-associated target genes. Cancer Cell 14: 36-46.

19. Zahir F, Firth HV, Baross A, Delaney AD, Eydoux P, et al. (2007) Novel deletions of 14q11.2 associated with developmental delay, cognitive impairment and similar minor anomalies in three children. Med Genet 44: 556-561.

20. Talkowski ME, Rosenfeld JA, Blumenthal I, Pillalamarri V, Chiang C, et al. (2012) Sequencing Chromosomal Abnormalities Reveals Neurodevelopmental Loci that Confer Risk across Diagnostic Boundaries. Cell 149: 525-537.

21. O’Roak BJ, Vives L, Girirajan S, Karakoc E, Krumm N, et al. (2012) Sporadic autism exomes reveal a highly interconnected protein network of de novo mutations. Nature 485 : 246-250.

22. Neale BM, Kou Y, Liu L, Ma'ayan A, Samocha KE, Sabo A, et al. (2012) Patterns and rates of exonic de novo mutations in autism spectrum disorders. Nature 485: 242-245.

23. Ong SE, Blagoev B, Kratchmarova I, Kristensen DB, Steen H, et al. (2002) Stable Isotope Labeling by Amino Acids in Cell Culture, SILAC, as a Simple and Accurate Approach to Expression Proteomics. Mol Cell Proteomics 1: 376-386.

24. Oellerich T, Bremes V, Neumann K, Bohnenberger H, Dittmann K, Hsiao HH, Engelke M, Schnyder T, Batista FD, Urlaub H, Wienands J. (2011) The B-cell antigen receptor signals through a preformed transducer module of SLP65 and CIN85. EMBO J 30: $3620-3634$.

25. Betancur, C. (2011) Etiological heterogeneity in autism spectrum disorders: more than 100 genetic and genomic disorders and still counting. Brain Res 1380: 42-77. 
26. Ishihara K, Oshimura M. and Nakao M. (2006) CTCF-dependent chromatin insulator is linked to epigenetic remodeling. Mol Cell 1: 733-742.

27. Bosman EA, Penn AC, Ambrose JC, Kettleborough R, Stemple DL, et al. (2005) Multiple mutations in mouse Chd7 provide models for CHARGE syndrome. Hum Mol Genet 14: 3463-3476.

28. Hurd EA, Capers PL, Blauwkamp MN, Adams ME, Raphael Y, et al. (2007) Loss of Chd7 function in gene-trapped reporter mice is embryonic lethal and associated with severe defects in multiple developing tissues. Mamm Genome 18: 94-104.

29. Bergman JE, Bosman EA, van Ravenswaaij-Arts CM, Steel KP. (2010) Study of smell and reproductive organs in a mouse model for CHARGE syndrome. Eur J Hum Genet 18: $171-177$.

30. Shevchenko A, Tomas H, Havlis J, Olsen JV, Mann M. (2006) In-gel digestion for mass spectrometric characterization of proteins and proteomes. Nat Protoc. 1: 2856-2860.

31. Nikolov M, Stützer A, Mosch K, Krasauskas A, Soeroes S, Stark H, Urlaub H, Fischle W. (2011) Chromatin affinity purification and quantitative mass spectrometry defining the interactome of histone modification patterns. Mol Cell Proteomics. 10: M110.005371.

\section{FIGURES}

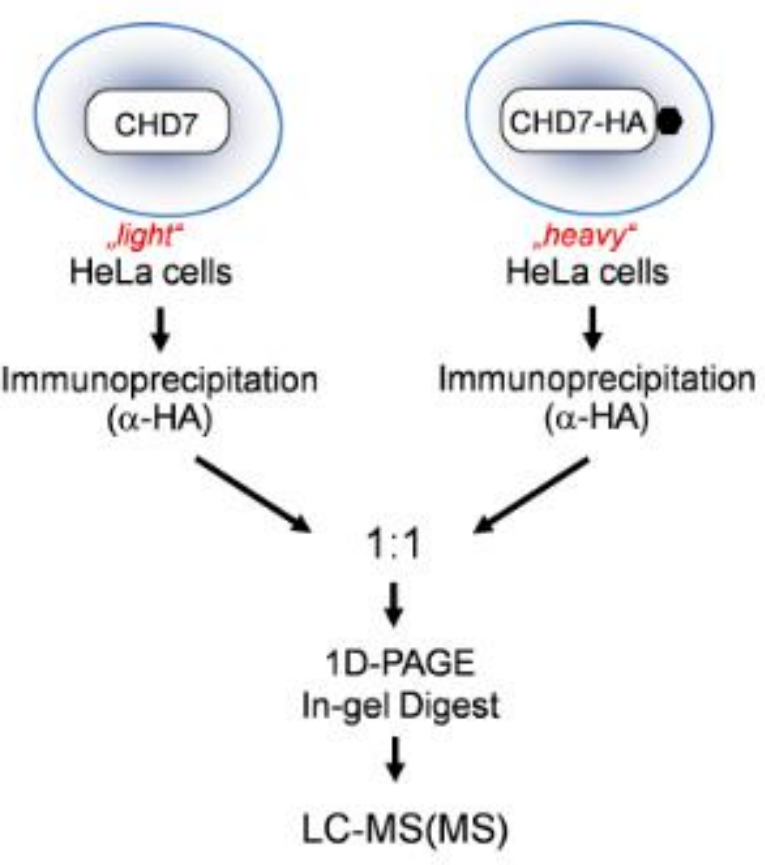

Figure 1: Schematic overview of the SILAC approach.

"Heavy"-labeled cells were co-transfected with the plasmids CHD7-CR1-3-pCMV-HA (containing amino acids 1593 - 2178, NP_060250.2, in fusion with an HA-tag) and CHD8-pCMV-cmyc (spanning amino acids 1789 - 2302, NP_065971.2, in fusion with an cmyc-tag). The CHD7 part was purified by anti-HA immunoprecipitation. As a negative control the same immunoprecipitation was performed in lysates of nontransfected "Light"-labeled HeLa cells. Purified proteins from both cell cultures were pooled in equimolar amounts and in-gel digested, followed by liquid-chromatography (LC)-coupled tandem mass spectrometry. 
A

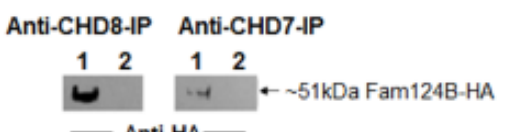

D

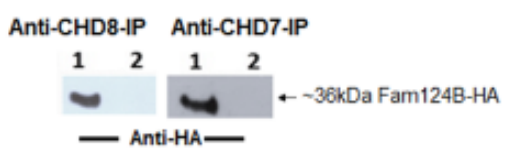

B

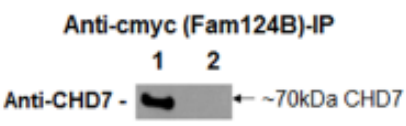

$E$

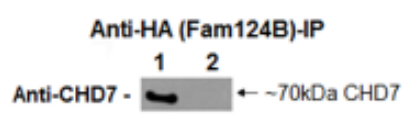

C

Anti-HA (Fam124B)-IP

12

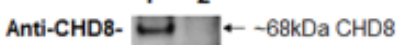

$\mathrm{F}$

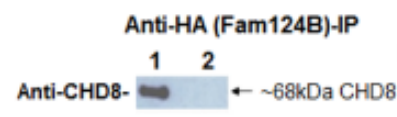

Figure 2: Co-immunoprecipitation of FAM124B with a part of CHD7 and CHD8.

HeLa cells were co-transfected with either the CHD7-CR1-3-pCMV-HA (amino acids 1593 - 2178, NP_060250.2) plasmid and FAM124B-1,3-pCMV-cmyc/FAM124B-1,3-pCMV-HA (transcript variant 1, NP_001116251.1) or with CHD8-pCMV-cmyc (amino acids 1789 - 2302, NP_065971.2) and FAM124B-1,3pCMV-HA (transcript variant 1, NP_001116251.1).

(A) Using the anti-CHD8 (abcam, ab84527) or the anti-CHD7 (abcam, ab31824) antibody for precipitation, we detected with the anti-HA antibody (Roche) an approximately $51 \mathrm{kDa}$ band corresponding to the estimated size of FAM124B transcript variant 1. Lane 1: co-transfected Co-IP, lane 2: untransfected HeLa cells as negative control. (B) Reciprocal immunoprecipitation with anti-cmyc antibody (precipitating FAM124B transcript variant 1), and detection with the anti-CHD7 antibody lead to a specific band $\sim 70 \mathrm{kDa}$, the estimated size for the CHD7 part fused to the HA-tag. Lane 1: co-transfected Co-IP, lane 2: untransfected HeLa cells as negative control. (C) Reciprocal experiment with anti-HA antibody (precipitating FAM124B transcript variant 1) and detection with the anti-CHD8 antibody detected a specific band $\sim 68 \mathrm{kDa}$, the estimated size for the CHD8 part fused to the cmyc-tag. Lane 1: co-transfected Co-IP, lane 2: untransfected HeLa cells as negative control. (D, E, F) The same experimental procedure was performed for FAM124B transcript variant 2, demonstrating a specific interaction of FAM124B transcript variant 2 with the CHD7 and CHD8 part as well. Lane 1: co-transfected Co-IP, lane 2: untransfected HeLa cells as negative control.
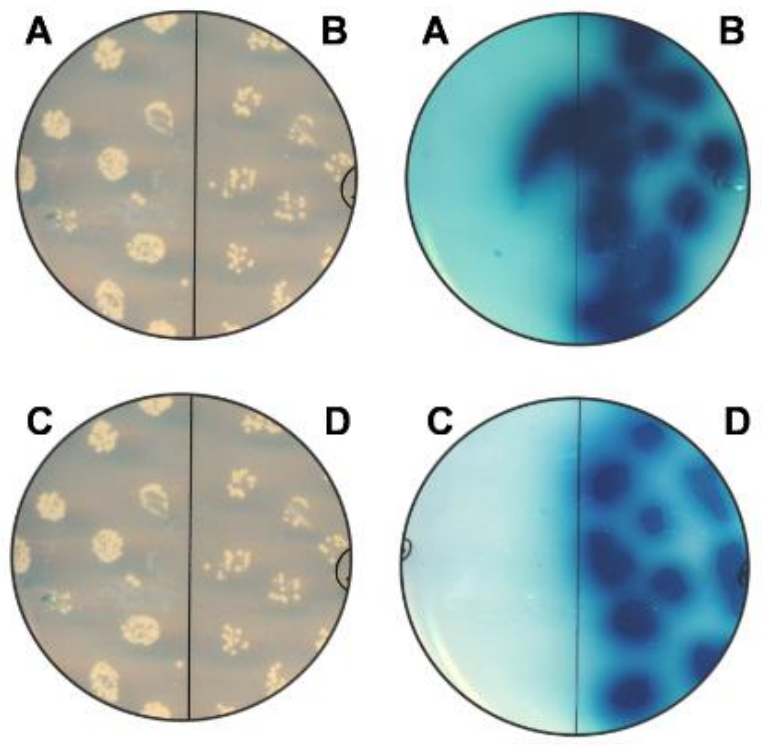

Figure 3: Yeast two hybrid assay.

(A) Direct yeast two hybrid experiment with the constructs FAM124B-1,3-pGADT7 (full lengths transcript variant 1) and CHD7-CR1-3-pGBKT7 (amino acids 1591-2181, NP_060250.2) demonstrating no direct interaction between FAM124B transcript variant 1 and the CHD7 part, while (B) direct yeast two hybrid experiment with the constructs FAM124B-1,3-pGADT7 (full lengths transcript variant 1) and CHD8-pGBKT7 (amino acids 1789-2302, NP_065971.2) shows a direct interaction. The same experiments were performed for FAM124B transcript variant 2. (C) Direct yeast 
two hybrid experiment with the constructs FAM124B-1,2-pGADT7 (full lengths transcript variant 2) and CHD7CR1-3-pGBKT7 (amino acids 1591-2181, NP_060250.2). (D) Direct yeast two hybrid experiment with the constructs FAM124B-1,2-pGADT7 (full lengths transcript variant 2) and CHD8-pGBKT7 (amino acids 17892302, NP_065971.2). FAM124B transcript variant 2 interacts directly with the CHD8 part, while no direct interaction with the $\mathrm{CHD} 7$ part could be observed.

A

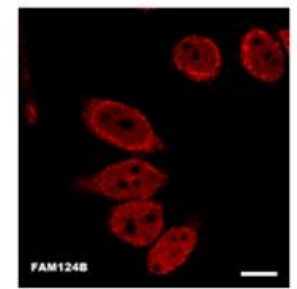

B

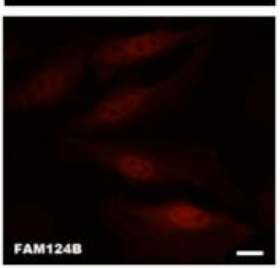

C

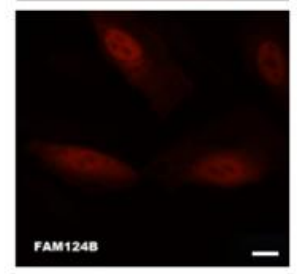

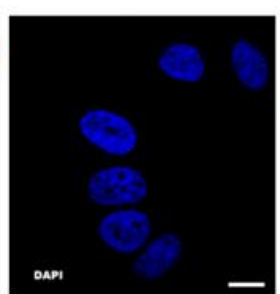
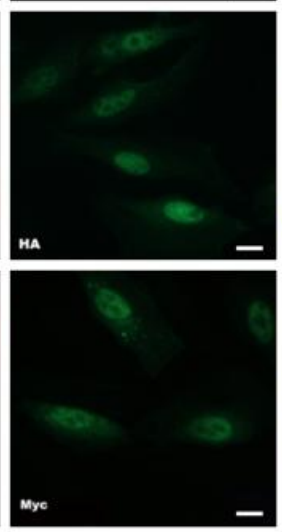
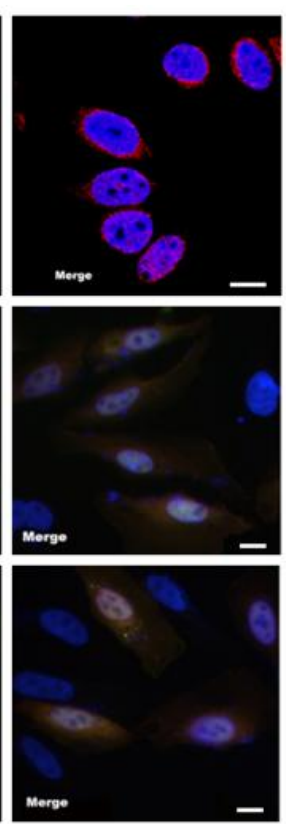

Figure 4: Subcellular localization of FAM124B.

(A) Immunofluorescence staining using a rabbit anti-Fam124B antibody (ProteinTech) on untransfected HeLa cells demonstrating a mainly nuclear localization of endogenous FAM124B.

(B) Immunofluorescence staining using the rabbit anti-Fam124B antibody and the antiHA antibody on HeLa cells transiently transfected with the plasmid FAM124B1,3-pCMV-HA (FAM124B transcript variant 1 fused to an hemagglutinin tag) confirmed the mainly nuclear distribution of

FAM124B and demonstrated the specifity of the FAM124B antibody.

(C) Immunofluorescence staining using the rabbit anti-Fam124B antibody and the anti-cmyc antibody on HeLa cells transiently transfected with the plasmid FAM124B-1,3-pCMV-cmy (FAM124B transcript variant 1 fused to an cmyc tag) confirmed the further results. Scale bar $=10 \mu \mathrm{m}$. 
A

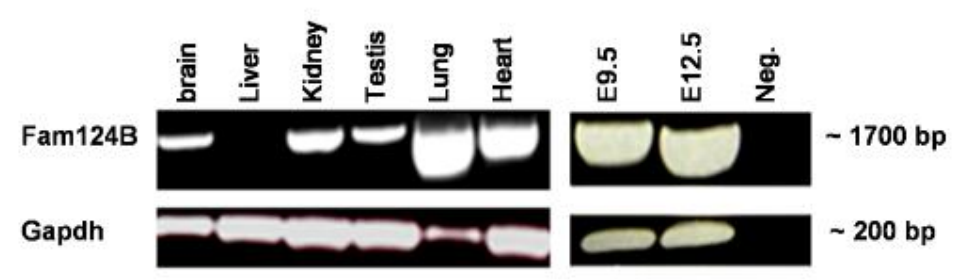

B

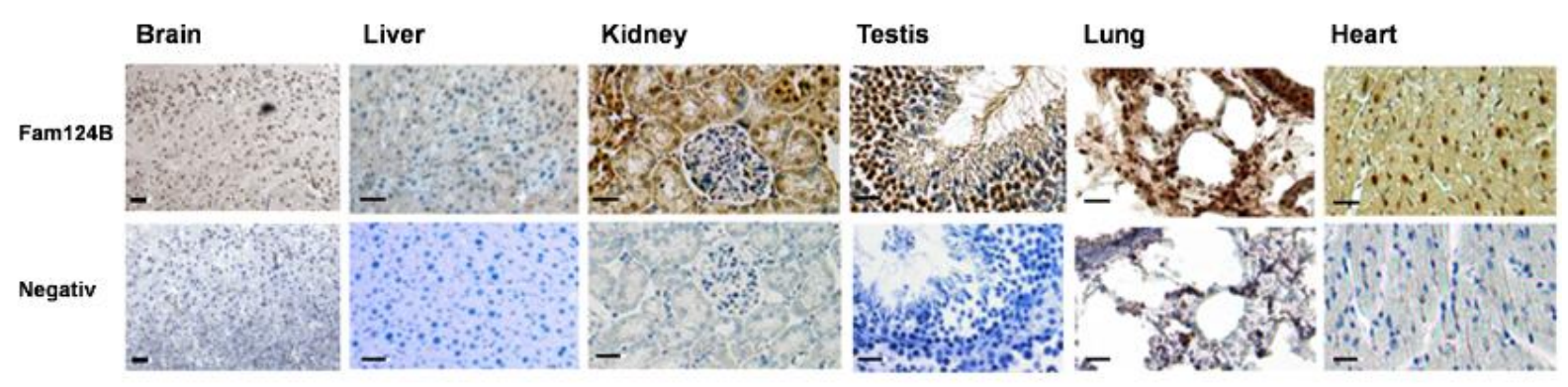

Figure 5: Expression pattern of murine Fam124B

(A) Expression pattern of murine Fam124B by semiquantitative reverse transcription polymerase chain reaction (RT-PCR) on wild type CD1 mouse tissues and E9.5 and E12.5 embryos demonstrating expression in various tissues and during development.

(B) Immunohistochemistry (IHC) performed in adult mouse tissues slightly counterstained with haemytoxylin (blue) confirmed the semiquantitative RT-PCR results with high expression (brown) in lung, heart, kidney, moderate expression in brain and testis, and very low expression in liver. Scale bar $=20 \mu \mathrm{m}$.
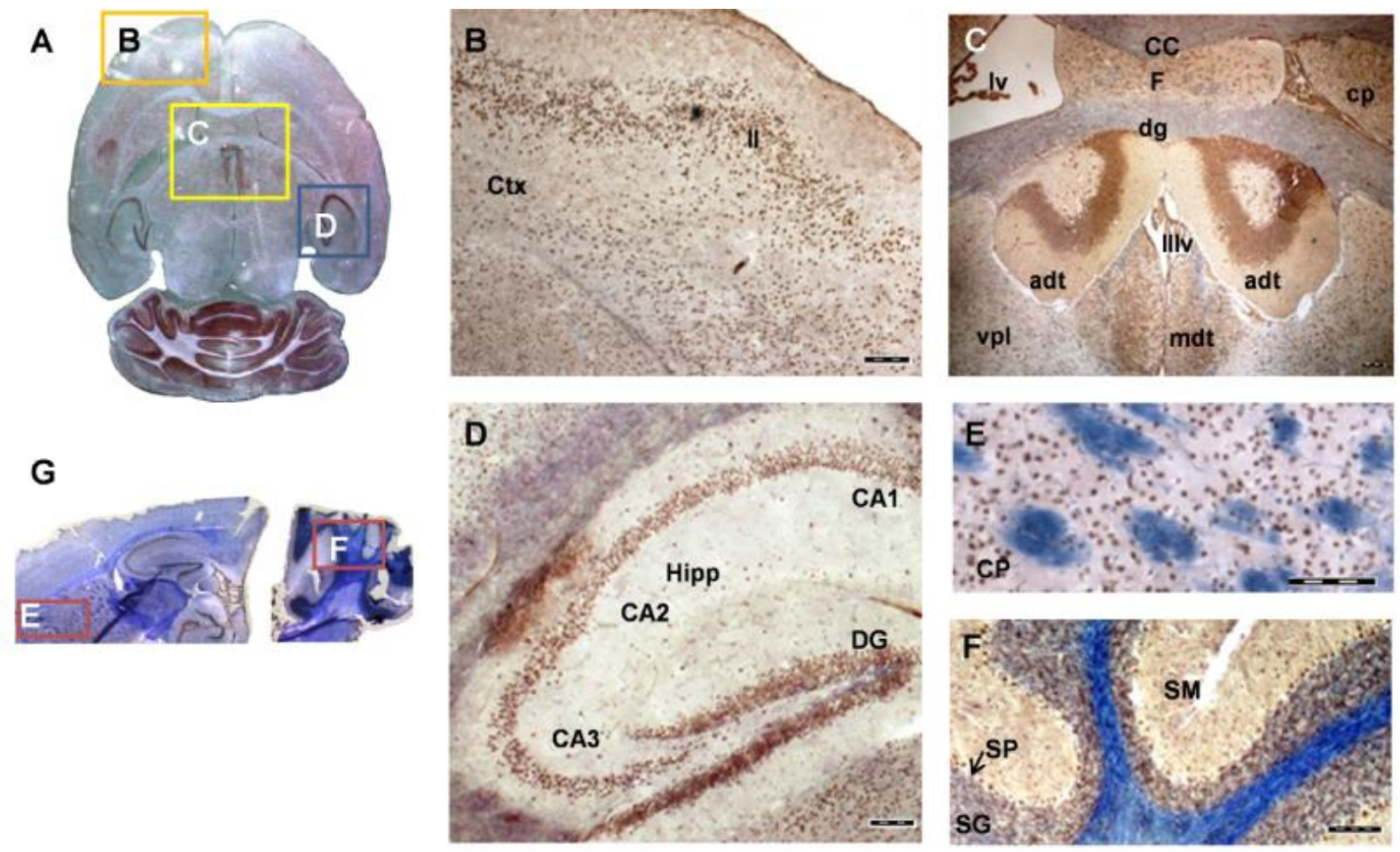

Figure 6: Fam124B expression in the mouse central nervous system.

(A) Overview of horizontal paraffin embedded brain sections (B, C, D). (G) Overview of sagittal brain cryosections (E,F). (B) Cortex, (C) Thalamic nuclei, (D) Hippocampus, (E) Caudate Putamen, (F) Cerebellum. 
$\mathrm{Ctx}=$ Cortex, $\mathrm{CC}=$ Corpus Callosum, Hipp $=$ Hippocampus, $\mathrm{CA} 1-3=$ Cornu Ammonis areas, $\mathrm{DG}=$ dentate gyrus, $\mathrm{CP}=$ Caudate Putamen, adt $=$ anterior dorsal thalamic nucleus, $\mathrm{dg}=$ granual layer of dentate gyrus, $\mathrm{lv}=$ left ventricle, $\mathrm{F}=$ fornix, $\mathrm{mdt}=$ mediodorsal thalamic nucleus, $\mathrm{IIIv}=$ third ventricle with choroid plexus, $\mathrm{vpl}=$ ventral posterior thalamic nucleus, lateral part, $\mathrm{SM}=$ stratum moleculare, $\mathrm{SP}=$ stratum purkinjense, $\mathrm{SG}=$ stratum granulosum, II = stratum granulosum externum. Scale bar $=100 \mu \mathrm{m}$.

A
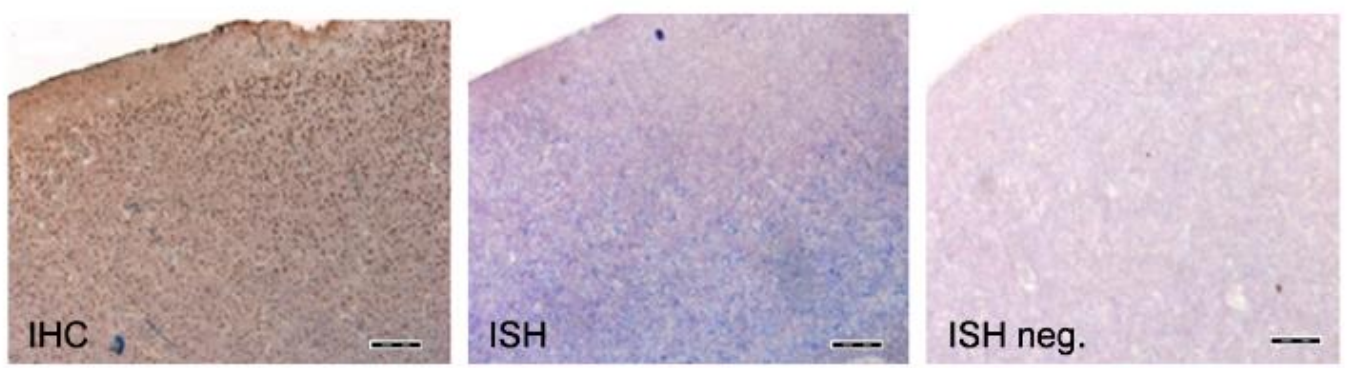

B
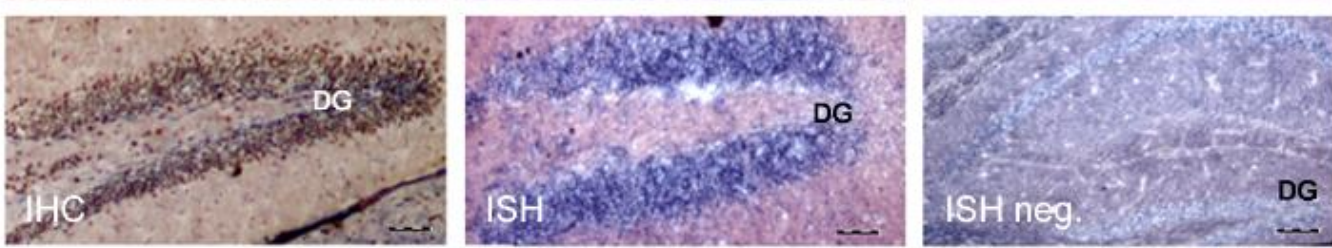

Figure 7: In situ hybridization (ISH) of Fam124B on mouse brain cryosections in comparison with immunostaining (IHC). (A) Cortex, (B) Hippocampus: An overlapping expression pattern could be demonstrated confirming the specificity of the FAM124B antibody. DG $=$ dentate gyrus. Scale bar $=100 \mu \mathrm{m}$.

A

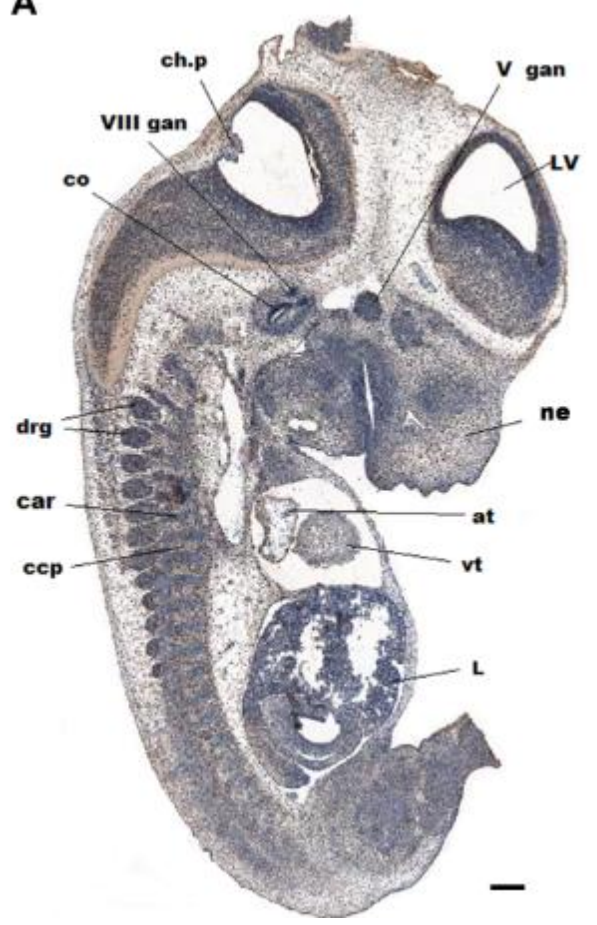

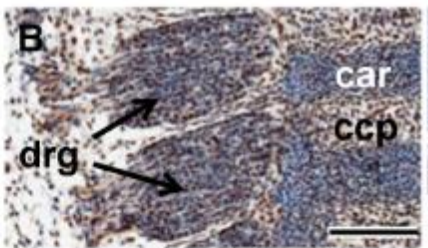
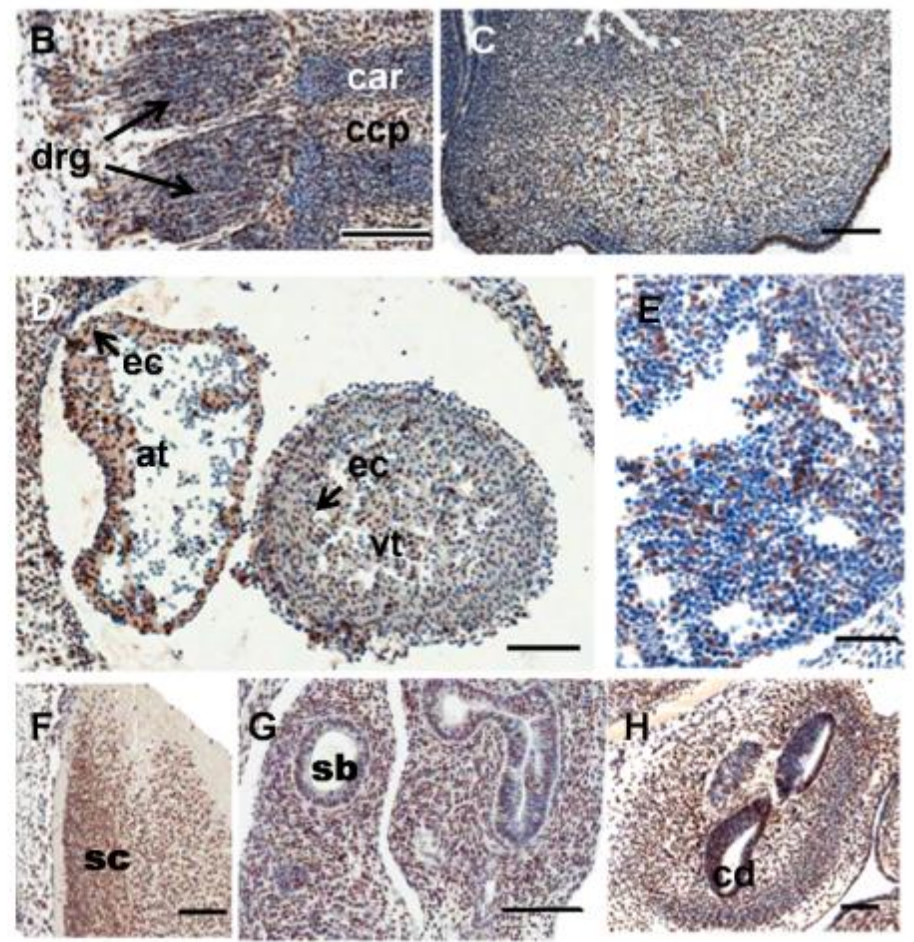

Figure 8: Fam124B expression at murine embryonic stage E12.5

Fam124B expression (brown) was found in a variety of embryonic tissues. Expression could be observed in several brain areas, spinal cord, dorsal root ganglia, developing cochlea and surrounding tissues, lung, heart, and kidney. Low expression was found in the developing liver and no expression (blue) in blood cells. 
(A) Overview of Fam124B immunostaining on sagittal section of an E12.5 wildtype embryo slightly counterstained with haemytoxylin, scale bar $=200 \mu \mathrm{m}$. Higher magnification of $(\mathbf{B})$ dorsal root ganglia, scale bar $=100 \mu \mathrm{m}$ (C) nasal region, scale bar $=100 \mu \mathrm{m}$ (D) the developing heart, scale bar $=100 \mu \mathrm{m}$ (E) developing liver, scale bar $=50 \mu \mathrm{m}$ (F) spinal cord (sc), scale bar $=50 \mu \mathrm{m}$ (G) developing lung with segmental bronchus $(\mathrm{sb})$, scale bar $=100 \mu \mathrm{m}(\mathbf{H})$ cochlea, and surrounding tissue, scale bar $=100 \mu \mathrm{m}$.

$\mathrm{LV}=$ lateral ventricle, ch.p $=$ choroid plexus differentiating from fourth ventricle, $c o=$ cochlea, $\mathrm{cd}=$ cochlear duct, ne = nasal epithelium, V gan = left trigeminal $(\mathrm{V})$ ganglion, drg = dorsal root ganglion, VIII gan = Vestibulocochlear $(\mathrm{VIII})$ ganglion, at $=$ left atrium of heart, $\mathrm{vt}=$ left heart ventricle, $\mathrm{ec}=$ endothelial cells, $\mathrm{car}=$ cartilage primordium of body of vertebra, $\mathrm{ccp}=$ cartilage condensation being primordium of vertebral body.
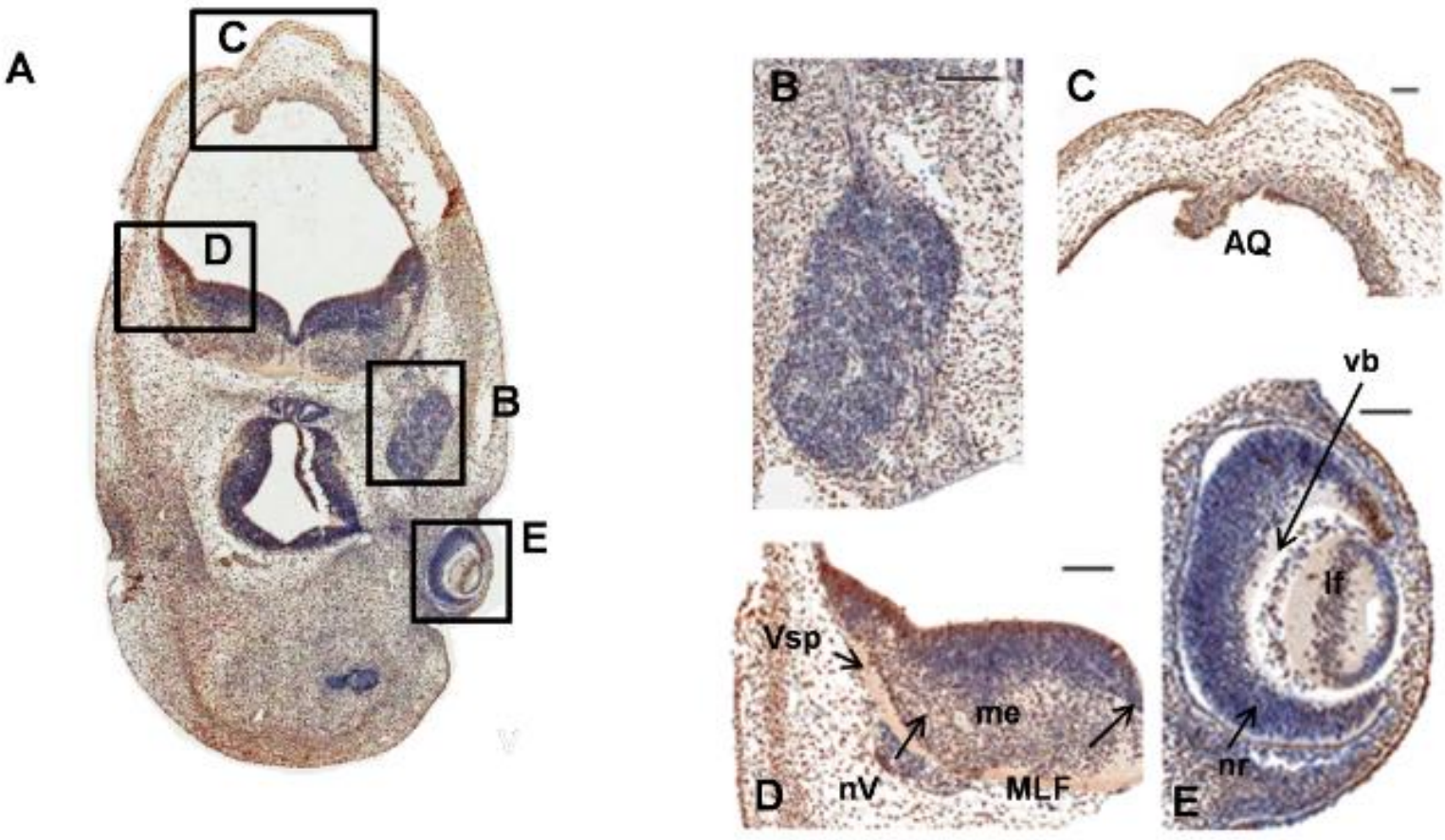

Figure 9: Fam124B expression in the developing brain at murine embryonic stage E12.5

(A) Overview of Fam124B immunostaining of the brain slightly counterstained with haemytoxylin. (B) Higher magnification of the trigeminal ganglion, (C) aqueduct of sylvius with choroid plexus = AQ (D) Higher magnification of the medulla (me) with spinal tract of trigeminal nerve ( $\mathrm{Vsp}), \mathrm{nV}=$ trigeminal nucleus, MLF= medial longitudinal fasciculus $(\mathbf{E})$ Higher magnification of the eye, $\mathrm{nr}=$ neural retina, $\mathrm{lf}=$ lens fibers, $\mathrm{vb}=$ vitreous body. Scale bar $=50 \mu \mathrm{m}$. 


\section{PLOS ONE}

\section{Identification and characterization of FAM124B as a novel component of a CHD7 and CHD8 containing complex \\ --Manuscript Draft--}

\begin{tabular}{|c|c|}
\hline \multicolumn{2}{|l|}{ Manuscript Number. } \\
\hline Artide Type: & Research Article \\
\hline Full Title: & $\begin{array}{l}\text { Identification and characterization of FAM124B as a novel component of a CHD7 and } \\
\text { CHD8 containing complex }\end{array}$ \\
\hline Short Tite: & Characterization of FAM 124B \\
\hline Comesponding Author. & $\begin{array}{l}\text { Silke Pauli } \\
\text { University Medical Center } \\
\text { Göttingen, GERMANY }\end{array}$ \\
\hline Kenwords: & FAM 124B; CHD8; CHD7; interaction studies; expression pattem \\
\hline Abstract & $\begin{array}{l}\text { Background: Mutations in the chromodomain helicase DNA binding protein } 7 \text { gene } \\
\text { (CHD7) lead to CHARGE syndrome, an autosomal dominant multiple malformation } \\
\text { disorder. Proteins involved in chromatin remodeling typically act in multiprotein } \\
\text { complexes. We could previously demonstrate that a part of human } \mathrm{CHD7} \text { interacts with } \\
\text { a part of human CHD8, another chromodomain helicase DNA binding protein } \\
\text { presumably being involved in the pathogenesis of neurodevelopmental (NDD) and } \\
\text { autism spectrum disorders (ASD). Because identification of novel CHD7 and CHD8 } \\
\text { interacting partners will provide further insights into the pathogenesis of CHARGE } \\
\text { syndrome and ASDNDD, we searched for additional associated polypeptides using } \\
\text { the method of stable isotope labeling by amino acids in cell culture (SILAC) in } \\
\text { combination with mass spectrometry. } \\
\text { Principle findings: The hitherto uncharacterized FAM } 124 \mathrm{~B} \text { (Family with sequence } \\
\text { similarity } 124 \mathrm{~B} \text { ) was identified as a potential interaction partner of both CHD7 and } \\
\text { CHD8. We confirmed the result by co-immunoprecipitation studies and showed by } \\
\text { direct yeast two hybrid experiments a direct binding to the CHD8 part. Furthermore, we } \\
\text { characterized FAM } 124 \mathrm{~B} \text { as a mainly nuclear localized protein with a widespread } \\
\text { expression in embryonic and adult mouse tissues. } \\
\text { Conclusion: Our results demonstrate that FAM124B is a potential interacting partner of } \\
\text { a CHD7 and CHD8 containing complex. From the overlapping expression pattern } \\
\text { between Chd7 and Fam } 124 \mathrm{~B} \text { at murine embryonic day } \mathrm{E} 12.5 \text { and the high expression } \\
\text { of Fam } 124 \mathrm{~B} \text { in the developing mouse brain, we conclude that Fam } 124 \mathrm{~B} \text { is a novel } \\
\text { protein possibly involved in the pathogenesis of CHARGE syndrome and } \\
\text { neurodevelopmental disorders. }\end{array}$ \\
\hline \multirow[t]{8}{*}{ Order of Authors: } & Tserendulam Batsukh \\
\hline & Yvonne Schulz \\
\hline & Stephan Wolf \\
\hline & Tamara I. Rabe \\
\hline & Thomas Oellerich \\
\hline & Henning Urlaub \\
\hline & Inga-Marie Schaefer \\
\hline & Silke Pauli \\
\hline \multirow[t]{2}{*}{ Suggested Reviewers: } & $\begin{array}{l}\text { Seema R. Lalani, MD } \\
\text { Baylor College of Medicine } \\
\text { seemal@bcm. edu } \\
\text { She worked since years in the field of CHARGE syndrome }\end{array}$ \\
\hline & $\begin{array}{l}\text { Bernd Wollnik } \\
\text { University of Cologne, Institute of Human Genetics }\end{array}$ \\
\hline
\end{tabular}




\section{Discussion}

Mutations in the chromodomain helicase DNA binding protein 7 gene (CHD7) are the underlying cause for CHARGE syndrome, an autosomal dominant inherited heterogeneous multiple malformation syndrome (Vissers et al. 2004). In 10-20\% of patients with typical signs of CHARGE syndrome and in 40-50\% of patients with an atypical presentation no mutation could be found and therefore the molecular cause is unknown. The characterization of CHD7 interacting partners can help to understand the pathogenesis of the disease. In our working group a part of CHD8, another member of the CHD family of proteins, was identified by yeast two hybrid library screen as a putative interaction partner of CHD7. The interaction was confirmed by bimolecular fluorescence assay (BiFC), direct Yeast two Hybrid and Co-IP experiments. Furthermore, we investigated the CHD7-CHD8 interaction in the presence of 4 CHD7 missense mutations. Indeed, three out of 4 mutations lead to a loss of interaction by direct interaction studies, while the interaction still remained in Co-IP studies. Because of these results we suggest that CHD7 and CHD8 interact directly (shown by the Y2H experiments) and indirectly via additional linker proteins (in Co-IP results). Therefore we searched for additional CHD7 and CHD8 associated proteins by using the method of SILAC in combination with mass spectrometry. As a novel interacting partner of a part of CHD7 and a part of CHD8 we identified the unknown protein FAM124B. We further characterized the expression profile and the subcellular localization of FAM124B. Moreover, our results let us suggest that FAM124B might be very important for embryonic development and could play a role in the pathogenesis of CHARGE syndrome and autism and neurodevelopmental disorders.

\subsection{Known CHD7 complexes and function}

Since the discovery that $C H D 7$ mutations lead to CHARGE syndrome, its functions have been studied to a greater extent. To date, CHD7 is known to be involved in several cell and tissue specific complexes (Takada et al. 2007, Bajpai et al. 2010, Schnetz et al. 2009, 2010). In human multipotent neural crest like cells, CHD7 regulates neural crest and placode formation by binding to components of the BAF/PBAF complex (Bajpai et al. 2010, Fig. 4.1A). BAF/PBAF complexes are chromatin remodeling complexes, which are involved in developmental transitions. The composition of the complex is tissue and developmental stage dependent (Ho \& Crabtree 2010).

With an approach of chromatin immunoprecipitation and microarray-based sequence analysis (ChIP-chip) in human colorectal carcinoma cells, human neuroblastoma cells, and mouse ES cells before and after differentiation into neural precursor cells, CHD7 has been 
demonstrated to have tissue and cell type specific temporal functions via localizing to methylated histone $\mathrm{H} 3$ lysine $4(\mathrm{H} 3 \mathrm{~K} 4)$ in enhancer regions of various genes (Schnetz et al. 2009). A further study in mouse embryonic stem (ES) cells indicates that CHD7 colocalizes with Oct4, Sox2, Nanog, and p300 and functions by binding to enhancers as a transcriptional modulator and fine-tuning the expression levels of ES cell-specific genes in either a positive or negative way (Schnetz et al. 2010, Fig. 4.1B). In addition, CHD7 forms a complex with NLK, SETDB1 and PPAR- $\gamma$ and binds to methylated lysine 4 and lysine 9 residues on histone $\mathrm{H} 3$ at PPAR- $\gamma$ target promoters in mesenchymal stem cells. Therefore it is suggested that CHD7 is involved in the regulation of cell fate specification (Takada et al. 2007, Fig. 4.1C).

Furthermore, in Drosophila, Kismet, a homolog of the human CHD7 protein, has been proven to be crucial for proper axon pruning and development of fly's central nervous system (Melicharek et al. 2010). Another functional study could demonstrate that Kismet promotes early transcriptional elongation through RNA polymerase II by recruiting the histone methyltransferases ASH1 and TRX to chromatin (Srinivasan et al. 2008).

CHD7 is localized in the nucleolus and the nucleoplasm (Zentner et al. 2010, Kita et al. 2012). Interestingly, recently it has been shown that CHD7 codes for two transcripts. The shorter transcript is generated by alternative splicing of exon 6 and contains only one chromodomain. This transcript variant was shown to localize in the nucleolus (Kita et al. 2012). CHD7 regulates positively rRNA biosynthesis and is associated with rDNA (Zentner et al. 2010). Indeed, it has been shown that both CHD7 transcripts regulate $45 \mathrm{~S}$ precursor rRNA production (Zentner et al. 2010, Kita et al. 2012). Moreover overexpression studies showed that the long CHD7 transcript (CHD7L) supports Sox2-mediated transcriptional regulation whereas the short CHD7 transcript (CHD7S) suppresses it (Kita et al. 2012). Treacher Collins syndrome (TCS) is a multiple congenital anomaly caused by mutations in the TCOF1 gene, encoding the protein treacle (Valdez et al. 2004, Dixon et al. 2007). TCS and CHARGE syndrome are distinct diseases, but share some common features such as eye and ear defects. Like CHD7, treacle is associated on rDNA and act as a positive regulator of rRNA synthesis. Indeed, Zentner et al. (2010) could show that CHD7 is needed for treacle (TCOF1) to associate with rDNA (Fig. 4.1D). These findings imply a functional link between CHARGE syndrome and Treacher Collins syndrome.

These reports show crucial roles for CHD7 in the transcriptional regulation of target genes, its effects on developmental stages and various tissue specific processes and the pathogenetic connection between CHARGE syndrome and other malformation syndromes like Treacher Collins syndrome. 
A
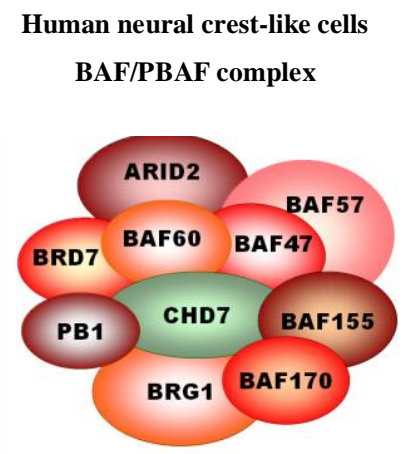

B

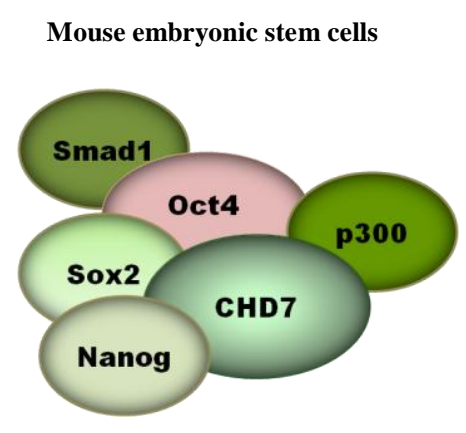

C

Mouse BM mesenchymal progenitor cells

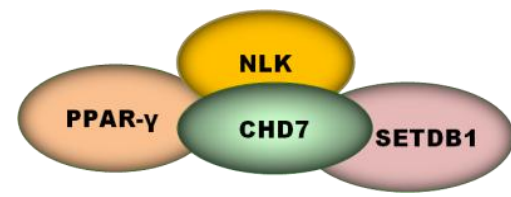

D

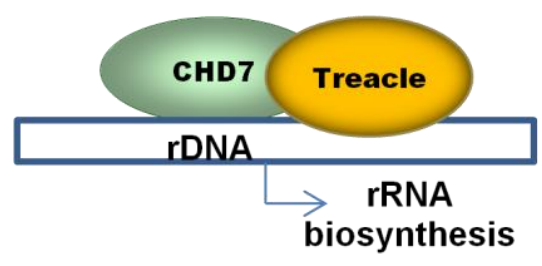

Figure 4.1. Models for CHD7 complexes. A: Human neural crest-like cells, BAF/PBAF complex (Bajpai et al. 2010), B: A complex in mouse embryonic stem cells (Schnetz et al. 2010), C: A complex in mouse bonemarrow mesenchymal progenitor cells (Takada et al. 2007), D: CHD7 and Treacle association on rDNA (Zentner et al. 2010).

\subsection{Known CHD8 complexes and function}

Chromodomain helicase DNA binding protein 8 (CHD8) is a chromatin remodeling enzyme that belongs to the CHD subgroup III. Typical additional domains of this subgroup are three conserved regions (CR1-3), a SANT and two BRK domains. CHD proteins utilize ATP hydrolysis to modify chromatin structure and to regulate transcriptional processes (Marfella \& Imbalzano 2007). CHD8 was first described in Xenopus by Sakamoto et al. (2000). They named the protein Duplin (for axis duplication inhibitor). It was shown that Duplin is a nuclear protein that directly binds to $\beta$-catenin and inhibits $\mathrm{Wnt} / \beta$-catenin signaling (Sakamoto et al. 2000). The second chromodomain is responsible for the $\beta$-catenin interaction. In addition, they could show that Duplin regulates $\beta$-catenin- T-cell factor (Tcf)-dependent downstream genes (Chung et al. 1997, Kobayashi et al. 2002). However, Duplin is an N-terminal fragment of Chd8 which lacks the catalytic Snf2 helicase domain and all further domains. Later, full length of CHD8 has been shown to bind also directly to $\beta$-catenin (Thompson et al. 2008).

Nishiyama et al. (2004) created Duplin knock-out mice. Duplin mutant homozygous embryos show growth retardation accompanied by massive apoptosis leading to death at E7.5. Later they demonstrated CHD8 binds to both p53 and histone H1 proteins. The p53-CHD8histone $\mathrm{H} 1$ complex is required for suppression of p53 target genes transcription, and therefore 
prevents apoptosis induced by genotoxicity (Nishiyama et al. 2009, Fig. 4.2A). Interestingly, the Wnt signaling pathway is regulated by CHD8 in a similar way. CHD8 promotes the $\beta$ catenin-CHD8-histone H1 trimeric complex on chromatin (Nishiyama et al. 2012, Fig. 4.2B).

CHD8 is shown to be involved in various protein complexes depending on the cell type and developmental stage. Mouse Chd8 has been shown to play a role in Ctcf-dependent insulator function by binding directly Ctcf (11-zinc finger protein or CCCTC-binding factor) (Ishihara et al. 2006). Furthermore, various experiments on smooth muscle cells (SMCs) could demonstrate that complexes including CHD8, Serum Response Factor (SRF) and CCTF play an essential role in differentiation and maintenance/survival of SMCs (Rodenberg et al. 2010, Fig. 4.2C).

Additionally, CHD8 was copurified with a large protein complex including Wdr5, Ash2L, and RbBP5 (WAR), which are known members of the Mixed Lineage Leukemia (MLL) histone modifying complex (Dou et al. 2005, Thompson et al. 2008, Yates et al. 2010, Fig. 4.2D). MLL1 or 2, the trithorax orthologs in Drosophila, built together with RbBP5-WDR5 and ASH2L a complex which acts as a methyltransferase. This complex composition regulates the HOXA2 gene transcription in a positive manner (Hess 2004, Wysocka et al. 2005). In contrary, it has been demonstrated through CHD8 shRNA downregulation in pluripotent human testicular embryonal carcinoma cell lines that CHD8 with the WAR complex members WDR5, ASH2L and RbBP5 negatively regulates HOXA2 expression (Yates et al. 2010).

CHD8 interacts with the human Staf protein for efficient U6 gene transcription in vivo and it has been demonstrated by Chip analysis that CHD8 binds to both Pol II and Pol III snRNA promoters (Yuan et al. 2007). Moreover, CHD8 binds specifically to histone H3 di-methylated at lysine 4 with its chromodomains (Rodríguez-Paredes et al. 2009). CHD8 also binds the elongating form of RNA polymerase II to control the expression of cyclin E2 and thymidylate synthetase (TYMS) (Rodríguez-Paredes et al. 2009).

In addition, CHD8 is associated directly with the androgen receptor (AR) which could demonstrate a role for CHD8 in AR-mediated regulation of target genes (Menon et al. 2010). Collectively, CHD8 has various interaction partners depending on the cell type. Depending on the complex partners CHD8 functions in different processes like repressing apoptosis, differentiation and survival of SMCs, transcriptional repression and regulation of specific target genes. 
A

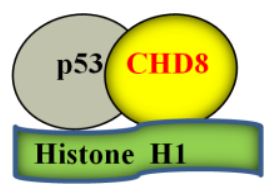

C

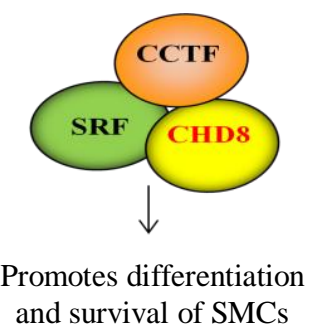

B

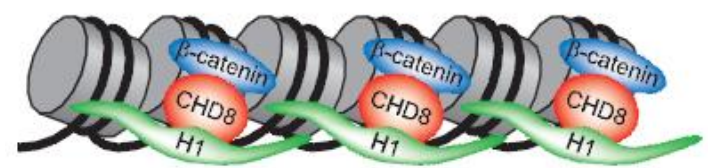

Chromatin compacting

Transcription silencing of target genes

D

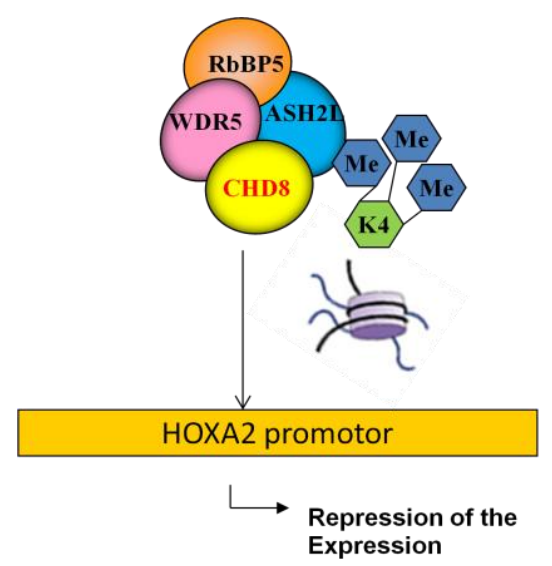

Figure 4.2. Models for CHD8 complexes. A: p53-CHD8-histone H1 complex regulates apoptosis during embryogenesis (Nishiyama et al. 2009), B: CHD8 interacts with $\beta$-catenin and subsequently recruits histone H1, resulting in chromatin compaction and transcriptional silencing of Wnt target genes (adapted and modified from Nishiyama et al. 2012), C: CHD8, SRF and CCTF complex is important for differentiation and survival of smooth muscle cells (Rodenberg et al. 2010), D: The human WAR (WDR5, RbBp5, ASH2L) complex repress HOXA2 gene expression when CHD8 is included (Thompson et al. 2008).

\subsection{CHD8 builds together with CHD7 a complex}

In our working group we searched for CHD7 interaction partners by performing yeast two hybrid library screen of a human fetal brain library. CHD8 was identified as a potential CHD7 interaction partner. The interaction was confirmed by direct yeast two hybrid and in HeLa cells by Co-IP and BiFC-assay (bimolecular fluorescence complementation assay). Interestingly, when we narrow down the interacting area of CHD8, a region of unknown functions without predicted domains was identified. The predicted sizes of the CHD7 and CHD8 proteins are 334 $\mathrm{kDa}$ and $290 \mathrm{kDa}$, respectively. Because of such a huge size of the endogenous CHD7 and CHD8 proteins, western blot detection needs to be done by a harsh nuclear isolation protocol as well as wet blotting technique. CHD8 is expressed relatively strong in HeLa cells (Nishiyama et al. 2009, 2012), whereas endogenous CHD7 expression is very low. Therefore, we were not able to perform Co-IP experiments with endogenous CHD7 in HeLa cells (data not shown). To demonstrate, the endogenous CHD7-CHD8 interaction we used the new method of Proximity Ligation Assay (PLA, Olink) (Fig. 4.3). In this method, two target 
proteins can be detected with specific antibodies produced in two different species. Specific oligonucleotide labeled secondary antibodies (PLA probes) generates fluorescence spots only when the two PLA probes have bound in close proximity. In our case, the PLA probes produce red fluorescence spots.

A

\section{CHD7/CHD8 Duolink PLA}

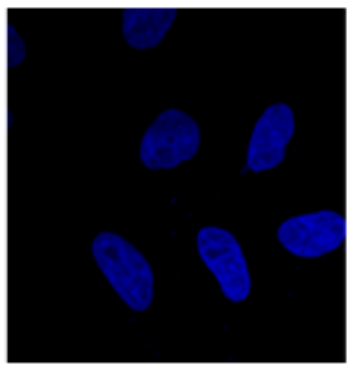

DAPI

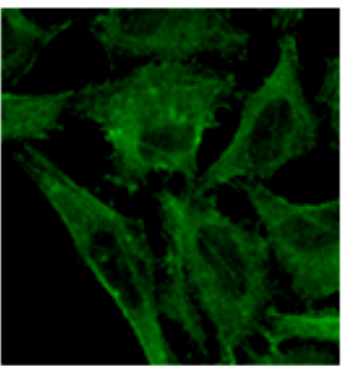

Phalloidin

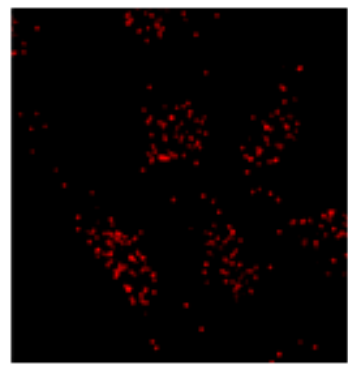

Duolink

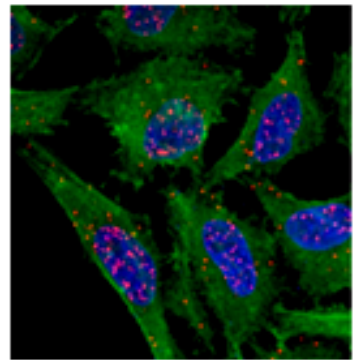

Overlay

B Negative control
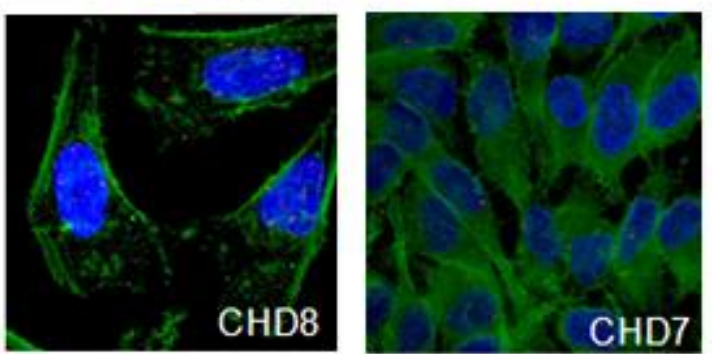

Figure 4.3. CHD7 and CHD8 endogenous interaction in HeLa cells shown by the Duolink PLA method.

Cell nuclei were counterstained with DAPI and cytoskeleton was stained by Phalloidin/FITC. Interacting areas are visualized as red fluorescence spots. A: CHD7 and CHD8 interaction can be seen in the nucleus. B: Technical negative control for the CHD7 and CHD8 antibodies. The primary CHD7 and CHD8 antibodies are used separately with 2 PLA probes. There are very few red dots in negative control which indicates antibodies do bind specifically (done by Yvonne Schulz 2011).

Moreover, in mammals CHD3 and CHD4, two other members of the CHD family, build together a core component of the NuRD complex (Xue et al. 1998, Hall \& Georgel 2007). In lower organisms like Drosophila, not all orthologs of the known human CHD genes are existing. For instance, Kismet is the only ortholog of all human CHD subgroup III members in Drosophila. Kismet mutant Drosophila larvae showed more severe influence on some transcription factors than CHD7, CHD8 or CHD9 solely did in mammals (Srinivasan et al. 2005, Rodríguez-Paredes et al. 2009). Because of these observations, it is suggested that other CHD subgroup members might have overtaken functions of Kismet. Furthermore, it is hypothesized that depletion of one CHD subgroup member leads to a gene-specific, but not a 
general influence (Rodríguez-Paredes et al. 2009). Deletions of the region 14q11.2 including the CHD8 and SUPT16H gene have been found in three patients with facial dysmorphism, developmental delay and cognitive impairments (Zahir et al. 2007). The authors concluded that haploinsufficiency of either the CHD8 and/or the SUPT16H are the reason for the phenotype in the patients (Zahir et al. 2007). Even though these patients' phenotype is different from CHARGE syndrome, we considered that missense mutations in the CHD 8 gene disturbing the function of its interacting partner CHD7 might lead to CHARGE syndrome. Therefore, we analyzed in our working group $25 \mathrm{CHD} 7$ negative CHARGE syndrome patients for missense mutations in the CHD8 gene. We did not find a pathogenic CHD8 mutation in our collective (Batsukh et al. 2010). Interestingly, it has been reported recently that some patients with autism (ASD) and neurodevelopmental disorders (NDD) have de novo missense or nonsense mutations in the CHD8 gene as well as microdeletions (Zahir et al. 2007, Neale et al. 2012, O`Roak et al. 2012, Talkowski et al. 2012). Because of these results, it is now clear that CHD8 mutations are not an underlying cause of CHARGE syndrome, but interestingly about two thirds of children with CHARGE syndrome suffer from autism spectrum disorders (Betancur 2011). Our findings that CHD7 and CHD8 interact with each other might shed some light in the understanding of the connection between ASDs/NDDs and CHARGE syndrome.

\subsection{Evaluating the effect of $4 \mathrm{CHD} 7$ missense mutations on the interaction between CHD8 and CHD7}

We wanted to check if the CHARGE syndrome causing CHD7 missense mutations have an effect on the CHD7-CHD8 interaction (Batsukh et al. 2010). We studied the three known CHD7 mutations (p.His2096Arg, p.Val2102Ile and p.Gly2108Arg) (Felix et al. 2006, Lalani et al. 2006, Jongmans et al. 2008) as well as a mutation newly identified in our lab (p.Trp2091Arg). All four missense mutations are within the CHD7 part involved in the CHD7CHD8 interaction (Batsukh et al. 2010). Interestingly, all four missense mutations lead to a phenotype in the patients classified as atypical CHARGE syndrome (Felix et al. 2006, Lalani et al. 2006, Jongmans et al. 2008, Batsukh et al. 2010). In direct Y2H experiments three (p.Trp2091Arg, p.His2096Arg and p.Gly2108Arg) of the four missense mutations disrupt the CHD7-CHD8 interaction. Our patient with the missense mutation p.Trp2091Arg has bilateral coloboma and microphthalmia of the left eye, microcephaly, unilateral deafness and mental retardation (Batsukh et al. 2010). Only one out of five affected members of two families with the missense mutation p.Gly2108Arg fulfilled the diagnostic criteria for CHARGE syndrome while the others showed a very mild phenotype (Jongmans et al. 2008) 
In contrast, Co-IP interaction study showed no disruption in CHD7-CHD8 interaction by the four missense mutations in the CHD7 part. While the $\mathrm{Y} 2 \mathrm{H}$ is a good technique to test direct interactions between proteins, the Co-IP is a method which allows purifying the whole complex. Because of the Co-IP results, we hypothesize that there must be a linker protein which still keeps the mutated CHD7 together with CHD8 in the same complex (Batsukh et al. 2010). Therefore, we further searched for possible linker proteins that could help us to understand the pathomechanism behind CHD7 mutations (see next 4.5).

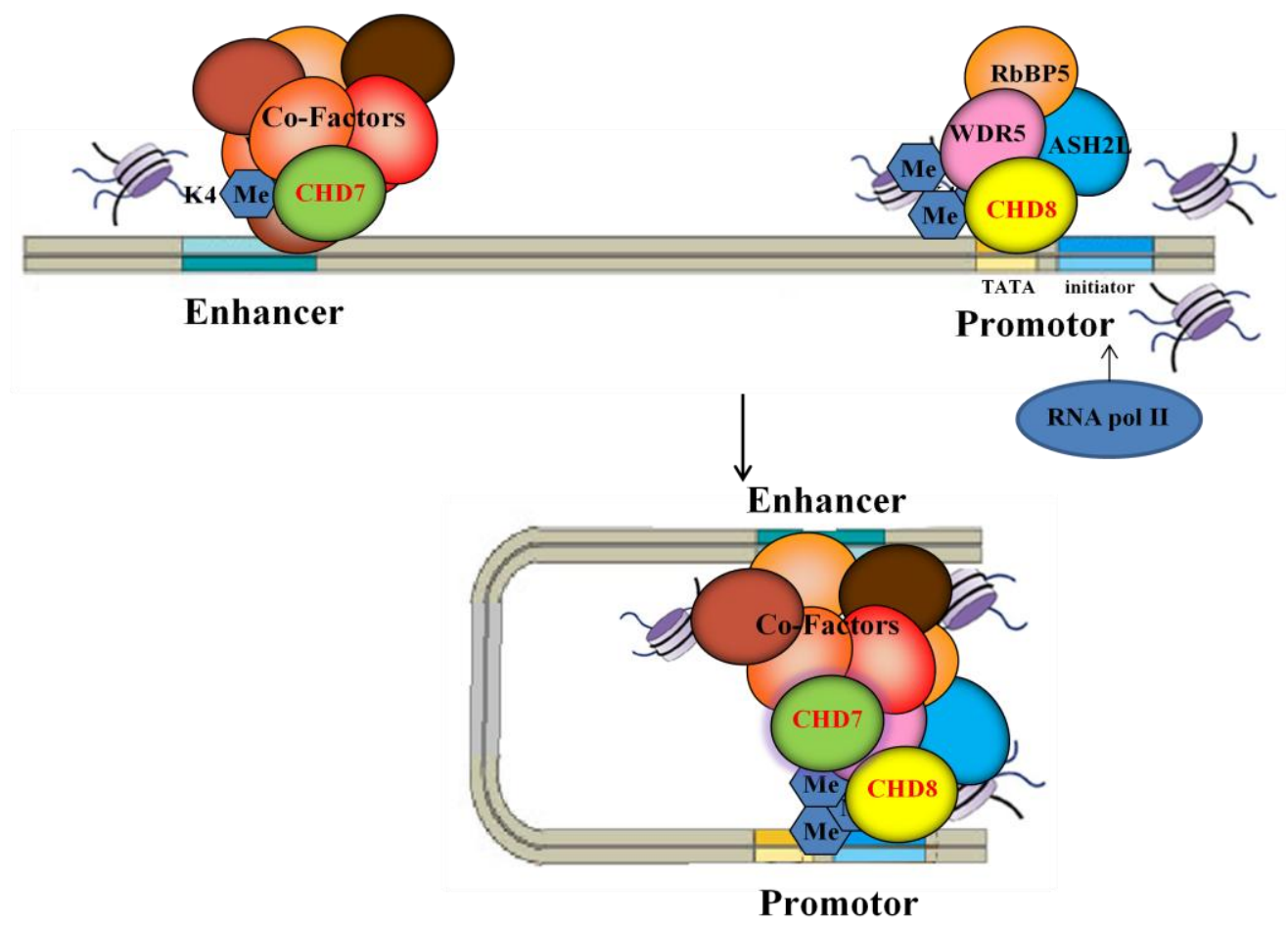

Figure 4.4. Hypothetical Enhancer and Promoter interaction via CHD7 and CHD8 containing protein/transcription factors (TF) complex mediated DNA-loop model. Protein and protein interactions between various TFs (including CHD7 and CHD8) and RNA pol II activate transcription (Modified from Garrath \& Grisham Biochemistry, 1999) (Thompson et al. 2008, Schnetz et al. 2010).

Collectively, from these studies we suggest a hypothetical DNA-loop model which is mediated by CHD7 and CHD8 containing protein complexes and leading to an enhancer and promoter interaction (Fig. 4.4). Furthermore, it can be postulated that CHD7 and CHD8 can build a core component of one big complex, probably present in a cell type and developmental stage specific manner. Further characterization of these complexes can help to understand the pathogenesis of CHARGE syndrome.

\subsection{FAM124B is associated with CHD7 and CHD8}

Our interaction study of CHD7 and CHD8 led us to conclude that both proteins are components of a huge complex, with additional proteins acting as linker proteins between 
CHD7 and CHD8. Therefore, we used the method of SILAC in combination with massspectrometry to further characterize such complex. In particular, we could find FAM124B as a potential interaction partner of CHD7 and CHD8 in all three repetitions of the experiment (manuscript in submission stage: Batsukh et al. 2012). We could confirm the interaction of FAM124B with both CHD7 and CHD8 by Co-IP. However, a direct interaction investigated by Yeast two hybrid experiments could only be demonstrated for both FAM124B transcripts with a CHD8 part, containing a region of unknown function and one BRK domain (amino acids 1789-2302). No interaction could be seen between FAM124B and the CHD7 part containing the CR1-3/SANT domain region (amino acids 1591-2181). Probably FAM124B interacts with CHD7 by binding to another than the tested region or via CHD8 or additional proteins (see 4.7).

\subsection{Subcellular localization and expression profile of Fam124B in comparison of Chd7 and Chd8}

We further investigated the subcellular localization of FAM124B. We could demonstrate that endogenous FAM124B is localized mainly in the nucleoplasm. CHD8 is a nuclear protein (Ishihara et al. 2006) whereas CHD7 is shown to be expressed in nucleolus and nucleoplasm (Zentner et al. 2010, Kita et al. 2012). Thus, we suggest the interaction between FAM124B, CHD8 and CHD7 might be in the nucleoplasm.

CHD7 expression patterns in all analyzed species (Human, mouse, chicken, zebrafish) are congruent with the organs affected in CHARGE syndrome (Bosman et al. 2005, Lalani et al. 2006, Sanlaville et al. 2006, Aramaki et al. 2007, Patten et al. 2012). Therefore, we analyzed the expression of Fam124B in comparison with Chd7 and Chd8 by immunostaining on different adult and embryonic mouse tissues (Fig 4.5-7). All the positive stained cells show brown color. The expression pattern of Fam124B correlates in the cornu ammonis of the hippocampus and in the cortex nicely with the Chd8 expression pattern. Chd7, Chd8 and Fam124B are all three highly expressed in the stratum purkinjense of the cerebellum (Fig. 4.5). Because it is known that Chd8 and Chd7 are highly expressed during early embryogenesis and the expression is decreased in some adult tissues (Nishiyama et al. 2004, 2009, Bosman et al. 2005) we expanded our studies on E12.5 mouse embryos. 
A

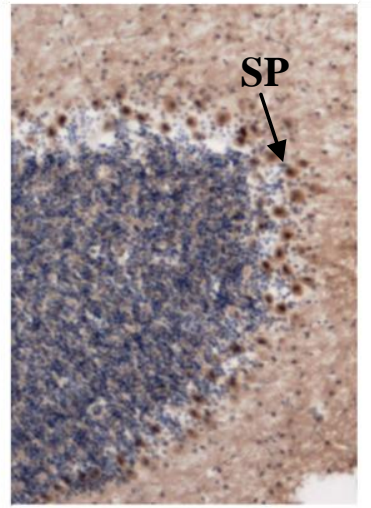

B

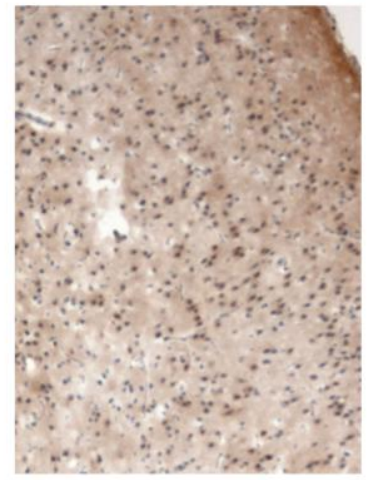

C

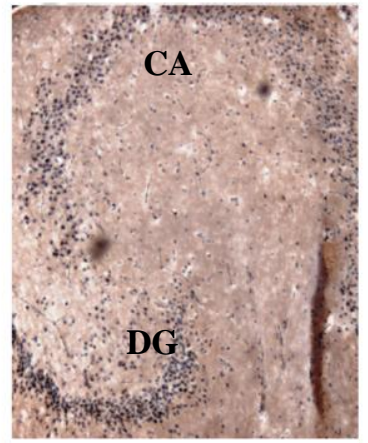

Chd7
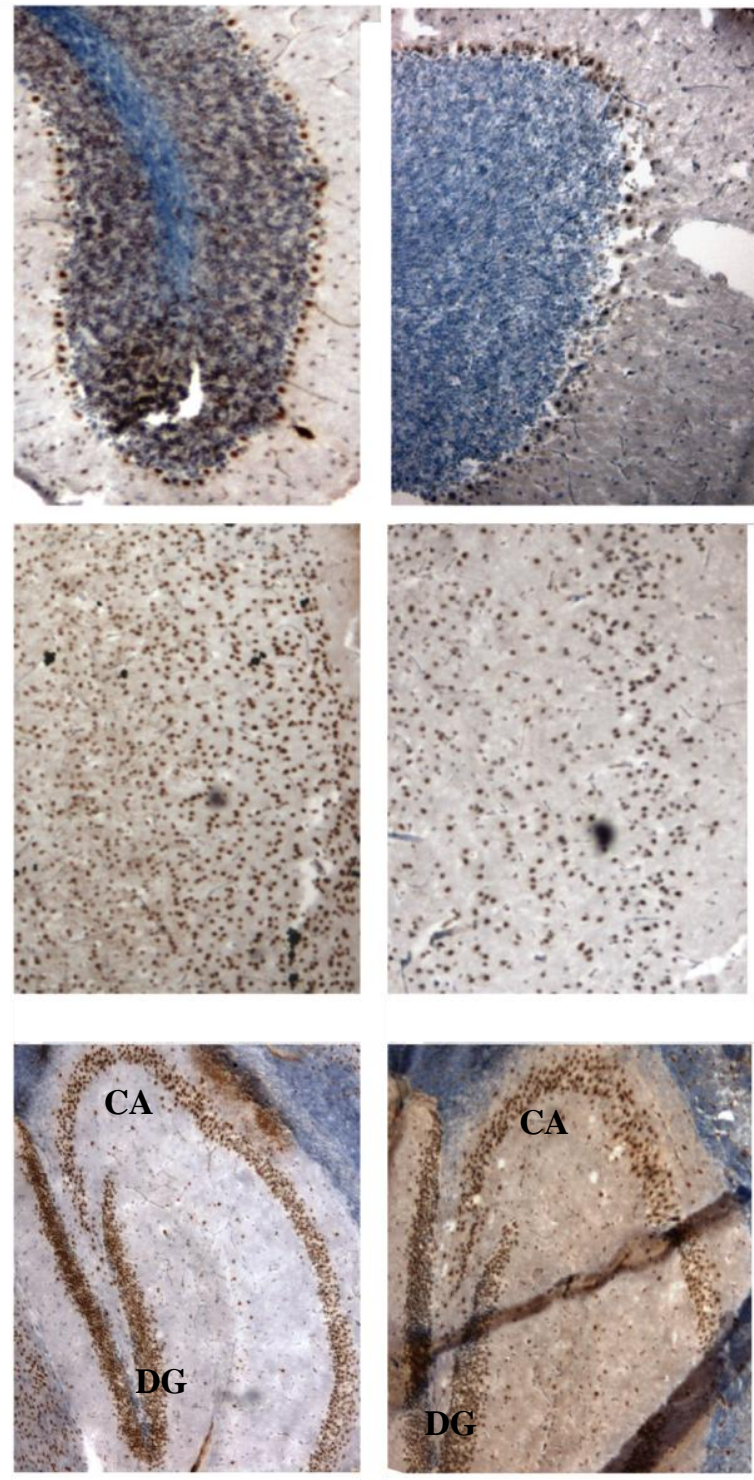

Chd8
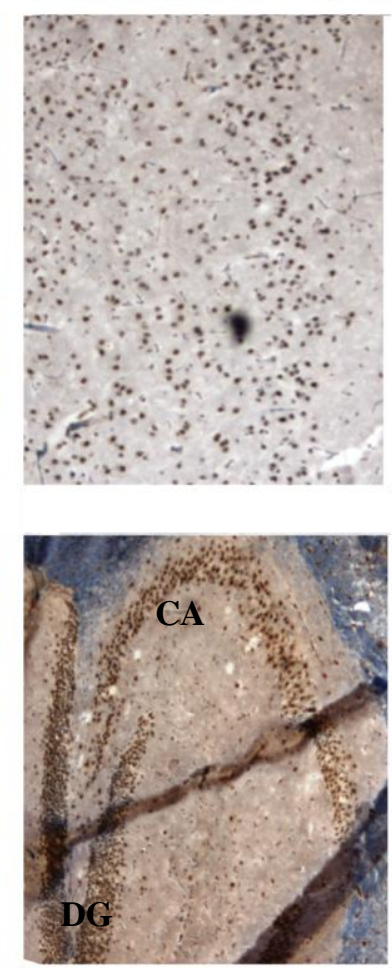

Fam124B
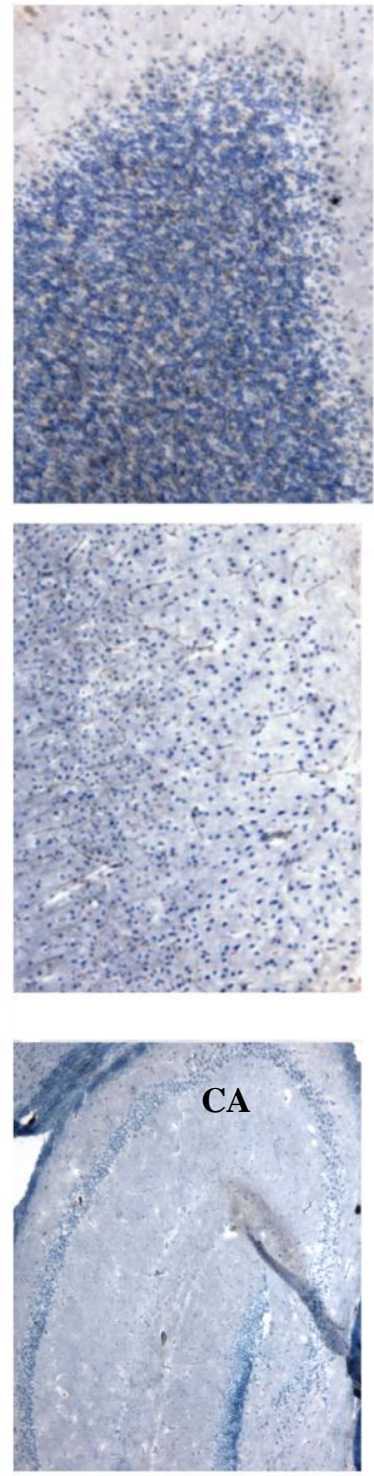

Negative

Figure 4.5. Immunostaining Fam124B of adult brain shown in comparison with Chd7 and Chd8.

Counterstained with hematoxylin eosin. A: Cerebellum, SP- stratum purkinjense; B: cortex area, C: Cornu ammonis of hippocampus (CA) and dentate gyrus (DG) area. 


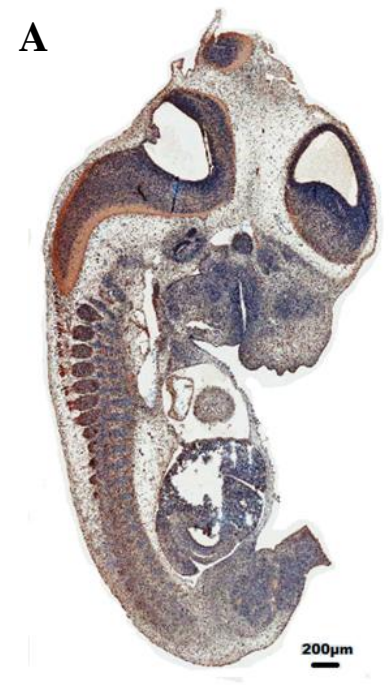

CHD7

\section{B}
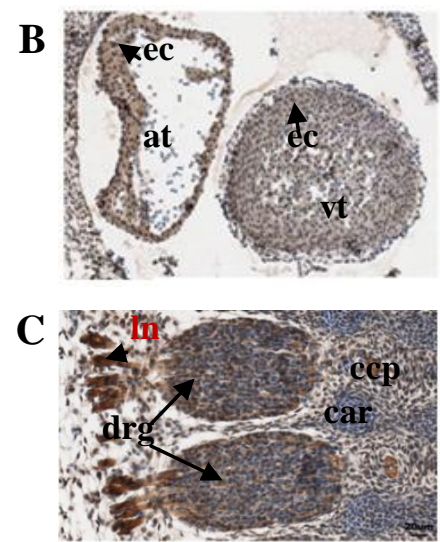

Chd7

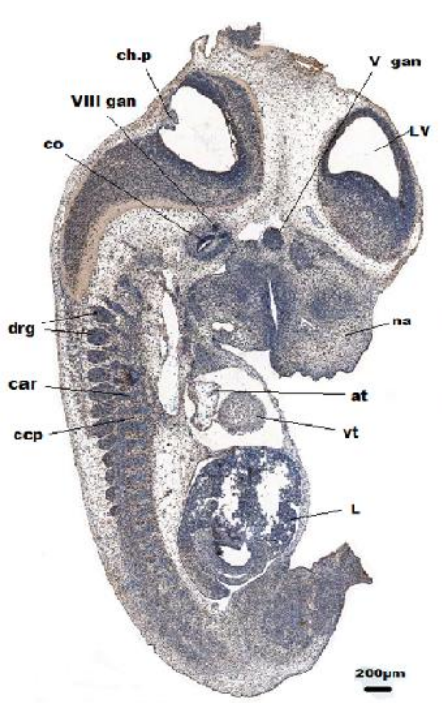

FAM124B
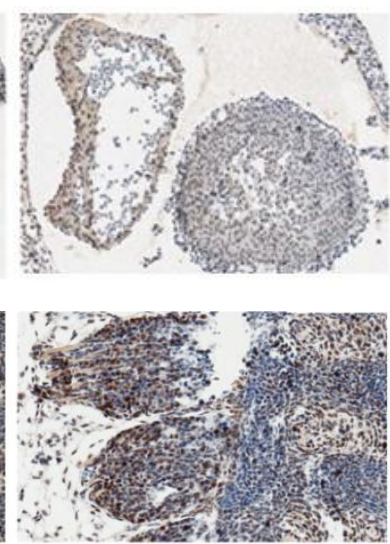

Chd8

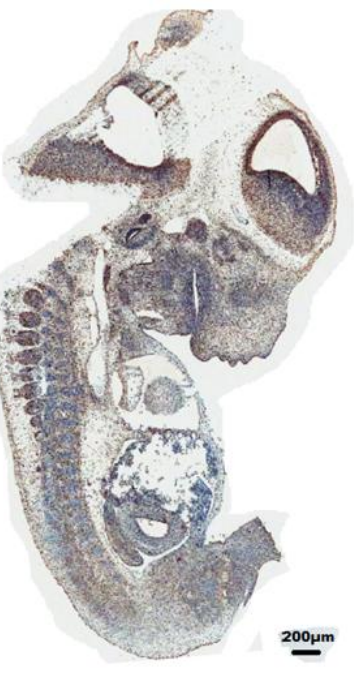

CHD8
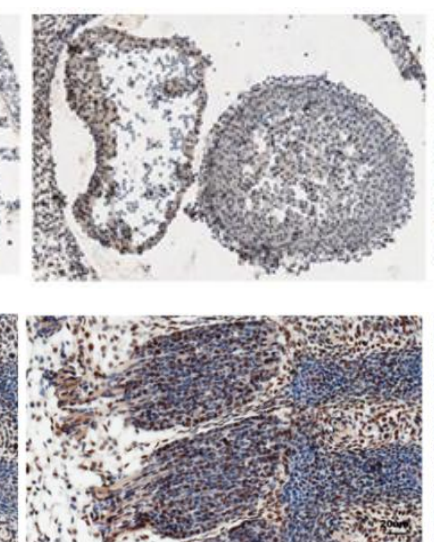

Fam124B

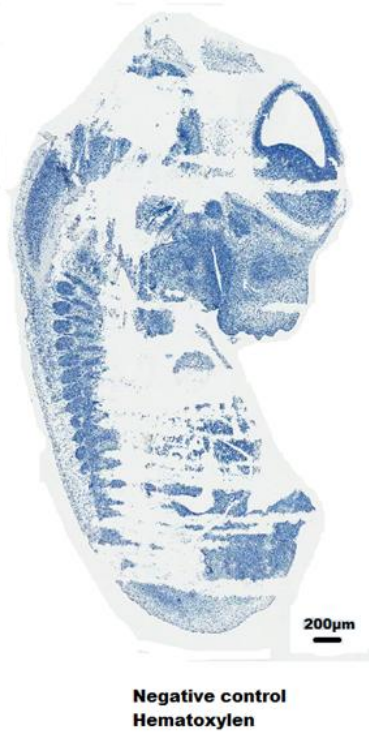

Hematoxylen
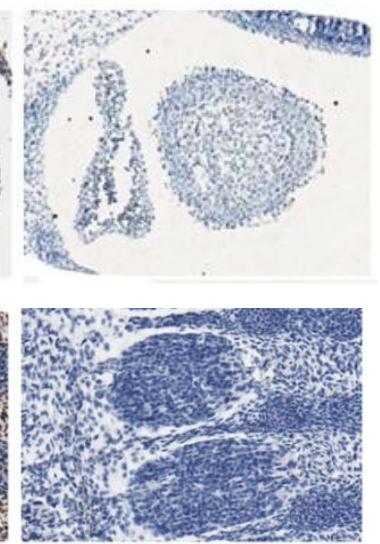

Negative

Figure 4.6. Chd7, Chd8 and Fam124B immunostainings on sagittal sections of an E12.5 wildtype embryo.

Counterstained with hematoxylin eosin. A: Overview of immunostainings on sagittal section of an E12.5 wildtype embryo, LV = lateral ventricle, ch.p = choroid plexus differentiating from fourth ventricle, $\operatorname{co}=\mathrm{cochlea}, \mathrm{cd}=$ cochlear duct, ne = nasal epithelium, $\mathrm{V}$ gan = left trigeminal $(\mathrm{V})$ ganglion, $\operatorname{drg}=$ dorsal root ganglion, VIII gan = Vestibulocochlear (VIII) ganglion, $\mathrm{L}=$ liver, na-nasal region, $\mathrm{ccp}=\mathbf{B}$ : the developing heart, at $=$ left atrium of heart, vt = left heart ventricle, ec = endothelial cells, $\mathbf{C}$ : dorsal root ganglion, car = cartilage primordium of body of vertebra, $\mathrm{ccp}=$ cartilage condensation being primordium of vertebral body, $\ln =$ lumbar nerve, $\mathrm{drg}=\mathrm{dorsal}$ root ganglion. 
A
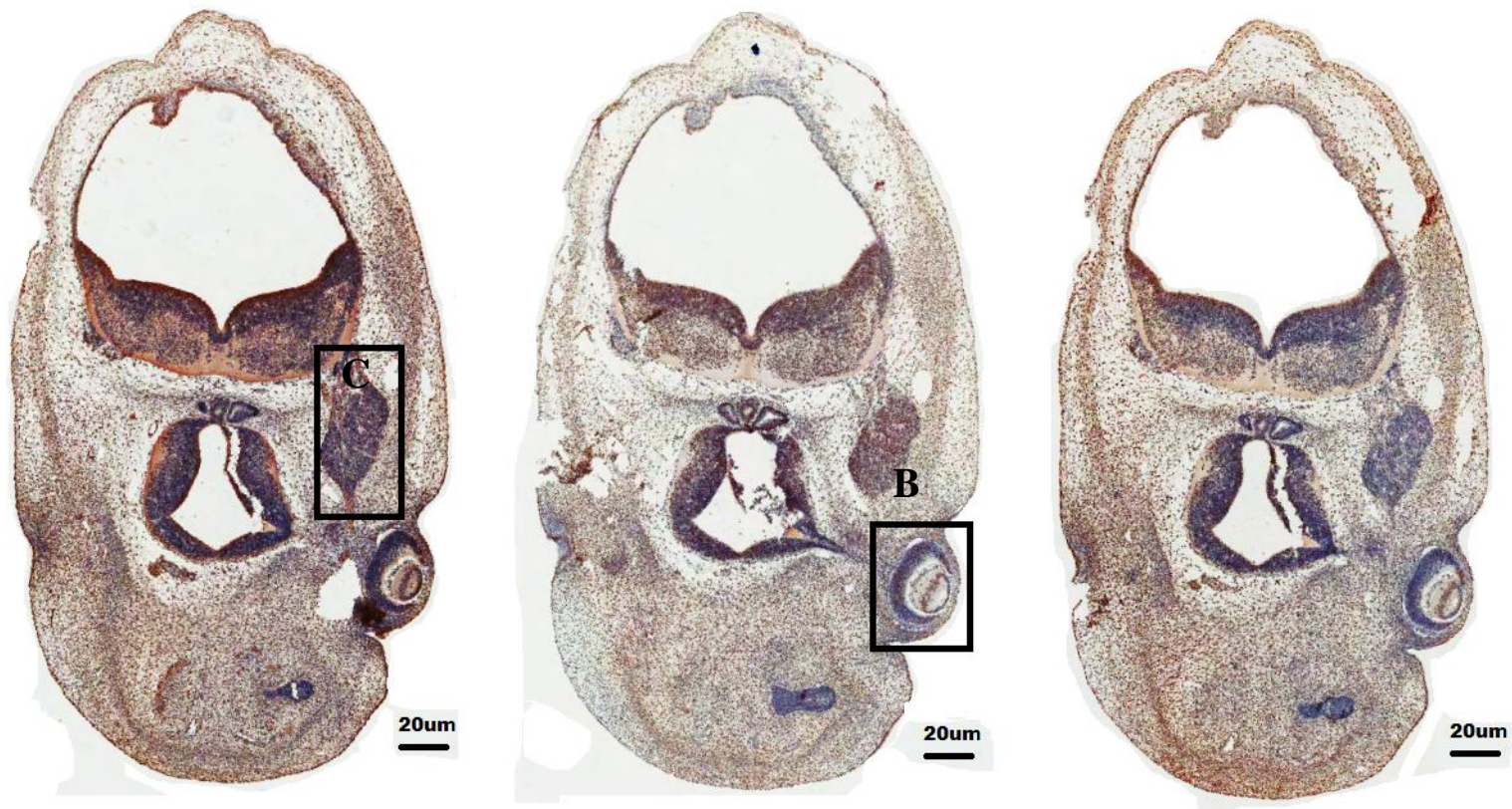

CHD7

CHD8

FAM124B

B
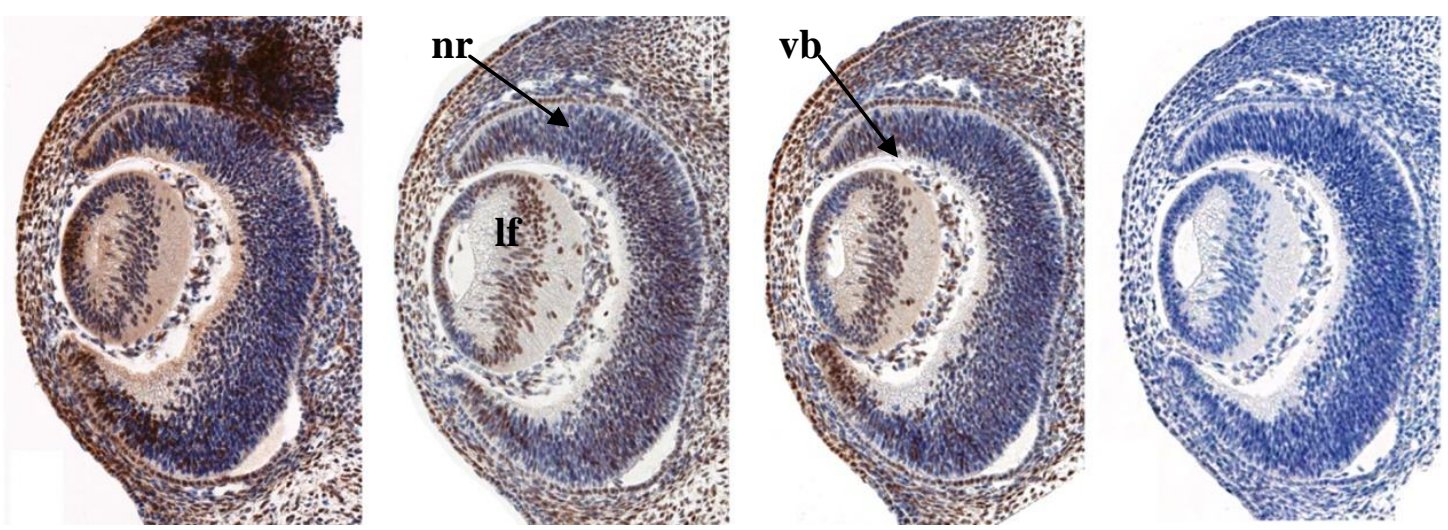

$\mathbf{C}$

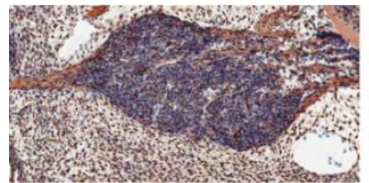

Chd7

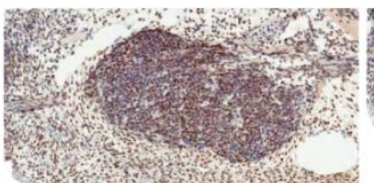

Chd8

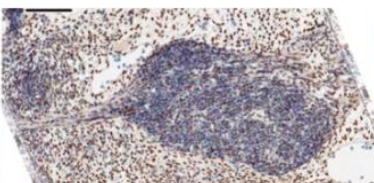

Fam124B

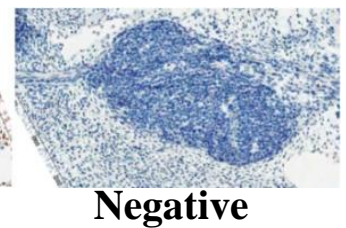

Figure 4.7. Chd7, Chd8 and Fam124B immunostaining on coronal sections of the E12.5 mouse embryo.

Counterstained with hematoxylin eosin. A: Overview of the immunostaining of E12.5 embryo, B: Higher magnification of the embryonic eye, $\mathrm{nr}=$ neural retina, if $=$ lens fibers, $\mathrm{vb}=$ vitreous body, $\mathbf{C}$ : Higher magnification of the trigeminal ganglion.

In sagittal and coronal sections of E12.5 embryos, the developing heart, the dorsal root ganglia, and the developing eyes were strongly stained by the Chd7, Chd 8 and Fam124B antibodies (Fig. 4.6, 4.7). Our Chd7 results fit with the results of Chd7 expression study performed on E12.5 mouse tissues, which demonstrated high expression in the developing brain (ventricles, hypothalamus, olfactory epithelium, olfactory tissues, pituitary, olfactory 
sensory neurons, vestibulocochlear ganglion, dorsal root ganglia, developing lung and heart) (Bosman et al. 2005). Lowest expression could be observed in the developing liver (Fig. 4.6). Fam124B expression at E12.5 was found in several brain areas, spinal cord, dorsal root ganglia, cochlea and surrounding tissues, lung, heart, and kidney. Therefore, Fam124B expression pattern correlates in many embryonic tissues with the Chd7 expression pattern.

We demonstrated that FAM124B is a nuclear protein which possibly builds together with CHD7 and CHD8 a complex. Fam124B is highly expressed at mouse developmental stage E12.5 with an overlapping correlation to Chd7 expression and a correlation to Chd8 expression especially in the developing mouse brain. Therefore, we assume a role for FAM124B in the pathogenesis of CHARGE syndrome and ASD/NDD.

\subsection{Structure and Function of FAM124B}

FAM124B is localized on chromosome 2q36.2. It has two transcripts in human and chimpanzee and only one in mouse and other species which is homologous to the longer human transcript. FAM124B is an evolutionary highly conserved protein which could have an important role in the cell (see 4.6). By bioinformatic prediction programs, we could not find any functional domain in FAM124B. Interestingly, alignment of the amino acid sequence of FAM124B from human to zebrafish revealed an area containing human amino acids 109-255 which show $100 \%$ homology between the species (Fig. 4.8). These data imply us that this region could contain an important hitherto unknown domain motif or this region is of functional relevance. Further investigations to clarify this aspect are needed.

In our study we could show that in vivo and in vitro FAM124B is localized in the nucleoplasm (manuscript in submission Batsukh et al. 2012). No previous characterization and functional studies on FAM124B gene have been performed. In order to identify additional proteins which interact with FAM124B, we overexpressed the FAM124B transcript variant 1 (longer transcript variant, NP_001116251.13) in HeLa cells and performed a pull down with the anti-Ha (Roche) antibody followed by SDS-PAGE electrophoresis separation and massspectrometry analysis (data not shown). Interestingly, two times out of three repetitions of the experiment we detected treacle, the protein mutated in Treacher Collins syndrome. It was shown that treacle and CHD7 bind to rDNA. Furthermore, it was demonstrated that the absence of CHD7 impaired the ability of treacle to bind rDNA (Zentner et al. 2010). Therefore, the authors suggest a connection between CHD7 and treacle and moreover they hypothesized a functional link between CHARGE and Treacher Collins syndrome (see 4.1). From our data we suggested that possibly treacle builds a complex together with CHD7, CHD8 and FAM124B. 
SFDNYEDAIRLYEMILQREATLQKSNFCFFVLYASKSFALQLSLKQLPPGMSVDPKESSVLQFKVQEIGQLVPLLPNPCM SFDNYEDAVRLYEMILQREATLQRSNECEFVLYASKSFALQLSLKQLPPGMSVDPKESSVLQFKVQEIGQLVPLLPNPCI SFDNYEDAIRLYEMILQREATLQKSNECEFVLYASKSFALQLSLKQLPPGMSVDPKESSVLQFKVQEIGQLVPLLPNPCI SFDNYEDAIRLYAMILQREATLQRSNFCFEVLYSTETFALQLSLRQLPLGTSVDPKEASVLQFKVQEIGQLVPLLPHPCV SFDNYEDAIRLYEMILQREATLQKSNFCFFVLYATNSFALQLSLKQLPPGMSVDPKDSSVLQFKVREIGQLVPLLPNPCI SFDNYEDAIRLYELILQKEATLQRSNFCEFVLYATESEALQLSLKQLPLGVSVDPKESSVLQEKVQEIGQLVPLLPHPCV SFDNYEDAIRLYEMILQREATLQRSDFCEFVLYATESFTLQLSLRQLPLGMAVDPKEASVLQEKVQEIGQLVPLLPHPCV SFDNYDDAVGLYEMILRKEATVRKSNECVFVLYATKTIAVQLCLKQLPIGMAAEPKESSLLQEKVQEMGQLVPLLPNPCI SFDNYEDAIRLYEMILQRDATVQRSNECFEVLYATEGFSLQLSLRQLPLGMPVDPKESSVLQFKVQEIGQLVPLLPNPCV SFDNYEDAIRLYEMLLQRDATVQKSDFCFFVLYATEGESLQLSLKQLPLGMSVDPKESSVLQERVQEIGQLVPLLPNPCV SFDNYEDAIRLYEMLLQRDATVQRSDFCEFVLYATEGESLQLSLKQLPLGMSVDPKESSVLQFRVQEIGQLVPLLPNPCV SFDNYEDIVRLYETVLQKRAEEQRPGFCWFTLLAEQGESLQLAI KQLSPGVRVEPCQSAVLQFRVREIGQLVPLLPNTCS SCDNYEDAVRLYETILQKEATTQRAGECFEVLYSTTHVSVQLSIKQLHPGISVQVKDACALQFAIHAVGQLVPLLPYPCV
[Homo sapiens] Human [Pan troglodytes] Chimpanze [Pongo abelii] Orangutan [Bos taurus] Cow [Callithrix jacchus] Marmoset [Canis lupus familiaris] Dog [Sus scrofa] Pig [Gallus gallus] Chicken [Cricetulus griseus] Hamster [Mus musculus] Mouse [Rattus norvegicus] Rat [Xenopus tropicalis] Frog [Danio rerio] Zebrafish

Figure 4.8. A homologous part of FAM124B protein alignment from Human to Zebrafish by Constraintbased Multiple alignment tool (COBALT, http://www.ncbi.nlm.nih.gov/tools/cobalt/). 145 to 224 amino acid sequence of Human FAM124B shows 100\% homology with all the other species.

Additionally, we could identify 3 times KU70, an ATP-dependent helicase II as a FAM124B interaction partner. KU70 was shown to interact with p53, a protein which interacts with CHD8 (Feki et al. 2005, Nishiyama et al. 2009). Therefore, FAM124B might have like CHD7 or CHD8 different functions, is involved in different mechanisms and is part of different complexes, maybe in a cell type and developmental stage dependent manner.

\subsection{Future endeavors and perspectives}

In the current study we have identified two new components of CHD7 containing complexes, CHD8 and FAM124B.

CHD8 mutations or disruptions are reported to be responsible for ASD/NDDs. Autism spectrum disorders are commonly associated with CHARGE syndrome. With the current study we provide the first functional link between these two conditions. A further characterization of CHD7 and CHD8 containing complexes is necessary to get deeper insights into the pathomechanism behind ASD/NDD and CHARGE or other related malformation syndromes. Such functional link at the molecular level was described in the literature for CHARGE syndrome and Treacher Collins syndrome, a clinically distinct disorder but affecting the same organ systems. TCOF1, the gene mutated in Treacher Collins syndrome and CHD7 coassociate at rDNA (Zentner et al. 2010). Possibly, the characterization of CHD7 and CHD8 complexes can also explain the overlap in the clinical features between CHARGE and other related disorders.

CHARGE syndrome belongs to the group of "neurocristopathies". Many of the symptoms seen in those syndromes are hypothesized to be the result from abnormalities in the 
development, migration, or interaction of the cephalic neural crest cells (Siebert et al. 1985). Indeed, Bajpai et al. (2010) could demonstrate by CHD7 knockdown studies in Xenopus laevis embryos that CHD7 is crucial for neural crest cell (NCC) formation and migration into the pharyngeal arches. We could observe the same effect in our group (Fig. 4.9).

A

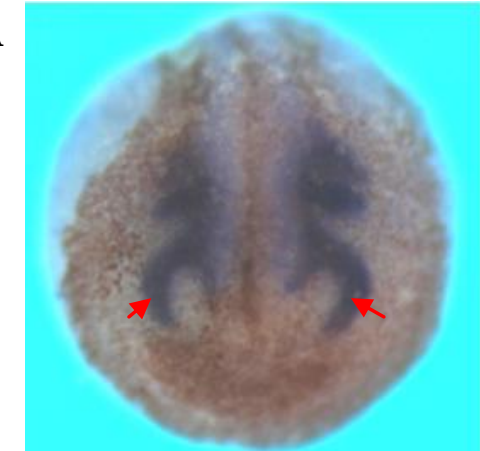

Co MO, 20ng

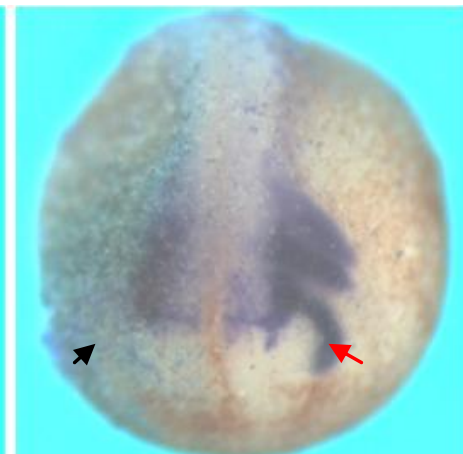

CHD7 MO, 10ng

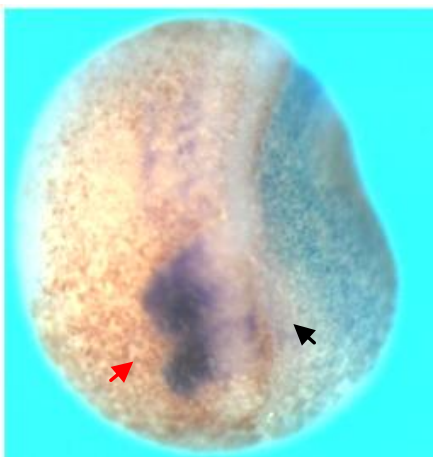

CHD7 MO, 20ng

B

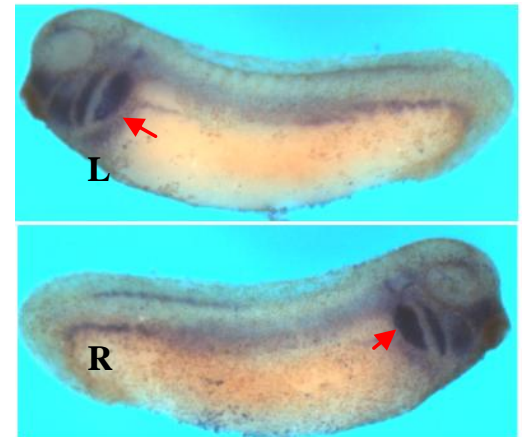

Co MO, 20ng

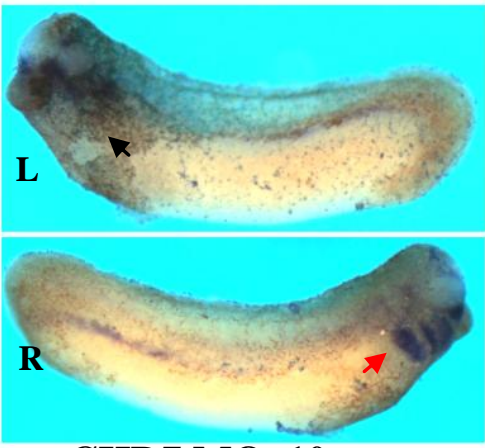

CHD7 MO, 10ng

Figure 4.9. Effect of CHD7 knockdown on expression of transcription factor Twist involved in neural crest formation. Two cell-stage Xenopus laevis embryos were injected with Control morpholino (CoMO, 20ng) and CHD7 morpholino (CHD7 MO, 10ng and 20ng) asymmetrically into a single blastomere and analyzed by whole mount in situ hybridization at neurula stage (st.21 and 26) to visualize expression pattern of Twist, a transcription factor that controls early neural crest formation. A: Xenopus laevis stage 21. B: stage 26, left (L) and right (R) side of the embryos. Red arrows indicate migrating neural crest cells while black arrow shows disrupted neural crest migration which CHD7 MO was injected. In CHD7 knockdown part, neural crest formation is severely affected which shows no expression of Twist (done by Yvonne Schulz 2012).

In the current study we identified the hitherto uncharacterized protein FAM124B as a novel component of a CHD7 and CHD8 containing complex. We examined the expression profile and subcellular localization but functional studies are still needed. It will be interesting to prove if a knockdown of FAM124B in Xenopus laevis embryos will lead to an abnormal formation and migration of neural crest cells, as well. Furthermore, it will be of great interest if an overexpression of FAM124B in Xenopus laevis embryos with a CHD7 knockdown can 
rescue the CHD7/CHARGE phenotype and if a knockdown of FAM124B and CHD7 together show a more severe synergistic effect.

Additionally, the creation and characterization of a "loss of function" FAM124B mouse model will provide information if a mutated FAM124B lead to CHARGE or a CHARGE related syndrome. In our working group, a FAM124B mutation screening of CHD7 negative CHARGE patients is already in progress. We believe that such studies can elucidate another gene involved in CHARGE syndrome and can explain the multiple defects seen in the patients. 


\section{References}

Adams ME, Hurd EA, Beyer LA, Swiderski DL, Raphael Y, Martin DM. (2007) Defects in vestibular sensory epithelia and innervation in mice with loss of Chd7 function: implications for human CHARGE syndrome. J Comp Neurol. 504:519-532.

Airio A, Pukkala E, Isomaki H. (1995) Elevated cancer incidence in patients with dermatomyositis: a population based study. J Rheumatol. 22:1300-1303.

Akhtar A, Zink D, Becker PB. (2000) Chromodomains are protein-RNA interaction modules. Nature. 407:405-409.

Allis CD, Jenuwein T, Reinberg D, Caparros ML (editors). (2007) Epigenetics, Cold Spring Harbor Laboratory Press, Cold Spring Harbor, New York. p.240.

Aramaki M, Udaka T, Kosaki R, Makita Y, Okamoto N, Yoshihashi H, Oki H, Nanao K, Moriyama N, Oku S, Hasegawa T, Takahashi T, Fukushima Y, Kawame H, Kosaki K. (2006) Phenotypic spectrum of CHARGE syndrome with CHD7 mutations. J Pediatr. 148:410-414.

Asakura Y, Toyota Y, Muroya K, Kurosawa K, Fujita K, Aida N, Kawame H, Kosaki K, Adachi M. (2008) Endocrine and radiological studies in patients with molecularly confirmed CHARGE syndrome. J Clin Endocrinol Metab. 93:920-924.

Bagchi A, Papazoglu C, Wu Y, Capurso D, Brodt M, Francis D, Bredel M, Vogel H, Mills AA. (2007) CHD5 is a tumor suppressor at human 1p36. Cell. 128(3):459-475.

Bajpai R, Chen DA, Rada-Iglesias A, Zhang J, Xiong Y, Helms J, Chang CP, Zhao Y, Swigut T, Wysocka J. (2010) CHD7 cooperates with PBAF to control multipotent neural crest formation. Nature. 463(7283):958-962.

Batsukh T, Pieper L, Koszucka AM, von Velsen N, Hoyer-Fender S, Elbracht M, Bergman JE, Hoefsloot LH, Pauli S. (2010) CHD8 interacts with CHD7, a protein which is mutated in CHARGE syndrome. Hum Mol Genet. 19(14):2858-2866.

Bergman JE, Bosman EA, van Ravenswaaij-Arts CM, Steel KP. (2010) Study of smell and reproductive organs in a mouse model for CHARGE syndrome. Eur J Hum Genet. 18(2):171177.

Bergman JE, Bocca G, Hoefsloot LH, Meiners LC, van Ravenswaaij-Arts CM. (2011a.) Anosmia predicts hypogonadotropic hypogonadism in CHARGE syndrome. J Pediatr. 158:474-479. 
Bergman JE, Janssen N, Hoefsloot LH, Jongmans MC, Hofstra RM, van Ravenswaaij- Arts CM. (2011b) CHD7 mutations and CHARGE syndrome: the clinical implications of an expanding phenotype. J Med Genet. 48:334-342.

Betancur C. (2011) Etiological heterogeneity in autism spectrum disorders: more than 100 genetic and genomic disorders and still counting. Brain Res.1380:42-77.

Blake KD, Davenport SL, Hall BD, Hefner MA, Pagon RA, Williams MS, Lin AE, Graham Jr JM. (1998) CHARGE association: an update and review for the primary pediatrician. Clin Pediatr (Phila). 37:159-173.

Bosman EA, Penn AC, Ambrose JC, Kettleborough R, Stemple DL, Steel KP. (2005) Multiple mutations in mouse Chd7 provide models for CHARGE syndrome. Hum Mol Genet. 14(22):3463-3476.

Bouazoune K, Mitterweger A, Langst G, Imhof A, Akhtar A, Becker PB, Brehm A. (2002) The dMi-2 chromodomains are DNA binding modules important for ATP-dependent nucleosome mobilization. Embo J. 21:2430-2440.

Boyer LA, Latek RR, Peterson CL. (2004) The SANT domain: a unique histone-tail-binding module? Nat Rev Mol Cell Biol. 5(2):158-163.

Brehm A, Tufteland KR, Aasland R, Becker PB. (2004) The many colours of chromodomains. Bioessays. 26(2):133-140.

Carta C, Pantaleoni F, Bocchinfuso G, Stella L, Vasta I, Sarkozy A, Digilio C, Palleschi A, Pizzuti A, Grammatico P, Zampino G, Dallapiccola B, Gelb BD, Tartaglia M. (2006) Germline missense mutations affecting KRAS Isoform B are associated with a severe Noonan syndrome phenotype. Am J Hum Genet. 79(1):129-135.

Cirstea IC, Kutsche K, Dvorsky R, Gremer L, Carta C, Horn D, Roberts AE, Lepri F, MerbitzZahradnik T, König R, Kratz CP, Pantaleoni F, et al. (2010) A restricted spectrum of NRAS mutations causes Noonan syndrome. Nat Genet. 42(1):27-29.

Chung CD, Liao J, Liu B, Rao X, Jay P, Berta P, Shuai K. (1997) Specific inhibition of Stat3 signal transduction by PIAS3. Science. 278(5344):1803-1805.

Cleary JO, PriceAN, Thomas DL, Scambler PJ, KyriakopoulouV,McCue K, Schneider JE,OrdidgeRJ, LythgoeMF. (2009) Cardiac phenotyping in ex vivo murine embryos using microMRI. NMR Biomed. 22:857-866. 
Deardorff MA, Kaur M, Yaeger D, Rampuria A, Korolev S, Pie J, Gil-Rodríguez C, Arnedo M, Loeys B, Kline AD, Wilson M, Lillquist K, et al. (2007) Mutations in cohesin complex members SMC3 and SMC1A cause a mild variant of cornelia de Lange syndrome with predominant mental retardation. Am J Hum Genet. 80(3):485-494.

Dixon J, Trainor P, Dixon MJ. (2007) Treacher Collins syndrome. Orthod Craniofac Res. 10(2):88-95. Review.

Dodé C, Hardelin JP. (2009) Kallmann syndrome. Eur J Hum Genet. 17(2):139-46.

Dou Y, Milne TA, Tackett AJ, Smith ER, Fukuda A, Wysocka J, Allis CD, Chait BT, Hess JL, Roeder RG. (2005) Physical association and coordinate function of the H3 K4 methyltransferase MLL1 and the H4 K16 acetyltransferase MOF. Cell. 121(6):873-885.

Eberharter A, Vetter I, Ferreira R, Becker PB. (2004) ACF1 improves the effectiveness of nucleosome mobilization by ISWI through PHD-histone contacts. Embo J. 23:4029-4039.

Feki A, Jefford CE, Berardi P, Wu JY, Cartier L, Krause KH, Irminger-Finger I. (2005) BARD1 induces apoptosis by catalysing phosphorylation of p53 by DNA-damage response kinase. Oncogene. 24(23):3726-3736.

Felix TM, Hanshaw BC, Mueller R, Bitoun P, Murray JC. (2006) CHD7 gene and nonsyndromic cleft lip and palate. Am J Med Genet A. 140:2110-2114.

Fischle W, Wang Y, Jacobs SA, Kim Y, Allis CD, Khorasanizadeh S. (2003) Molecular basis for the discrimination of repressive methyl-lysine marks in histone $\mathrm{H} 3$ by Polycomb and HP1 chromodomains. Genes Dev. 17:1870-1881.

Flanagan JF, Mi LZ, Chruszcz M, Cymborowski M, Clines KL, Kim Y, Minor W, Rastinejad F, Khorasanizadeh S. (2005) Double chromodomains cooperate to recognize the methylated histone H3 tail. Nature. 438:1181-1185.

Garrath RH, Grisham CM. (1999) Biochemistry, second edition, Figure 31.32.

Gaspar-Maia A, Alajem A, Polesso F, Sridharan R, Mason MJ, Heidersbach A, RamalhoSantos J, McManus MT, Plath K, Meshorer E, Ramalho-Santos M. (2009) Chd1 regulates open chromatin and pluripotency of embryonic stem cells. Nature. 460(7257):863-868.

Ge Q, Nilasena DS, O'Brien CA, Frank MB, Targoff IN. (1995) Molecular analysis of a major antigenic region of the 240-kD protein of Mi-2 autoantigen. J Clin Invest. 96:1730-1737. 
Gui Y, Guo G, Huang Y, Hu X, Tang A, Gao S, Wu R, Chen C, Li X, Zhou L, He M, Li Z, Sun X, Jia W, Chen J, et al. (2011) Frequent mutations of chromatin remodeling genes in transitional cell carcinoma of the bladder. Nat Genet. 43(9):875-878.

Hall JA, Georgel PT. (2007) CHD proteins: a diverse family with strong ties. Biochem Cell Biol. 85(4):463-476.

Heintzman ND, Hon GC, Hawkins RD, Kheradpour P, Stark A, Harp LF, Ye Z, Lee LK, Stuart RK, Ching CW, Ching KA, Antosiewicz-Bourget JE, et al. (2009) Histone modifications at human enhancers reflect global cell-type-specific gene expression. Nature. 459(7243):108-112.

Hess JL. (2004) MLL: a histone methyltransferase disrupted in leukemia. Trends Mol. Med. 10:500-507.

Ho L, Crabtree GR. (2010) Chromatin remodelling during development. Nature. 463:474484.

Horsch U, Scheele A (editors). (2011) Compendium on CHARGE syndrome. Median-Verlag von Killisch-Horn GmbH. Heidelberg. p.11

Hurd EA, Capers PL, Blauwkamp MN, Adams ME, Raphael Y, Poucher HK, Martin DM. (2007) Loss of Chd7 function in gene-trapped reporter mice is embryonic lethal and associated with severe defects in multiple developing tissues. Mamm Genome. 18:94-104.

Hurd EA, Poucher HK, Cheng K, Raphael Y, Martin DM. (2010) The ATP-dependent chromatin remodeling enzyme CHD7 regulates pro-neural gene expression and neurogenesis in the inner ear. Development. 137:3139-3150.

Ishihara K, Oshimura M, Nakao M. (2006) CTCF-dependent chromatin insulator is linked to epigenetic remodeling. Mol Cell. 23(5):733-742.

Jacobs-McDaniels NL, Albertson RC. (2011) Chd7 plays a critical role in controlling leftright symmetry during zebrafish somitogenesis. Dev Dyn. 240(10):2272-2280.

Janssen N, Bergman JE, Swertz MA, Tranebjaerg L, Lodahl M, Schoots J, Hofstra RM, van Ravenswaaij-Arts CM, Hoefsloot LH. (2012) Mutation update on the CHD7 gene involved in CHARGE syndrome. Hum Mutat. 33(8):1149-1160.

Jongmans MC, Admiraal RJ, van der Donk KP, Vissers LE, Baas AF, Kapusta L, van Hagen JM, Donnai D, de Ravel TJ, Veltman JA, Geurts van Kessel A, De Vries BB, et al. (2006) 
CHARGE syndrome: the phenotypic spectrum of mutations in the CHD7 gene. J Med Genet. 43:306-314.

Jongmans MC, Hoefsloot LH, van der Donk KP, Admiraal RJ, Magee A, van de Laar I, Hendriks Y, Verheij JB, Walpole I, Brunner HG, van Ravenswaaij CM. (2008) Familial CHARGE syndrome and the CHD7 gene: a recurrent missense mutation, intrafamilial recurrence and variability. Am J Med Genet A. 146A(1):43-50.

Kalscheuer VM, Feenstra I, Van Ravenswaaij-Arts CM, Smeets DF, Menzel C, Ullmann R, Musante L, Ropers HH. (2008) Disruption of the TCF4 gene in a girl with mental retardation but without the classical Pitt-Hopkins syndrome. Am J Med Genet A. 146A(16):2053-2059.

Kehle J, Beuchle D, Treuheit S, Christen B, Kennison JA, Bienz M, Muller J. (1998) dMi-2, a hunchbackinteracting protein that functions in polycomb repression. Science. 282:1897-1900.

Kelley DE, Stokes DG, Perry RP. (1999) CHD1 interacts with SSRP1 and depends on both its chromodomain and its ATPase/helicase-like domain for proper association with chromatin. Chromosoma. 108:10-25.

Kim J, Daniel J, Espejo A, Lake A, Krishna M, Xia L, Zhang Y, Bedford MT. (2006) Tudor, MBT and chromo domains gauge the degree of lysine methylation. EMBO Rep. 7:397-403.

Kita Y, Nishiyama M, Nakayama KI. (2012) Identification of CHD7(S) as a novel splicing variant of CHD7 with functions similar and antagonistic to those of the full-length CHD7(L). Genes Cells. 17(7):536-547.

Kobayashi M, Kishida S, Fukui A, Michiue T, Miyamoto Y, Okamoto T, Yoneda Y, Asashima M, Kikuchi A. (2002) Nuclear localization of Duplin, a beta-catenin-binding protein, is essential for its inhibitory activity on the Wnt signaling pathway. J Biol Chem. 277(8):58165822.

Krantz ID, McCallum J, DeScipio C, Kaur M, Gillis LA, Yaeger D, Jukofsky L, Wasserman N, Bottani A, Morris CA, Nowaczyk MJ, Toriello H, et al. (2004) Cornelia de Lange syndrome is caused by mutations in NIPBL, the human homolog of Drosophila melanogaster Nipped-B. Nat Genet. 36(6):631-635.

Lalani SR, Safiullah AM, Molinari LM, Fernbach SD, Martin DM, Belmont JW. (2004) SEMA3E mutation in a patient with CHARGE syndrome. J Med Genet. 41:e94.

Lalani SR, Safiullah AM, Fernbach SD, Harutyunyan KG, Thaller C, Peterson LE, McPherson JD, Gibbs RA, White LD, Hefner M, Davenport SL, Graham JM, Bacino CA, Glass NL, 
Towbin JA, et al. (2006) Spectrum of CHD7 mutations in 110 individuals with CHARGE syndrome and genotype-phenotype correlation. Am J Hum Genet. 78:303-314.

Law ME, Templeton KL, Kitange G, Smith J, Misra A, Feuerstein BG, Jenkins RB. (2005) Molecular cytogenetic analysis of chromosomes 1 and 19 in glioma cell lines. Cancer Genet Cytogenet. 160:1-14.

Layman WS, McEwen DP, Beyer LA, Lalani SR, Fernbach SD, Oh E, Swaroop A, Hegg CC, Raphael Y, Martens JR, Martin DM. (2009) Defects in neural stem cell proliferation and olfaction in Chd7 deficient mice indicate a mechanism for hyposmia in human CHARGE syndrome. Hum Mol Genet. 18:1909-1923.

Layman WS, Hurd EA, Martin DM. (2010) Chromodomain proteins in development: lessons from CHARGE syndrome. Clin Genet. 78:11-20.

Layman WS, Hurd EA, Martin DM. (2011) Reproductive dysfunction and decreased GnRH neurogenesis in a mouse model of CHARGE syndrome. Hum Mol Genet. 20:3138-3150.

Lee YW, Kim SC, Shin YL, Kim JW, Hong HS, Lee YK, Ki CS. (2009) Clinical and genetic analysis of the CHD7 gene in Korean patients with CHARGE syndrome. Clin Genet. 75:290293.

Lemos TA, Passos DO, Nery FC, Kobarg J. (2003) Characterization of a new family of proteins that interact with the C-terminal region of the chromatin-remodeling factor CHD-3. FEBS Lett. 533:14-20.

Lutz T, Stöger R, Nieto A. (2006) CHD6 is a DNA-dependent ATPase and localizes at nuclear sites of mRNA synthesis. FEBS Lett. 580(25):5851-5857.

Marfella CG, Imbalzano AN. (2007) The Chd family of chromatin remodelers. Mutat Res. 618(1-2):30-40.

Marfella CG, Ohkawa Y, Coles AH, Garlick DS, Jones SN, Imbalzano AN. (2006) Mutation of the SNF2 family member Chd2 affects mouse development and survival. J Cell Physiol. 209(1):162-171.

Melicharek DJ, Ramirez LC, Singh S, Thompson R, Marenda DR. (2010) Kismet/CHD7 regulates axon morphology, memory and locomotion in a Drosophila model of CHARGE syndrome. Hum Mol Genet. 19(21):4253-4264.

Menon T, Yates JA, Bochar DA. (2010) Regulation of androgen-responsive transcription by the chromatin remodeling factor CHD8. Mol Endocrinol. 24(6):1165-1174. 
Messmer S, Franke A, Paro R. (1992) Analysis of the functional role of the Polycomb chromo domain in Drosophila melanogaster. Genes Dev. 6(7):1241-1254.

Min J, Zhang Y, Xu RM. (2003) Structural basis for specific binding of Polycomb chromodomain to histone H3 methylated at Lys 27. Genes Dev 17:1823-1828.

Musio A, Selicorni A, Focarelli ML, Gervasini C, Milani D, Russo S, Vezzoni P, Larizza L. (2006) X-linked Cornelia de Lange syndrome owing to SMC1L1 mutations. Nat Genet. 38(5):528-530.

Nava C, Hanna N, Michot C, Pereira S, Pouvreau N, Niihori T, Aoki Y, Matsubara Y, Arveiler B, Lacombe D, Pasmant E, Parfait B, Baumann C, Héron D, Sigaudy S, et al. (2007) Cardiofacio-cutaneous and Noonan syndromes due to mutations in the RAS/MAPK signalling pathway: genotype-phenotype relationships and overlap with Costello syndrome. J Med Genet. 44(12):763-771.

Neale BM, Kou Y, Liu L, Ma'ayan A, Samocha KE, Sabo A, Lin CF, Stevens C, Wang LS, Makarov V, Polak P, Yoon S, et al. (2012) Patterns and rates of exonic de novo mutations in autism spectrum disorders. Nature. 485(7397):242-245.

Nishiyama M, Nakayama K, Tsunematsu R, Tsukiyama T, Kikuchi A, Nakayama KI. (2004) Early embryonic death in mice lacking the beta-catenin-binding protein Duplin. Mol Cell Biol. 24(19):8386-8394.

Nishiyama M, Oshikawa K, Tsukada Y, Nakagawa T, Iemura S, Natsume T, Fan Y, Kikuchi A, Skoultchi AI, Nakayama KI. (2009) CHD8 suppresses p53-mediated apoptosis through histone H1 recruitment during early embryogenesis. Nat Cell Biol. 11(2):172-182.

Nishiyama M, Skoultchi AI, Nakayama KI. (2012) Histone H1 recruitment by CHD8 is essential for suppression of the Wnt- $\beta$-catenin signaling pathway. Mol Cell Biol. 32(2):501512.

O'Roak BJ, Vives L, Girirajan S, Karakoc E, Krumm N, Coe BP, Levy R, Ko A, Lee C, Smith JD, Turner EH, Stanaway IB, Vernot B, Malig M, Baker C, et al. (2012) Sporadic autism exomes reveal a highly interconnected protein network of de novo mutations. Nature. 485(7397):246-250.

Pagon RA, Graham Jr JM, Zonana J, Yong SL. (1981) Coloboma, congenital heart disease, and choanal atresia with multiple anomalies: CHARGE association. J Pediatr. 99:223-227. 
Patten SA, Jacobs-McDaniels NL, Zaouter C, Drapeau P, Albertson RC, Moldovan F. (2012) Role of Chd7 in zebrafish: a model for CHARGE syndrome. PLoS One. 7(2):e31650.

Pena PV, Davrazou F, Shi X, Walter KL, Verkhusha VV, Gozani O, Zhao R, Kutateladze TG. (2006) Molecular mechanism of histone $\mathrm{H} 3 \mathrm{~K} 4 \mathrm{me} 3$ recognition by plant homeodomain of ING2. Nature. 442:100-103.

Pray-Grant MG, Daniel JA, Schieltz D, Yates JR 3rd, Grant PA. (2005) Chd1 chromodomain links histone H3 methylation with SAGA- and SLIK-dependent acetylation. Nature. 433:434438.

Ragvin A, Valvatne H, Erdal S, Arskog V, Tufteland KR, Breen K, AM OY, Eberharter A, Gibson TJ, Becker PB, Aasland R. (2004) Nucleosome binding by the bromodomain and PHD finger of the transcriptional cofactor p300. J Mol Biol. 337:773-788.

Randall V, McCue K, Roberts C, Kyriakopoulou V, Beddow S, Barrett AN, Vitelli F, Prescott K, Shaw-Smith C, Devriendt K, Bosman E, Steffes G, et al. (2009) Great vessel development requires biallelic expression of Chd7 and Tbx1 in pharyngeal ectoderm in mice. J Clin Invest. 119:3301-3310.

Razzaque MA, Nishizawa T, Komoike Y, Yagi H, Furutani M, Amo R, Kamisago M, Momma K, Katayama H, Nakagawa M, Fujiwara Y, Matsushima M, et al. (2007) Germline gain-of-function mutations in RAF1 cause Noonan syndrome. Nat Genet. 39(8):1013-1017.

Roberts AE, Araki T, Swanson KD, Montgomery KT, Schiripo TA, Joshi VA, Li L, Yassin Y, Tamburino AM, Neel BG, Kucherlapati RS. (2007) Germline gain-of-function mutations in SOS1 cause Noonan syndrome. Nat Genet. 39(1):70-74.

Rodenberg JM, Hoggatt AM, Chen M, Touw K, Jones R, Herring BP. (2010) Regulation of serum response factor activity and smooth muscle cell apoptosis by chromodomain helicase DNA-binding protein 8. Am J Physiol Cell Physiol. 299(5):C1058-1067.

Rodríguez-Paredes M, Ceballos-Chávez M, Esteller M, García-Domínguez M, Reyes JC. (2009) The chromatin remodeling factor CHD8 interacts with elongating RNA polymerase II and controls expression of the cyclin E2 gene. Nucleic Acids Res. 37(8):2449-2460.

Sakamoto I, Kishida S, Fukui A, Kishida M, Yamamoto H, Hino S, Michiue T, Takada S, Asashima M, Kikuchi A. (2000) A novel beta-catenin-binding protein inhibits beta-catenindependent Tcf activation and axis formation. J Biol Chem. 275(42):32871-32878. 
Sanlaville D, Etchevers HC, Gonzales M, Martinovic J, Clément-Ziza M, Delezoide AL, Aubry MC, Pelet A, Chemouny S, Cruaud C, Audollent S, Esculpavit C, et al. (2006) Phenotypic spectrum of CHARGE syndrome in fetuses with CHD7 truncating mutations correlates with expression during human development. J Med Genet. 43(3):211-217.

Sarkozy A, Carta C, Moretti S, Zampino G, Digilio MC, Pantaleoni F, Scioletti AP, Esposito G, Cordeddu V, Lepri F, Petrangeli V, Dentici ML, et al. (2009) Germline BRAF mutations in Noonan, LEOPARD, and cardiofaciocutaneous syndromes: molecular diversity and associated phenotypic spectrum. Hum Mutat. 30(4):695-702.

Schnetz MP, Bartels CF, Shastri K, Balasubramanian D, Zentner GE, Balaji R, Zhang X, Song L, Wang Z, Laframboise T, Crawford GE, Scacheri PC. (2009) Genomic distribution of CHD7 on chromatin tracks H3K4 methylation patterns. Genome Res. 19(4): 590-601.

Schnetz MP, Handoko L, Akhtar-Zaidi B, Bartels CF, Pereira CF, Fisher AG, Adams DJ, Flicek P, Crawford GE, Laframboise T, Tesar P, Wei CL, Scacheri PC. (2010) CHD7 targets active gene enhancer elements to modulate ES cell-specific gene expression. PLoS Genet. 6(7):e1001023.

Schubbert S, Zenker M, Rowe SL, Böll S, Klein C, Bollag G, van der Burgt I, Musante L, Kalscheuer V, Wehner LE, Nguyen H, West B, Zhang KY, Sistermans E, Rauch A, et al.(2006) Germline KRAS mutations cause Noonan syndrome. Nat Genet. 38(3):331-336.

Schwab U, Stein H, Gerdes J, Lemke H, Kirchner H, Schaadt M, Diehl V. (1982) Production of a monoclonal antibody specific for Hodgkin and Sternberg-Reed cells of Hodgkin's disease and a subset of normal lymphoid cells. Nature. 299:65-67.

Seelig HP, Moosbrugger I, Ehrfeld H, Fink T, Renz M, Genth E. (1995) The major dermatomyositis-specific Mi-2 autoantigen is a presumed helicase involved in transcriptional activation. Arthritis Rheum. 38:1389-1399.

Seelig HP, Renz M, Targoff IN, Ge Q, Frank MB. (1996) Two forms of the major antigenic protein of the dermatomyositis-specific Mi-2 autoantigen. Arthritis Rheum. 39:1769-1771.

de la Serna IL, Ohkawa Y, Imbalzano AN. (2006) Chromatin remodelling in mammalian differentiation: lessons from ATP-dependent remodellers. Nat Rev Genet. 7(6):461-473.

Shi X, Hong T, Walter KL, Ewalt M, Michishita E, Hung T, Carney D, Pena P, Lan F, Kaadige MR, Lacoste N, Cayrou C, Davrazou F, Saha A, Cairns BR, et al. (2006) ING2 PHD domain links histone H3 lysine 4 methylation to active gene repression. Nature. 442:96-99. 
Shur I, Benayahu D. (2005) Characterization and functional analysis of CReMM, a novel chromodomain helicase DNA-binding protein. J Mol Biol. 352:646-655.

Shur I, Socher R, Benayahu D. (2006) In vivo association of CReMM/CHD9 with promoters in osteogenic cells. J Cell Physiol. 207:374-378.

Siebert JR, Graham Jr JM, MacDonald C. (1985) Pathologic features of the CHARGE association: support for involvement of the neural crest. Teratology. 31:331-336.

Sillibourne JE, Delaval B, Redick S, Sinha M, Doxsey SJ. (2007) Chromatin remodeling proteins interact with pericentrin to regulate centrosome integrity. Mol Biol Cell. 18(9):36673680.

Sims RJ 3rd, Nishioka K, Reinberg D. (2003) Histone lysine methylation: a signature for chromatin function. Trends Genet. 19:629-639.

Sims RJ 3rd, Chen CF, Santos-Rosa H, Kouzarides T, Patel SS, Reinberg D. (2005) Human but not yeast CHD1 binds directly and selectively to histone H3 methylated at lysine 4 via its tandem chromodomains. J Biol Chem. 280:41789-41792.

Sims JK, Wade PA. (2011) SnapShot: Chromatin remodeling: CHD. Cell. 144(4):626-626.e1. Smith CL and Peterson CL. (2005) ATP-dependent chromatin remodeling. Curr Top Dev Biol. 65:115-148.

Solari F, Ahringer J. (2000) NURD-complex genes antagonise Ras-induced vulval development in Caenorhabditis elegans. Curr Biol.10:223-226.

Srinivasan S, Armstrong JA, Deuring R, Dahlsveen IK, McNeill H, Tamkun JW. (2005) The Drosophila trithorax group protein Kismet facilitates an early step in transcriptional elongation by RNA Polymerase II. Development. 132(7):1623-1635.

Srinivasan S, Dorighi KM, Tamkun JW. (2008) Drosophila kismet regulates histone H3 lysine 27 methylation and early elongation by RNA polymerase II. PLoS Genet. 4(10):e1000217

Talkowski ME, Rosenfeld JA, Blumenthal I, Pillalamarri V, Chiang C, Heilbut A, Ernst C, Hanscom C, Rossin E, Lindgren AM, Pereira S, Ruderfer D, et al. (2012) Sequencing chromosomal abnormalities reveal neurodevelopmental loci that confer risk across diagnostic boundaries. Cell. 149(3):525-537. 
Tartaglia M, Mehler EL, Goldberg R, Zampino G, Brunner HG, Kremer H, van der Burgt I, Crosby AH, Ion A, Jeffery S, Kalidas K, Patton MA, et al. (2001) Mutations in PTPN11, encoding the protein tyrosine phosphatase SHP-2, cause Noonan syndrome. Nat Genet. 29(4):465-468.

Thompson PM, Gotoh T, Kok M, White PS, Brodeur GM. (2003) CHD5, a new member of the chromodomain gene family, is preferentially expressed in the nervous system. Oncogene. 22:1002-1011.

Thompson BA, Tremblay V, Lin G, Bochar DA. (2008) CHD8 is an ATP-dependent chromatin remodeling factor that regulates beta-catenin target genes. Mol Cell Biol. 28(12):3894-3904.

Tong JK, Hassig CA, Schnitzler GR, Kingston RE, Schreiber SL. (1998) Chromatin deacetylation by an ATP-dependent nucleosome remodelling complex. Nature. 395:917-921.

Tonkin ET, Wang TJ, Lisgo S, Bamshad MJ, Strachan T. (2006) NIPBL, encoding a homolog of fungal Scc2-type sister chromatid cohesion proteins and fly Nipped-B, is mutated in Cornelia de Lange syndrome. Nat Genet. 36(6):636-641.

Tsukiyama T. (2002) The in vivo functions of ATP-dependent chromatin-remodelling factors. Nat Rev Mol Cell Biol. 3(6):422-429. Review.

Valdez BC, Henning D, So RB, Dixon J, Dixon MJ. (2004) The Treacher Collins syndrome (TCOF1) gene product is involved in ribosomal DNA gene transcription by interacting with upstream binding factor. Proc Natl Acad Sci USA. 101(29):10709-10714.

Verloes A. (2005) Updated diagnostic criteria for CHARGE syndrome: a proposal. Am J Med Genet A. 133:306-308.

Vissers LE, van Ravenswaaij CM, Admiraal R, Hurst JA, de Vries BB, Janssen IM, van der Vliet WA, Huys EH, de Jong PJ, Hamel BC, Schoenmakers EF, Brunner HG, et al. (2004) Mutations in a new member of the chromodomain gene family cause CHARGE syndrome. Nat Genet. 36(9):955-957.

Vuorela P, La-Mello S, Saloranta C, PenttinenM, PoyhonenM,Huoponen K, Borozdin W, Bausch B, Botzenhart EM,Wilhelm C, Kaariainen H, Kohlhase J. (2007) Molecular analysis of the CHD7 gene in CHARGE syndrome: identification of 22 novel mutations and evidence for a low contribution of large CHD7 deletions. Genet Med. 9:690-694. 
Wade PA, Jones PL, Vermaak D, Wolffe AP. (1998) A multiple subunit Mi-2 histone deacetylase from Xenopus laevis cofractionates with an associated Snf2 superfamily ATPase. Curr Biol. 8:843- 846.

Wang HB, Zhang Y. (2001) Mi2, an auto-antigen for dermatomyositis, is an ATP-dependent nucleosome remodeling factor. Nucleic Acids Res. 29:2517-2521.

Wessels K, Bohnhorst B, Luhmer I,Morlot S, Bohring A, Jonasson J, Epplen JT, Gadzicki D, Glaser S, Gohring G, Malzer M, Hein A, and others. (2010) Novel CHD7 mutations contributing to themutation spectrumin patients with CHARGE syndrome. Eur J Med Genet. $53: 280-285$.

White PS, Thompson PM, Gotoh T, Okawa ER, Igarashi J, Kok M, Winter C, Gregory SG, Hogarty MD, Maris JM, Brodeur GM. (2005) Definition and characterization of a region of 1p36.3 consistently deleted in neuroblastoma. Oncogene. 24(16):2684-2694.

Williams CJ, Naito T, Arco PG, Seavitt JR, Cashman SM, De Souza B, Qi X, Keables P, Von Andrian UH, Georgopoulos K. (2004) The chromatin remodeler Mi-2beta is required for CD4 expression and T cell development. Immunity. 20(6):719-733.

Williams MS. (2005) Speculations on the pathogenesis of CHARGE syndrome. Am J Med Genet A. 133:318-325.

Wincent J, Holmberg E, Stromland K, Soller M, Mirzaei L, Djureinovic T, Robinson KL, Anderlid BM, Schoumans J. (2008) CHD7 mutation spectrum in 28 Swedish patients diagnosed with CHARGE syndrome. Clin Genet. 74:31-38.

Wolffe AP. (1992) New insights into chromatin function in transcriptional control. FASEB J. 6(15):3354-3361. Review.

Woodage T, Basrai MA, Baxevanis AD, Hieter P, Collins FS. (1997) Characterization of the CHD family of proteins. Proc Natl Acad Sci U S A. 94(21):11472-11477.

Wysocka J, Myers MP, Laherty CD, Eisenman RN, Herr W. (2003) Human Sin3 deacetylase and trithorax-related Set1/Ash2 histone H3-K4 methyltransferase are tethered together selectively by the cell-proliferation factor HCF-1. Genes Dev. 17: 896-911.

Xue Y, Wong J, Moreno GT, Young MK, Cote J, Wang W. (1998) NURD, a novel complex with both ATP dependent chromatin-remodeling and histone deacetylase activities. Mol Cell. 2:851-861. 
Yates JA, Menon T, Thompson BA, Bochar DA. (2010) Regulation of HOXA2 gene expression by the ATP-dependent chromatin remodeling enzyme CHD8. FEBS Lett. 584(4):689-693.

Yoshida T, Hazan I, Zhang J, Ng SY, Naito T, Snippert HJ, Heller EJ, Qi X, Lawton LN, Williams CJ, Georgopoulos K. (2008) The role of the chromatin remodeler Mi-2 $\beta$ in hematopoietic stem cell self renewal and multilineage differentiation. Genes Dev. 22:11741189.

Yuan CC, Zhao X, Florens L, Swanson SK, Washburn MP, Hernandez N. (2007) CHD8 associates with human Staf and contributes to efficient U6 RNA polymerase III transcription. Mol Cell Biol. 27(24):8729-8738.

Zahir F, Firth HV, Baross A, Delaney AD, Eydoux P, Gibson WT, Langlois S, Martin H, Willatt L, Marra MA, Friedman JM. (2007) Novel deletions of 14q11.2 associated with developmental delay, cognitive impairment and similar minor anomalies in three children. $\mathbf{J}$ Med Genet. 44(9):556-561.

Zenker M, Voss E, Reis A. (2007) Mild variable Noonan syndrome in a family with a novel PTPN11 mutation. Eur J Med Genet. 50(1):43-47.

Zentner GE, Hurd EA, Schnetz MP, Handoko L, Wang C, Wang Z, Wei C, Tesar PJ, Hatzoglou M, Martin DM, Scacheri PC. (2010) CHD7 functions in the nucleolus as a positive regulator of ribosomal RNA biogenesis. Hum Mol Genet. 19(18):3491-3501.

Zhang Y, LeRoy G, Seelig HP, Lane WS, Reinberg D. (1998) The dermatomyositis-specific autoantigen $\mathrm{Mi} 2$ is a component of a complex containing histone deacetylase and nucleosome remodeling activities. Cell. 95:279-289. 


\section{Abbreviations}

aa

ASD

ASH1

ATP

BAF

$\mathrm{BiFC}$

bp

BSA

BRK

${ }^{\circ} \mathrm{C}$

cDNA

Co-IP

CHD

ChIP-chip

Chromo

COBALT

CR

Ctcf

Cy3

DAB

DAPI

dATP

DMEM

DNA

DNAse

DPBS

dpc

Duplin

EDTA

EGFP

ESC

et al. amino acid

Autism Spectrum Disorder

Absent, Small or Homeotic 1

adenosintriphosphate

Brahma associated factor complex

bimolecular fluorescence complementation

base pair

bovine serum albumin

Brahma and Kismet domain

degree Celsius

complementary DNA

co-immunoprecipitation

chromodomain helicase DNA-binding

chromatin immunoprecipitation ("ChIP") with

microarray technology ("chip")

chromatin organization modifier

Constraint-based Multiple alignment tool

conserved region

11-zinc finger protein or CCCTC-binding factor

indocarbocyanine

3,3'-diaminobenzidine tetrahydrochloride

diamidino-2-phenylindole dihydrochloride

desoxyriboadenosintriphosphate

Dulbecco's modified Eagle's medium

deoxyribonucleic acid

deoxyribonuclease

Dulbecco's phosphate buffered saline

days post coitum

for axis duplication inhibitor

ethylene diamine tetra-acetic acid

enhanced green fluorescent protein

embryonic stem cell

et alii (and others) 
FAM124B

FBS

Fig.

FITC

Gapdh

HEPES

HPLC

Hprt

HRP

$\mathrm{IgG}$

ICC

IHC

IHH

IPTG

ISH

$\mathrm{kb}$

$\mathrm{kDa}$

LC

$\min$

$\mathrm{ml}$

MLL

MLPA

MRCV-CV1

MO

mRNA

MS

NCBI

NDD

ng

NIH3T3

NuRD

PAGE

PBAF

PBS
Family with sequence similarity 124B

fetal bovine serum

Figure

fluorescein isothiocyanate

glyceraldehyde-3-phosphate dehydrogenase gene

N-(-hydroxymethyl) piperazin, N'-3-propanesulfoneacid

High-performance liquid chromatography

hypoxanthine guanine phosphoribosyl transferase gene

horseradish peroxidase

immunoglobulin $\mathrm{G}$

immunocytochemistry

immunohistochemistry

idiopathic hypogonadotropic hypogonadism

Isopropyl- $\beta$-thiogalactopyranoside

In situ hybridization

kilobase pairs

kilodalton

liquid-chromatography

minute

milliliter

mixed lineage leukemia

Multiplex Ligation-dependent Probe Amplification

human fibroblast cell line

morpholino

messenger RNA

mass spectrometry

national center for biotechnology information

neurodevelopmental disorders

nanogram

mouse embryonic fibroblast cell line

nucleosome remodeling and deacetylase

polyacrylamide gel electrophoresis

Polybromo containing complex

Phosphate Buffered Saline 
PCR

PFA

$\mathrm{pH}$

PHD

PLA

rDNA

RNA

rpm

RT

RT-PCR

SANT

Sdha

SDS

SILAC

SMC

SNF2

Taq DNA polymerase

TPBS

Tcf

TCS

TE

Tris

TRX

UTR

WAR

WT

$X-\alpha$-gal

$\mathrm{Y} 2 \mathrm{H}$

$\mu \mathrm{g}$

$\mu l$ polymerase chain reaction

paraformaldehyde

preponderance of hydrogen ions

plant homeo domain

proximity ligation assay

ribosomal DNA

ribonucleic acid

rotation per minute

room temperature

reverse transcriptase-PCR

Switching-defective protein 3, Adaptor 2, Nuclear

receptor corepressor, Transcription factor IIIB

succinate dehydrogenase complex, subunit A

sodium dodecylsulfate

stable isotope labeling by amino acids in cell culture

smooth muscle cell

sucrose non-fermenting 2

Thermus aquaticus DNA polymerase

Phosphate Buffered Saline with Tween-20

T-cell factor

Treacher Collins syndrome

Tris-EDTA buffer

trihydroxymethylaminomethane

trithorax

untranslated region

WDR5, ASH2L and RbBP5

wild-type

5-bromo-4-chloro-3-indolyl- $\alpha$-D-galactopyranoside

yeast two hybrid

microgram

microliter

The names of nucleic/amino acids are abbreviated in accordance with internationally accepted codes. 


\section{Acknowledgement}

I am so grateful for being able to work and study at the Institute of Human Genetics, under supervision of Prof. Dr. med. Dr. h. c. Wolfgang Engel. I would like to express my sincere gratitude to him for his helpful comments, excellent guidance, valuable discussions and financial support throughout my $\mathrm{PhD}$ study.

I take this opportunity with great pleasure to thank my superviser, Dr. Silke Pauli, who gave me such an interesting project to do. I am sincerely grateful to her generous helps, understandings, friendly and insightful discussions, and expert guidance during the entire course of my $\mathrm{PhD}$ work and help in the preparation of the thesis.

My sincere thanks to my co-referee Prof. Dr. Sigrid Hoyer-Fender and the other members of the thesis committee Prof. Dr. Peter Burfeind, Prof. Dr. Hubertus Jarry, Prof. Dr. Jochen Reiss and Prof. Dr. Andreas Wodarz for taking time out from their busy schedule to work as my examiners and for their critical reading of my thesis.

I would like to acknowledge and extend my heartfelt gratitude to all people who helped me, shared the ideas and cooperation, specifically to Dr. Tamara I. Rabe for her friendly help for ISH experiments; to Dr. Henning Urlaub and Thomas Oellerich for SILAC/MS experiment; Dr. Inga-Marie Schaefer for interpreting IHC results.

My warm thanks to all of my friends and colleagues who made my life and work in Goettingen with a lot of wonderful memories. I would like to express my special thanks to my Mongolian friends, especially to Gunjee, Nomintuya, Dembee, Khishgee, Sanaa, Altaa, Baigal, Duuya, Byambaa, Lkhagvaa, Ankhaa, Khaliunaa, Dagii, Chimgee, Oggie, Ali, Sunjee's family and all others. Moreover, I want to express my gratitute to my lab mates Yvonne, Johanna, Krzysztof, Neele, Nina, Astrid, Karina, Ralf, Ania, Steffi and other institute friends Krishna, Xingbo, Tan, 2xSandra, Nadja, Chiru, Belal, Lukasz, Henning and Daria for their friendly atmosphere, continuous supports and numerous happy moments. To all those whose names are inadvertently left out, please accept my sincere and warmest gratitude.

Special acknowledgements and thanks to my mother, Mukhjargal Dugarsuren and all my family members for their love, encouragement and numerous heartfelt supports. Who I am today is because of your love. Also, I would like to mention my dear late dad, Batsukh Shatar, and my dear grandma, Dolgorjav Ravdan. Thank you for your love, care and wisdoms you taught me. I wish you could have lived to see it happen.

Last but not least, I am so grateful to Heavenly Father, God, whose love, blessing, protection and guidance are always with me all the way of my life. 


\section{Curriculum Vitae}

\section{Personal details:}

Name:

Place of Birth:

Date of Birth:

Nationality:

Address:

Telephone:

Email:

\section{Education:}

2009-current

$2005-2007$

$2001-2005$

$1994-2001$

1991-1994

\section{Career:}

2007-2009
Tserendulam Batsukh

Ulaanbaatar, Mongolia

$24^{\text {th }}$ March 1984

Mongolian

Goßler Straße 13/Nord24

Göttingen 37073, Germany

+49-17625950386

cq_84@yahoo.com, b.tserendulam@gmail.com

PhD study at Institute of Human Genetics, Georg-August

University, Goettingen, Germany.

Topic of PhD thesis: "Novel interaction partners of the chromatin remodeler CHD7, a protein mutated in CHARGE syndrome".

Master of Science at Faculty of Biology, National University of Mongolia, Ulaanbaatar, Mongolia.

Bachelor of Science at Faculty of Biology, department of Molecular Biology \& Genetics, National University of Mongolia, Ulaanbaatar, Mongolia.

Secondary School №11 which is specialized in mathematics and physics, Ulaanbaatar, Mongolia.

Primary School №23 which is specialized in foreign languages, Ulaanbaatar, Mongolia.

Researcher at Institute of Biology, Mongolian Academy of Sciences, Ulaanbaatar, Mongolia. 


\section{List of Publications}

Batsukh T, Pieper L, Koszucka AM, von Velsen N, Hoyer-Fender S, Elbracht M, Bergman JE, Hoefsloot LH, Pauli S. (2010) CHD8 interacts with CHD7, a protein which is mutated in CHARGE syndrome. Hum Mol Genet. 19(14):2858-2866. (doi:10.1093/hmg/ddq189)

Batsukh T, Schulz Y, Wolf S, Rabe TI, Oellerich T, Urlaub H, Schaefer IM, Pauli S. (2012) Identification and characterization of FAM124B as a novel component of a CHD7 and CHD8 containing complex (manuscript in submission stage). 